\title{
Paternal exposure to benzo(a)pyrene : a genetic risk in offspring?
}

Citation for published version (APA):

Verhofstad, N. (2010). Paternal exposure to benzo(a)pyrene : a genetic risk in offspring? [Doctoral Thesis, Maastricht University]. Datawyse / Universitaire Pers Maastricht. https://doi.org/10.26481/dis.20101221nv

Document status and date:

Published: 01/01/2010

DOI:

$10.26481 /$ dis.20101221nv

Document Version:

Publisher's PDF, also known as Version of record

\section{Please check the document version of this publication:}

- A submitted manuscript is the version of the article upon submission and before peer-review. There can be important differences between the submitted version and the official published version of record.

People interested in the research are advised to contact the author for the final version of the publication, or visit the DOI to the publisher's website.

- The final author version and the galley proof are versions of the publication after peer review.

- The final published version features the final layout of the paper including the volume, issue and page numbers.

Link to publication

\footnotetext{
General rights rights.

- You may freely distribute the URL identifying the publication in the public portal. please follow below link for the End User Agreement:

www.umlib.nl/taverne-license

Take down policy

If you believe that this document breaches copyright please contact us at:

repository@maastrichtuniversity.nl

providing details and we will investigate your claim.
}

Copyright and moral rights for the publications made accessible in the public portal are retained by the authors and/or other copyright owners and it is a condition of accessing publications that users recognise and abide by the legal requirements associated with these

- Users may download and print one copy of any publication from the public portal for the purpose of private study or research.

- You may not further distribute the material or use it for any profit-making activity or commercial gain

If the publication is distributed under the terms of Article $25 \mathrm{fa}$ of the Dutch Copyright Act, indicated by the "Taverne" license above, 


\section{Paternal exposure to benzo(a)pyrene a genetic risk in offspring?}


Copyright (๑) 2010 Nicole Verhofstad, Maastricht ISBN 9789461590091

Layout: Nicole Verhofstad

Cover design: Pim de Brabander

Cover photo of sperm cells: SKML

Production: Datawyse / Universitaire Pers Maastricht
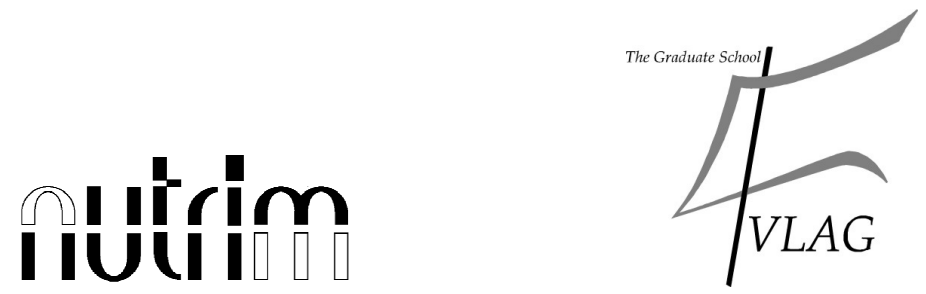

The studies presented in this thesis were performed within NUTRIM School for Nutrition, Toxicology and Metabolism which participates in the Graduate School VLAG (Food Technology, Agrobiotechnology, Nutrition and Health Sciences), accredited by the Royal Netherlands Academy of Arts and Sciences. 


\title{
Paternal exposure to benzo(a)pyrene a genetic risk in offspring?
}

\author{
PROEFSCHRIFT \\ ter verkrijging van de graad van doctor \\ aan de Universiteit Maastricht, \\ op gezag van Rector Magnificus, prof. mr. G.P.M.F. Mols \\ volgens het besluit van het College van Decanen, \\ in het openbaar te verdedigen \\ op dinsdag 21 december 2010 om 12.00 uur \\ door \\ Nicole Verhofstad \\ geboren te Best op 29 oktober 1980
}

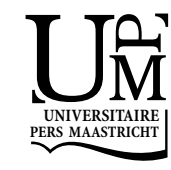




\section{Promotores}

Prof. dr. F.J. van Schooten

Prof. dr. H. van Steeg (Leids Universitair Medisch Centrum, RIVM)

\section{Copromotor}

Dr. R.W.L. Godschalk

\section{Beoordelingscommissie}

Prof. dr. J.G.R. de Mey (voorzitter)

Dr. G. Brunborg (Norwegian Institute of Public Health, Norway)

Dr. C.T.A. Evelo

Prof. dr. J.C.S. Kleinjans

Prof. dr. A.H. Piersma (Universiteit Utrecht, RIVM) 


\section{Contents}

$\begin{array}{lll}\text { Chapter } 1 & \text { General introduction } & 7\end{array}$

Chapter 2 New methods for assessing male germ line mutations in humans and genetic risks in their offspring

Chapter 3 DNA adduct kinetics in reproductive tissues of DNA repair 39 proficient and deficient male mice after oral exposure to benzo(a)pyrene

Chapter 4 Benzo(a)pyrene induces similar gene expression changes in 53 testis of DNA repair proficient and deficient mice

Chapter 5 Evaluation of benzo(a)pyrene-induced gene mutations in male germ cells

Chapter 6 Expanded Simple Tandem Repeat (ESTR) mutations in offspring of benzo(a)pyrene exposed DNA repair deficient male mice

Chapter 7 Summary and general discussion

Dankwoord

Curriculum Vitae 



\section{Chapter 1}

General introduction 
During life, we are continuously exposed to chemical compounds that can adversely affect our health. Some of these compounds can also affect the health of the offspring by damaging the parental germ line DNA. This initial DNA damage does not necessarily have to lead to serious diseases, since our body possesses multiple DNA repair mechanisms that are capable of removing different kinds of damage in a highly efficient manner. However, there are situations in which DNA damage can become persistent in the DNA by the induction of a change in the nucleotide sequence. Mutations in somatic cells are known to be involved in the onset of genetic diseases such as cancer, but when appearing in the genetic material of germ cells, these mutations are transferred to the next generation and may increase the risk of childhood diseases (inborn errors). Paternal exposures, for example under occupational circumstances, have already been associated with childhood cancer [1] and developmental defects. It is indeed recognized that between 2 and 5 percent of all live-born infants have a major developmental defect. Therefore, in order to reduce risks in offspring, effects of paternal exposures to chemical compounds require more investigations.

\section{Policy regarding mutagenicity testing}

The mutagenicity of compounds is investigated with short-term in vitro and in vivo mutagenicity tests in both somatic and germ cells. Mutagenicity has three endpoints: gene mutations (mutagenicity), structural chromosome aberrations (clastogenicity) and numerical chromosome aberrations (aneuploidy). To completely cover the genotoxic potential of chemicals all three endpoints have to be investigated. The first steps in the strategy are in vitro tests. Generally, the standard information required for all substances is data from an in vitro gene mutation study in bacteria (Ames test), an in vitro gene mutation study in mammalian cells and an in vitro cytogenicity study in mammalian cells (chromosome aberration test or micronucleus test). Appropriate in vivo mutagenicity studies shall be considered in case of a positive result in any of the genotoxicity studies. The standard information required for all substances is data from an in vivo gene mutation study and an in vivo cytogenicity study (chromosome aberration test or micronucleus test). If there is a positive result from any in vivo somatic cell study available, the potential for germ cell mutagenicity should be considered on the basis of all available data, including toxicokinetic evidence. If no clear conclusion about germ cell mutagenicity can be made, additional investigations shall be considered.

\section{Policy regarding germ line mutagenicity testing}

Germ cell tests play a decisive role in classifying and labelling of chemical compounds for genotoxicity. A chemical can be classified as a germ line mutagen, if it has been tested positive for its ability to induce heritable mutations in germ cells. To minimize animal use, tests that detect effects in germ cells should be performed first. However, if quantification of these effects is required, assays for the transmission of mutations to the offspring are essential. The guidance document for genotoxicity under Registration Evaluation and Authorization of Chemical Substances (REACH), the new European Community (EC) policy for authorization of new and existing chemicals, requires that chemical compounds should be considered for testing on mutagenicity in germ cells when they are mutagenic in somatic cells. Still, it remains 
uncertain whether mutations in germ cells are transmitted to the offspring. Damaged germ cells may not be able to fertilize an egg, or there may be loss during implantation. Therefore, it is also necessary to test the offspring for parentally transmitted mutations. Tests that determine changes in transgenes or hypervariable tandem repeat DNA are stated as an alternative to classical tests. As the last test also allows the measurement of heritable damage in humans, it is a recommended alternative.

\section{Mutagenicity testing in progeny}

Since it is apparent that exposures to chemical compounds and radiation are not only affecting the exposed population but also the generations thereafter, mutagenicity testing in progeny is necessary to assess transmittable genetic risks. The Morphological Specific Locus (MSL) test and the Dominant Lethal test are established methods that show that mutations occur in F1 or subsequent populations, and these tests actually focus on visible phenotypic alterations in the offspring. Unfortunately, these tests have low sensitivity, need large numbers of animal progeny, are very timeconsuming and are expensive. Therefore, there is an urgent need for new methodologies.

Recently developed methods, such as DNA fingerprinting of tandem repeat sequences and randomly amplified polymorphic DNA PCR (RAPD PCR), seem to overcome these drawbacks, since they appear to be more sensitive, require less animals and seem to be suitable for studying genetic risks in human populations. Several well-known germ line mutagens have been successfully tested with these assays. Studies in environmentally exposed animals using these methodologies also showed that polycyclic aromatic hydrocarbons (PAHs) may be candidate germ line mutagens $[2,3]$, whereas results from classic germ line tests were inconclusive [4]. These new, promising methods are further introduced and compared in chapter 2.

\section{Exposure to polycyclic aromatic hydrocarbons}

PAHs are a group of structurally related compounds, which are formed during the incomplete combustion of organic materials such as wood, diesel and tobacco. The best studied mutagenic PAH is benzo(a)pyrene (B[a]P), which has been found in, among others, coal tar, diesel exhaust, charbroiled meat and tobacco smoke, and is commonly present in the environment as a pollutant (for structure see figure 1). In addition, $\mathrm{B}[\mathrm{a}] \mathrm{P}$ is an important occupational pollutant for male workers in the steel and asphalt industry. People can be exposed to B[a]P via inhalation of polluted air, ingestion of polluted food, or deposition on and subsequent absorption through the skin.

\section{Biotransformation to a DNA damaging compound}

$B[a] P$ is lipid soluble and tends to accumulate in exposed individuals, unless it is metabolised to more water soluble derivatives that can be excreted in urine or faeces [5]. Paradoxically, B[a]P would not be harmful if it was not metabolised to its reactive derivatives that can react with DNA. The metabolism of $B[a] P$ is shown in figure 1.

The initial step in the transformation of $\mathrm{B}[\mathrm{a}] \mathrm{P}$ is the formation of epoxides, which is the addition of an oxygen molecule across a double bond by cytochrome P450 monooxygenases [6]. Epoxidation of $\mathrm{B}[\mathrm{a}] \mathrm{P}$ leads to the formation of $( \pm)-\mathrm{B}[\mathrm{a}] \mathrm{P}-7,8-$ 
epoxide, which is in turn substrate for epoxide hydrolase to form dihydrodiols. These diols are again a substrate for cytochrome P450 enzymes, which convert the diols into ( \pm )-anti- and ( \pm )-syn-B[a]P-7,8-dihydrodiol-9,10-epoxides (BPDE). Of these conformations, $( \pm)$-anti-BPDE is the most predominant and most reactive metabolite regarding covalent DNA binding, and as a result in producing tumours. The predominant adduct found in DNA after exposure to $B[a] P$ is a covalent binding to the 2amino group $\left(\mathrm{N}^{2}\right)$ of guanine; the BPDE- $\mathrm{N}^{2}-\mathrm{dG}$ adduct. Other minor interactions of BPDE are for example with the $\mathrm{N}^{7}$-position of guanine or the exocyclic amino groups of adenine and cytosine [7]. In addition, B[a]P can be transformed to quinones and semi-quinones that can lead to the formation of oxygen radicals by redox cycling. These reactive oxygen species can also react with DNA and form oxidative DNA damage, like 8-oxodeoxyguanine (8-oxodG) as indicated in figure 1.

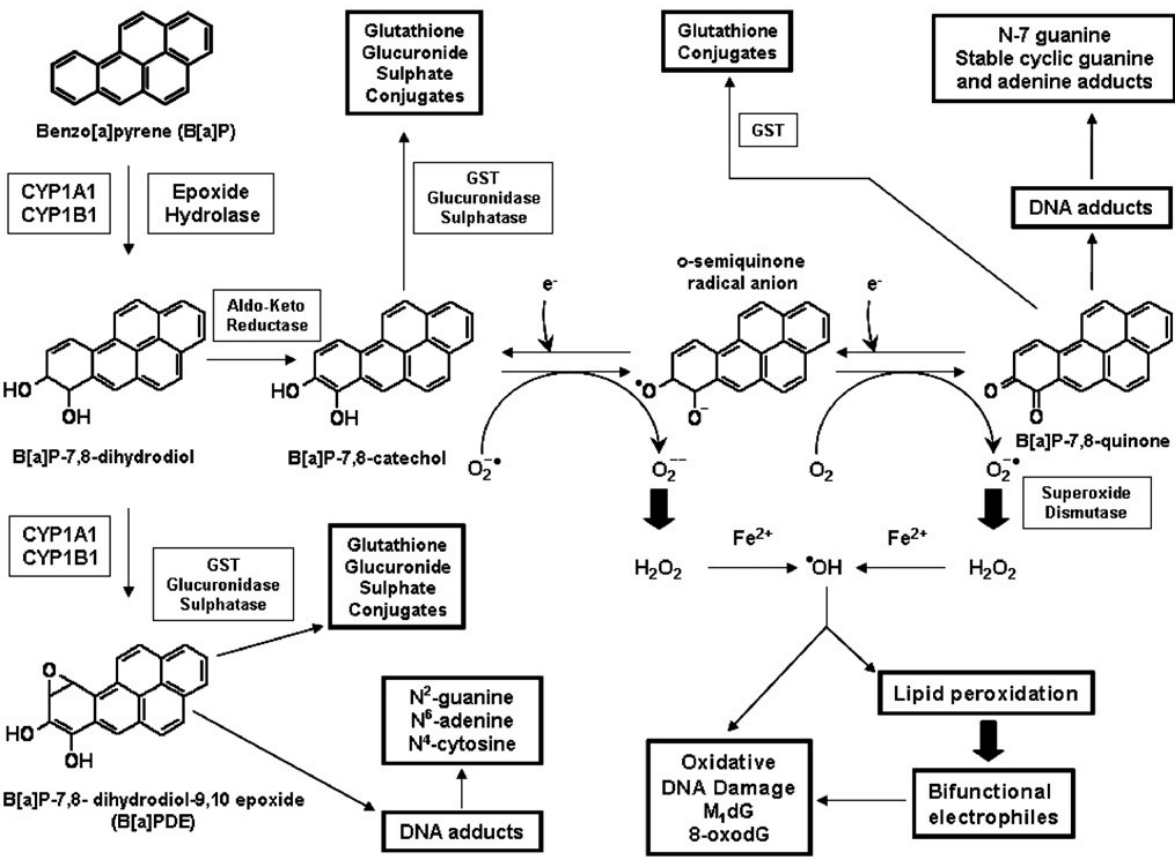

Figure 1. Mechanism for metabolization, activation and detoxification of B[a]P (from Singh et al. [8]).

\section{Mutagenic and carcinogenic potency of $B[a] P$}

In 1933, B[a]P was the first compound to be linked to the development of cancer [9]. Since then, B[a]P has been studied extensively. We know now that the mutagenic and carcinogenic potency of $\mathrm{B}[\mathrm{a}] \mathrm{P}$ is associated to the DNA binding capacity of its metabolites [10]. The formation of bulky DNA adducts and oxidative damage after exposure to $\mathrm{B}[\mathrm{a}] \mathrm{P}$ may lead to a change in the nucleotide sequence due to misincorporation of a nucleotide opposite the damaged base during DNA replication. DNA lesions induced by $\mathrm{B}[\mathrm{a}] \mathrm{P}$ are known to produce mostly $\mathrm{G} \rightarrow \mathrm{T}$ transversions [11-13], which have been associated with carcinogenesis [14]. In addition, $G \rightarrow T$ transver- 
sions caused by BPDE-DNA adducts were related to changes found in the $p 53$ tumour suppressor gene in human cancers $[15,16]$. Therefore, these mutations may be the initial step in the onset of cancer development; if they occur in regulatory important proto-oncogenes and tumour suppressor genes, they may eventually lead to disruption of cell cycle regulation and proliferation of cells (tumour promotion). Fortunately, mutations can be prevented by different DNA repair mechanisms that are active before and during DNA replication, removing different sorts of DNA damage, including the types of DNA damage induced by $B[a] P$ derivatives. In the case of high levels of DNA damage, fixation of DNA damage induced by $B[a] P$ can partially be prevented by the activation of proteins, such as p53, leading to apoptosis, and at even higher doses necrosis will occur [17].

\section{Nucleotide excision repair}

As mentioned above, cells possess different DNA repair mechanisms for removing chemically induced DNA damage to maintain the genetic integrity of the genome, including nucleotide excision repair (NER). In principle, NER is a complex but highly conserved process involved in the removal of a broad range of DNA helix distorting lesions, such as those induced by ultraviolet (UV) light and compounds which give rise to bulky adducts. Therefore, NER is considered to be the most relevant repair mechanism for bulky DNA lesions induced after B[a]P exposure, such as BPDE-DNA adducts.

Two sub-pathways of NER have been described (see figure 2): global genome repair (GGR) is dealing with the elimination of bulky DNA lesions in the entire genome, whereas transcription coupled repair (TCR) specifically removes lesions that block RNA synthesis [18]. Both pathways can be divided into multiple steps, of which only the first step, recognition of the site where the DNA helix is distorted, is different and requires specific proteins. For GGR, a heterotrimeric complex has been identified: xeroderma pigmentosum complementation group $C$ (XPC) protein in complex with RAD23 homolog B (RAD23B) and centrin 2 (CETN2). Damage recognition and the stability of this complex is facilitated by a DNA damage binding complex, involving damage-specific DNA binding complex 1 (DDB1, XPE) and complex 2 (DDB2), at the site of damage $[19,20]$. Both complexes cause local unwinding of the DNA, enabling other repair proteins to reach the damaged site. For TCR, it is thought that a stalled RNA polymerase is able to attract other NER proteins, such as excision repair cross-complementing rodent repair deficiency, complementation group 8 (ERCC8, also known as Cockayne syndrome group A (CSA)) and complementation group 6 (ERCC6, CSB), by direct interaction or to modify local chromatin structure to create optimal conditions for the repair.

The next steps following the initial recognition are similar for GGR and TCR. General transcription factor IIH (TFIIH), which includes ERCC3 (XPB) and ERCC2 (XPD), is thought to be involved in further unwinding of the DNA, because of its unwinding capacity during transcription, while XPB and XPD are both required for their ATP-dependent helicase activity. Subsequently, 5'- and 3'-incisions are made by two endonucleases, i.e. ERCC5 (XPG) en ERCC4 (XPF)/ ERCC1 respectively, releasing 24-32 bases containing the DNA damage. The gap is then filled by DNA polymerase $\delta$ or $\varepsilon$, using the 3 '-terminus and the complementary DNA strand as a template. This step is supported by other NER proteins, such as XPA, proliferating cell nuclear anti- 
gen (PCNA), replication protein A (RPA) and replication factor C (RFC). In the end, the 3 '-nick is closed by DNA ligase $\mathrm{I}$.

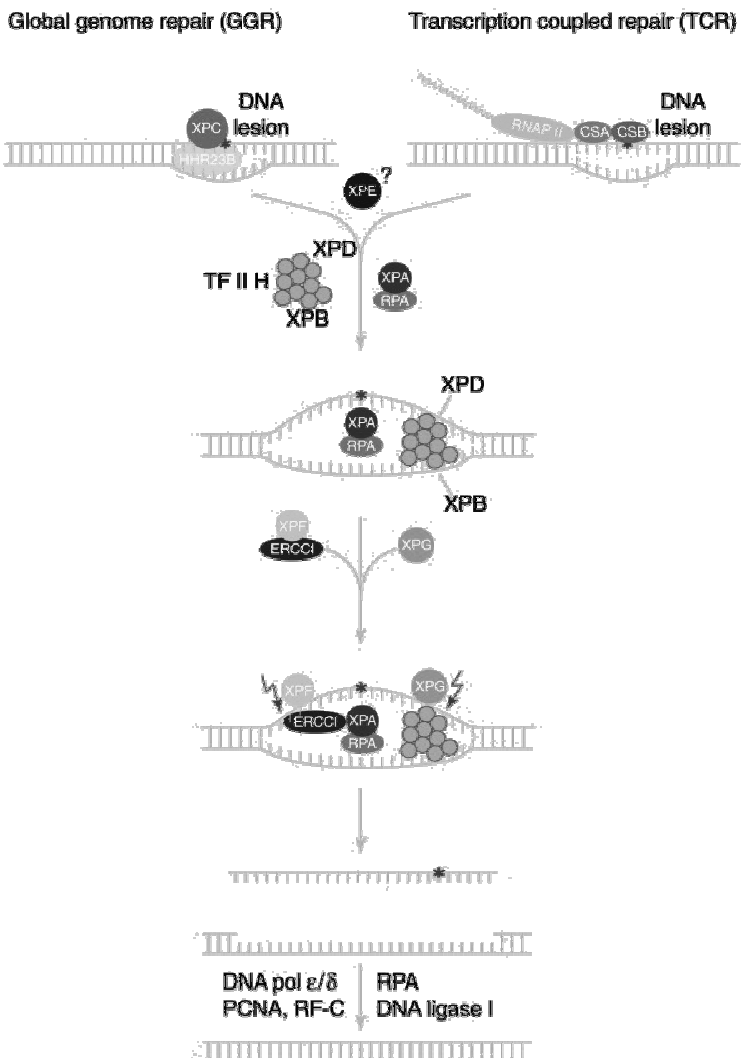

Figure 2. Overview of the nucleotide excision repair pathway. XPC, XPD, XPB, $\mathrm{XPA}, \mathrm{XPF}$ and $\mathrm{XPG}$, xeroderma pigmentosum complementation group $\mathrm{C}, \mathrm{D}, \mathrm{B}, \mathrm{A}$, $\mathrm{F}$ and G; RAD23B, RAD23 homolog B; RNAPII, RNA polymerase II; CSA and CSB, Cockayne syndrome group A and B; TFIIH, transcription factor IIH; RPA, replication protein $A$; ERCC1, excision repair cross-complementing rodent repair deficiency complementation group 1; DNA pol $\varepsilon / \delta$, DNA polymerase $\varepsilon / \delta$; PCNA, proliferating cell nuclear antigen (adapted from Van Steeg et al. [21]).

\section{The role of XPC in DNA repair}

XPC plays an important role in the early steps of GGR, especially in damage recognition, open complex formation, and repair protein complex formation. Mutations in this gene result in Xeroderma pigmentosum, a rare autosomal recessive disorder characterized by increased sensitivity to sunlight with the development of carcinomas at an early age. In the past few years, it has become clear how XPC is involved in NER and how it exerts its functions in a mostly accurate and efficient manner. 
XPC is essential to initiate GGR, and constantly screens the double helix for the presence of DNA lesions [22]. Hereby, XPC deploys a dynamic sensor interface that detects the presence of unpaired bases in the double helix [22], which explains the wide substrate specificity of NER [20]. The search is carried out by $\beta$-hairpin domains $\mathrm{BHD} 1 / \mathrm{BHD} 2$ in conjunction with the $\beta$-turn extension of BHD3, resulting in the formation of a labile nucleoprotein intermediate. When damaged sites are localized, the single-stranded DNA binding activity of BHD3 promotes the transition to a stable recognition complex by capturing extruded nucleotides in the undamaged strand. Subsequently, a more static repair-initiating complex is installed without direct contact with the damaged bases themselves [22, 23]. For the second step in GGR, RAD23B and CETN2 are thought to stabilise the DNA binding of XPC, and to inhibit its degradation. XPC is then thought to attract TFIIH to verify the damaged site (together with XPA) and to locally unwind the DNA duplex around the damaged site [20]. More specific information on the role of XPC in GGR can be found in a review paper by Sugasawa [20].

Besides its role in GGR, XPC is thought to be involved in base excision repair (BER) of oxidative DNA damage. This is supported by the report on hypersensitivity of Xpc deficient cells to oxygen [24], and by the finding that XPC activates 8oxoguanine glycosylase 1 (OGG1), which is involved in BER of 8-oxodG [25]. In addition, age-dependent mutations in $X p c$ deficient $\left(X p c^{--/}\right)$mice showed an increase in $\mathrm{G} \rightarrow \mathrm{C}$ and $\mathrm{T} \rightarrow \mathrm{A}$ changes, which are reported to be induced by 8-oxodG [26]. Altogether, XPC is playing diverse roles in protecting the genome against different kinds of damage.

\section{Xpc deficient mouse model}

Several mouse models have been developed that are deficient for one of the proteins involved in NER, to unravel mechanistic information about the role of these proteins in tumour development and diseases like Xeroderma pigmentosum and Cockayne syndrome [27]. Also viable $X p c^{-/-}$mice have been generated, which develop normally and are fertile [28, 29]. This mouse model strongly mimics the human phenotype as they are highly susceptible to develop skin cancer at UV irradiated areas [29, 30]. Initially, no increased incidence of spontaneous tumours was found in $X p c^{-/-}$mice until the age of one year [28, 29, 31]. Nevertheless, more recent studies showed an enhanced frequency of lung tumours and a trend towards increased liver tumours [24, 32]. Additionally, a significant shorter life span was found for $X p c^{-/-}$mice compared to wild type (Wt) mice [24, 27]. Since mutations are thought to be a prerequisite for tumour development, spontaneous mutant frequencies have been analysed as well. $X p c^{-/-}$mice exhibited a strong age-related increase in lacZ (a transgene) mutant frequencies in lung, liver, spleen and heart, while brain, testis and small intestine revealed no effects from the $X p c$ deficiency $[24,26]$. The increased mutant frequencies in lung and liver confirm the tumour spectrum found in these animals.

Next, this mouse model has been successfully used to examine the susceptibility to develop cancer in different types of tissue after exposure to chemical compounds. Exposure to 2-acetylaminofluorene (2-AAF) or its activated derivative $\mathrm{NOH}-\mathrm{AAF}$ showed a predisposition of $\mathrm{Xpc}^{-1-}$ mice to develop lung and liver cancer [33]. However, no significant increase in tumour response was found in the urinary bladder by 2-AAF, despite the increased lacZ mutant frequencies found in these mice [34]. Xpc ${ }^{-1-}$ 
mice were also more sensitive to 3,4-epoxy-1-butane and $\mathrm{B}[\mathrm{a}] \mathrm{P}$ at mutagenic doses relative to exposed Wt mice [35].

Until now, it has been shown that the $X p c$ deficient mouse model indicates a higher sensitivity towards DNA damage compared to Wt mice, and therefore, seems to be a good model to study the mutagenic potency of chemicals, possibly also in the germ line.

\section{Susceptibility of male germ cells towards exposure}

It is known that exposure to genotoxic compounds is affecting our health, and it has become clear that these exposures may also damage male germ cells. There are reports of increasing rates of poor sperm quality as well as testicular cancer in time. It has also been shown that paternal exposure to chemical compounds can lead to transgenerational genomic instability [36, 37]. B[a]P has already been studied for its adverse effects on spermatogenesis, but it remains unclear whether it is harming the germ line DNA and the generations hereafter.

\section{Spermatogenesis}

Spermatogenesis is the process of cell differentiation in the testis by which spermatozoa are generated from spermatogonia. Spermatogenesis is essentially similar in all mammals, and can be divided into three phases: 1) the proliferative phase, in which spermatogonia undergo rapid successive mitotic divisions, 2) the meiotic phase and 3) differentiation of the haploid spermatids (spermiogenesis) (figure 3). Spermatozoa, the final product of spermatogenesis, are transported to and stored in seminal vesicles until ejaculation. The duration of spermatogenesis is 64 days in humans and 35 days in mice, the transport of spermatozoa to the seminal vesicles takes additionally 8-17 days in humans and approximately 7 days in mice [38,39]. Spermatogonial stem cells originate from primordial germ cells that proliferate in utero. After birth they initiate the proliferating phase when they undergo mitotic division to generate two haploid daughter cells. One gives rise to a type A spermatogonium and the other remains as a stem cell. Type A spermatogonia undergo further mitotic divisions where so-called pale and dark type A and type B spermatogonia are formed. Type B spermatogonia represent the onset of germ cell development to spermatids; they enter meiosis and are then called primary spermatocytes [39, 40].

The meiotic phase takes 24 days in humans and 14 days in mice and starts in the basal compartment of the testis, where the leptotene stages of the prophase occurs. After crossing the blood-testis barrier via the intermediate compartment and reaching the adluminal compartment, the spermatocytes continue with the next prophase stages; the zygotene, pachytene and diplotene stages (figure 4). Replication of DNA, condensation of chromosomes, the pairing of homologous chromosomes and homologous crossing-over occurs during the prophase. Primary spermatocytes have two sets of chromosomes (4n), but are still diploid (2n). They undergo the first meiotic division to become secondary spermatocytes, which consist of one pair of chromosomes (2n), and are diploid. The second meiotic division is rapid and results in four haploid round spermatids. The round spermatids undergo a series of changes (spermiogenesis), where the acrosome and flagellum develop, the nuclei condensate and cytoplasmic constituents are eliminated. At this point they have become spermatozoa that are ready for release into the seminiferous tubular lumen and for trans- 
port to the seminal vesicle [40]. During the chromatin condensation, histones are replaced by transition proteins, and finally by protamines bound to each other with extensive disulfide cross-links, resulting in the formation of a compact chromatin structure which is largely devoid of transcriptional activity [41].

The efficiency of spermatogenesis is several folds lower in humans than in mice. Mice spermatogonia go through 8 mitotic steps before entering meiosis as spermatocytes. Humans on the other hand, pass only two mitotic steps before entering meiosis [43]. Furthermore, germ cell loss during spermatogenesis and the number of malformed spermatozoa are extremely high. Only approximately 12 percent of the spermatogenic content is available for reproduction in humans [40].

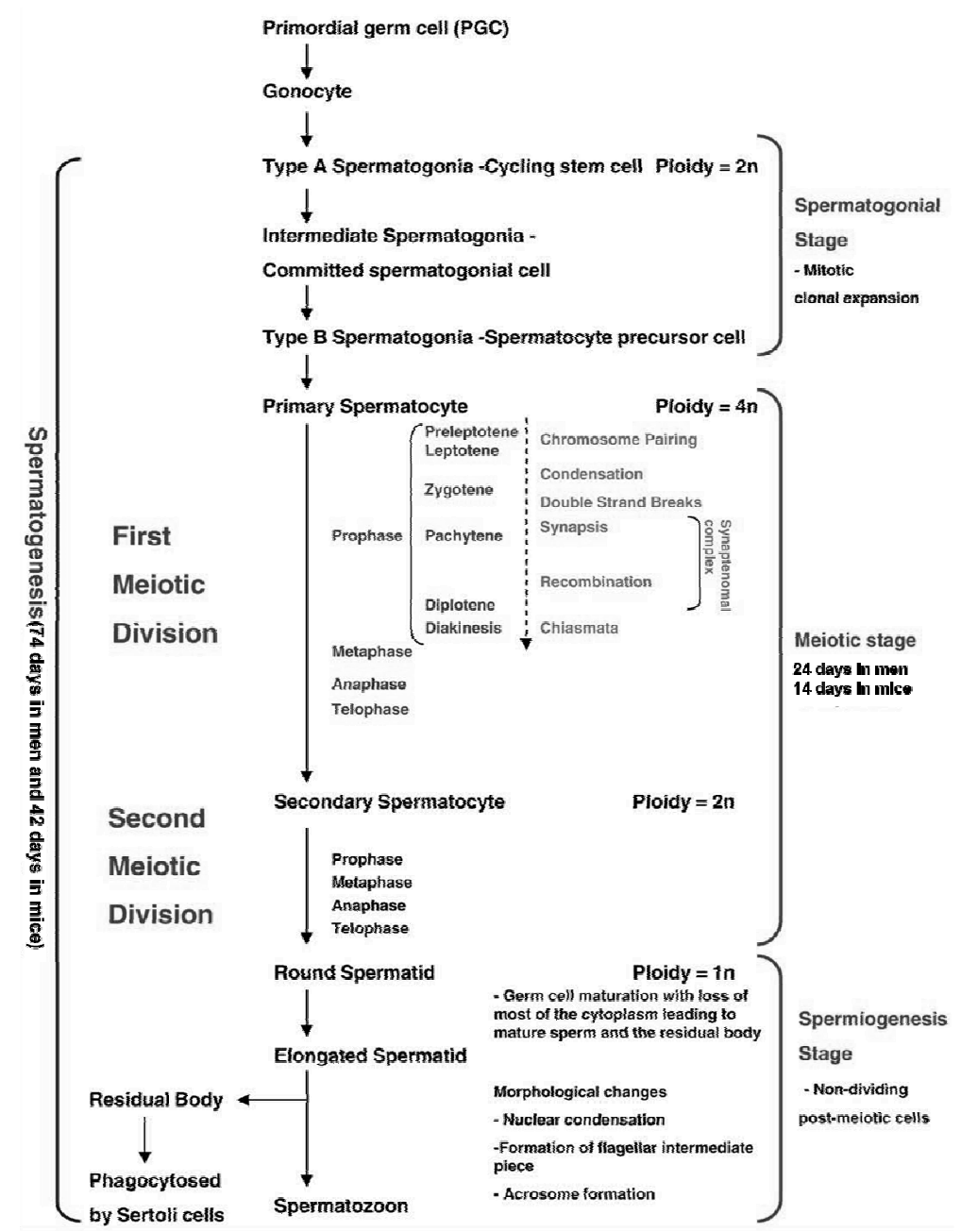

Figure 3. Overview of spermatogenesis (adapted from Olsen et al. [42]). 


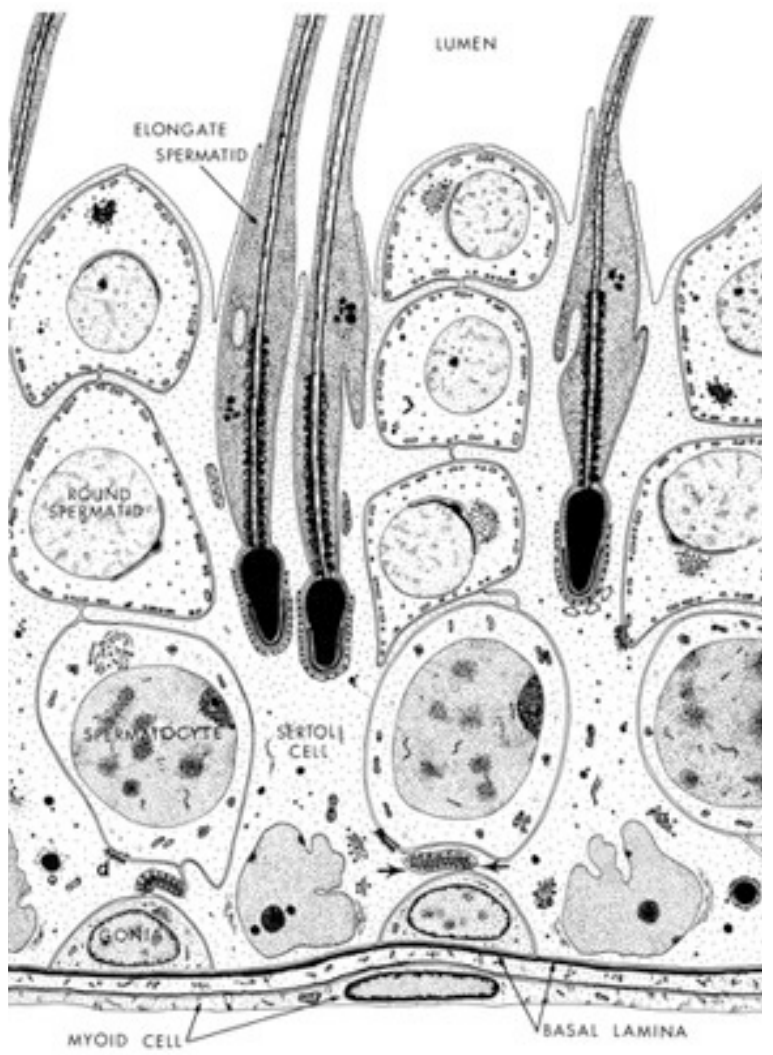

Figure 4. Overview of seminiferous tubule showing spermatogonia, spermatocytes and spermatids. The bold arrows indicate the bloodtestis barrier (from Russell et al. [44]).

\section{Effects of benzo(a)pyrene exposure on male germ cells}

\section{In vitro studies}

$\mathrm{B}[\mathrm{a}] \mathrm{P}$ has been tested for its effects on animal or human spermatozoa in in vitro systems. In rat spermatocytes, relatively low concentrations $(0.1 \mu \mathrm{M})$ of $\mathrm{B}[\mathrm{a}] \mathrm{P}$ inhibited the progression through meiotic divisions and high concentrations $(>1 \mu \mathrm{M})$ were highly cytotoxic [45]. In in vitro studies with human spermatozoa, B[a]P was found to assess mutagenic effects (clastogenicity) after the addition of liver S9, a metabolic activator of $\mathrm{B}[\mathrm{a}] \mathrm{P}[46,47]$. However, the complex process of spermatogenesis is difficult to reproduce in vitro, thus more relevant information on the effects of $\mathrm{B}[\mathrm{a}] \mathrm{P}$ on male germ cells can be obtained from animal and human studies.

\section{Animal studies}

The effects of B[a]P exposure itself as well as the effects of tobacco smoke, containing $\mathrm{B}[\mathrm{a}] \mathrm{P}$, have been tested on several sperm related end-points in animal models. It is clear that B[a]P causes BPDE-DNA adduct formation in all compartments of 
the mouse testis and that $\mathrm{B}[\mathrm{a}] \mathrm{P}$ (at high concentrations) induces apoptosis and necrosis in germ cells, mainly affecting spermatogonia [48]. In addition, it has been shown that subchronic exposure to inhaled B[a]P contributes to impaired testicular and epididymal function and reduced testosterone concentrations in rats $[49,50]$.

Several studies on the effects of smoking have been performed in mice and rats. From a mouse study, it has become clear that smoking is affecting the quality of sperm. Different effects were found for sidestream smoke and mainstream smoke (main smoke inhaled by active smokers); sidestream smoke significantly affected sperm motility, whereas mainstream smoke did not. While only mainstream smoke induced DNA strand breaks in sperm, both sidestream and mainstream smoke increased sperm chromatin structure abnormalities [51]. Regarding fertility, it was found that mainstream smoke affected fertilization, the embryonic implantation rate and the rate of embryonic development, while sidestream smoke affected fertilization only [51, 52]. Finally, it was found that mainstream tobacco smoke induced genetic mutations in spermatogonial stem cells of exposed male mice [53]. Although tobacco smoke contains the mutagenic compound $\mathrm{B}[\mathrm{a}] \mathrm{P}$, it is not clear from these studies, whether the observed effects can be attributed to B[a]P exposure.

\section{Human studies}

The effects of $B[a] P$ exposure on spermatogenesis and male germ cells in humans have been determined by studying the effects of smoking in men. From these studies it is clear that cigarette smokers have increased levels of oxidative damage [54], DNA strand breaks [55], DNA adducts [56], and chromosomal abnormalities [57, $58]$ in their sperm. In addition, diminished semen volume, sperm concentration, total sperm count and motile spermatozoa have been associated with cigarette smoking [59]. Smoking may therefore affect the quality of the sperm, but it is still unknown whether these types of damage also result in permanent mutations in spermatogonial stem cells that can be transferred to the next generation.

\section{Aim and outline of the thesis}

Although $B[a] P$ has been investigated thoroughly for its mutagenic and carcinogenic capacity in the last century, it still remains unclear whether there is a relation between DNA adduct formation and the production of germ line mutations. Classical studies were inconclusive, probably because molecular protective mechanism, such as DNA repair, may at least in part prevent mutation induction by $\mathrm{B}[\mathrm{a}] \mathrm{P}$ in the male germ line. Therefore the aim of the present thesis is to further investigate whether $\mathrm{B}[\mathrm{a}] \mathrm{P}$ is a germ line mutagen and whether DNA repair represents a relevant molecular protective mechanism affecting the relation between DNA adduct formation and the production of germ line mutations.

In chapter 2, the classical and newly developed methods for the detection of heritable gene mutations will be reviewed and compared. To study the aim of the present thesis, we used, in chapter 3, DNA repair proficient (Wt) and DNA repair deficient $\left(\mathrm{Xpc}^{-/-}\right)$male mice that were exposed to B[a]P. We describe the DNA damaging effects of $B[a] P$ in the reproductive tissue and male germ cells of these mice, and the role of GGR/NER in the removal of DNA damage by comparing DNA adduct kinetics in $\mathrm{Wt}$ and $X p c^{-/-}$mice after a single dose of $\mathrm{B}[\mathrm{a}] \mathrm{P}$. This study indicated that GGR/NER is playing an important role in the efficient removal of $B[a] P$ induced DNA 


\section{CHAPTER 1}

damage. In absence of DNA repair, additional protective mechanisms could protect the male germ line. This was further investigated by comparing the gene expression profiles of $\mathrm{Wt}$ and $X p c^{-/-}$mice after $\mathrm{B}[\mathrm{a}] \mathrm{P}$ exposure as described in chapter 4 . Moreover, the mutagenic potential of $\mathrm{B}[\mathrm{a}] \mathrm{P}$ in testes and male germ cells of subchronically exposed $\mathrm{Wt}$ and $\mathrm{Xpc}^{-/-}$mice was studied in chapter 5 by using the lacZ gene mutation assay. In the study described in chapter $\mathbf{6}$, we investigated the impact of subchronic exposure to $\mathrm{B}[\mathrm{a}] \mathrm{P}$ on the formation of heritable gene mutations in hypervariable expanded simple tandem repeat (ESTR) loci in the offspring of $\mathrm{Xpc}^{-/-}$mice. Finally, the results of all experiments are summarized and discussed in chapter 7 . 


\section{References}

1. Colt, J.S. and Blair, A. (1998) Parental occupational exposures and risk of childhood cancer. Environ Health Perspect, 106 Suppl 3, 909-925.

2. Somers, C.M., Yauk, C.L., White, P.A., Parfett, C.L. and Quinn, J.S. (2002) Air pollution induces heritable DNA mutations. Proc Natl Acad Sci USA, 99, 15904-15907.

3. Atienzar, F.A. and Jha, A.N. (2004) The random amplified polymorphic DNA (RAPD) assay to determine DNA alterations, repair and transgenerational effects in B(a)P exposed Daphnia magna. Mutat Res, 552, 125-140.

4. Russell, L.B., Selby, P.B., von Halle, E., Sheridan, W. and Valcovic, L. (1981) The mouse specific-locus test with agents other than radiations: interpretation of data and recommendations for future work. Mutation research, 86, 329-354.

5. Hall, M. and Grover, P.L. (1990) Polycyclic aromatic hydrocarbons: metabolism, activation and tumour initiation. In: Chemical Carcinogenesis and Mutagenesis. Raven Press, New York, USA.

6. Niesink, R.J.M., De Vries, J. and Hollinger, M.A. (1996) Chapter 3: Biotransformation: detoxication and bioactivation. In: Toxicology, principles and applications CRC Press LLC, Boca Raton, USA.

7. Gelboin, H.V. (1980) Benzo[alpha]pyrene metabolism, activation and carcinogenesis: role and regulation of mixed-function oxidases and related enzymes. Physiological reviews, 60, 1107-1166.

8. Singh, R., Sram, R., Binkova, B., Kalina, I., Popov, T., Georgieva, T., Garte, S., Taioli, E. and Farmer, P. (2007) The relationship between biomarkers of oxidative DNA damage, polycyclic aromatic hydrocarbon DNA adducts, antioxidant status and genetic susceptibility following exposure to environmental air pollution in humans. Mutation research, 620, 83-92.

9. Baird, W.M., Hooven, L.A. and Mahadevan, B. (2005) Carcinogenic polycyclic aromatic hydrocarbonDNA adducts and mechanism of action. Environ Mol Mutagen, 45, 106-114.

10. Brookes, P. and Lawley, P.D. (1964) Evidence for the Binding of Polynuclear Aromatic Hydrocarbons to the Nucleic Acids of Mouse Skin: Relation between Carcinogenic Power of Hydrocarbons and Their Binding to Deoxyribonucleic Acid. Nature, 202, 781-784.

11. Zhang, Y., Wu, X., Guo, D., Rechkoblit, O., Geacintov, N. and Wang, Z. (2002) Two-step error-prone bypass of the (+)- and (-)-trans-anti-BPDE-N2-dG adducts by human DNA polymerases eta and kappa. Mutation research, 510, 23-35.

12. Zhang, Y., Wu, X., Guo, D., Rechkoblit, O. and Wang, Z. (2002) Activities of human DNA polymerase kappa in response to the major benzo[a]pyrene DNA adduct: error-free lesion bypass and extension synthesis from opposite the lesion. DNA repair, 1, 559-569.

13. Yu, D., Berlin, J., Penning, T. and Field, J. (2002) Reactive oxygen species generated by PAH oquinones cause change-in-function mutations in p53. Chemical research in toxicology, 15, 832-842.

14. Le Calvez, F., Mukeria, A., Hunt, J., Kelm, O., Hung, R., Tanire, P., Brennan, P., Boffetta, P., Zaridze, D. and Hainaut, P. (2005) TP53 and KRAS mutation load and types in lung cancers in relation to tobacco smoke: distinct patterns in never, former, and current smokers. Cancer research, 65, 5076-5083.

15. Denissenko, M.F., Pao, A., Tang, M. and Pfeifer, G.P. (1996) Preferential formation of benzo[a]pyrene adducts at lung cancer mutational hotspots in P53. Science, 274, 430-432.

16. Vineis, P. and Caporaso, N. (1995) Tobacco and cancer: epidemiology and the laboratory. Environmental Health Perspectives, 103, 156-160.

17. Roos, W. and Kaina, B. (2006) DNA damage-induced cell death by apoptosis. Trends in molecular medicine, 12, 440-450.

18. Gillet, L.C. and Scharer, O.D. (2006) Molecular mechanisms of mammalian global genome nucleotide excision repair. Chem Rev, 106, 253-276.

19. van Hoffen, A., Balajee, A.S., van Zeeland, A.A. and Mullenders, L.H. (2003) Nucleotide excision repair and its interplay with transcription. Toxicology, 193, 79-90.

20. Sugasawa, K. (2009) Regulation of damage recognition in mammalian global genomic nucleotide excision repair. Mutat Res,

21. van Steeg, H. and Kraemer, K.H. (1999) Xeroderma pigmentosum and the role of UV-induced DNA damage in skin cancer. Molecular Medicine Today, 5, 86-94.

22. Camenisch, U., Trautlein, D., Clement, F.C., Fei, J., Leitenstorfer, A., Ferrando-May, E. and Naegeli, H. (2009) Two-stage dynamic DNA quality check by xeroderma pigmentosum group C protein. Embo J, 28, 2387-2399.

23. Maillard, O., Solyom, S. and Naegeli, H. (2007) An aromatic sensor with aversion to damaged strands confers versatility to DNA repair. PLoS biology, 5, e79.

24. Melis, J.P., Wijnhoven, S.W., Beems, R.B., Roodbergen, M., van den Berg, J., Moon, H., Friedberg, E., van der Horst, G.T., Hoeijmakers, J.H., Vijg, J. and van Steeg, H. (2008) Mouse models for xeroderma pigmentosum group A and group C show divergent cancer phenotypes. Cancer Res, 68, 1347-1353. 
25. D'Errico, M., Parlanti, E., Teson, M., de Jesus, B.M., Degan, P., Calcagnile, A., Jaruga, P., Bjoras, M., Crescenzi, M., Pedrini, A.M., Egly, J.M., Zambruno, G., Stefanini, M., Dizdaroglu, M. and Dogliotti, E. (2006) New functions of XPC in the protection of human skin cells from oxidative damage. Embo J, 25, 4305-4315.

26. Uehara, Y., Ikehata, H., Furuya, M., Kobayashi, S., He, D., Chen, Y., Komura, J.I., Ohtani, H., Shimokawa, I. and Ono, T. (2009) XPC is involved in genome maintenance through multiple pathways in different tissues. Mutat Res,

27. Wijnhoven, S.W., Hoogervorst, E.M., de Waard, H., van der Horst, G.T. and van Steeg, H. (2007) Tissue specific mutagenic and carcinogenic responses in NER defective mouse models. Mutat Res, 614, 77-94.

28. Cheo, D.L., Ruven, H.J., Meira, L.B., Hammer, R.E., Burns, D.K., Tappe, N.J., van Zeeland, A.A., Mullenders, L.H. and Friedberg, E.C. (1997) Characterization of defective nucleotide excision repair in $X P C$ mutant mice. Mutat Res, 374, 1-9.

29. Sands, A.T., Abuin, A., Sanchez, A., Conti, C.J. and Bradley, A. (1995) High susceptibility to ultravioletinduced carcinogenesis in mice lacking XPC. Nature, 377, 162-165.

30. Cheo, D.L., Meira, L.B., Burns, D.K., Reis, A.M., Issac, T. and Friedberg, E.C. (2000) Ultraviolet B radiation-induced skin cancer in mice defective in the Xpc, Trp53, and Apex (HAP1) genes: genotypespecific effects on cancer predisposition and pathology of tumors. Cancer Res, 60, 1580-1584.

31. Friedberg, E.C., Bond, J.P., Burns, D.K., Cheo, D.L., Greenblatt, M.S., Meira, L.B., Nahari, D. and Reis, A.M. (2000) Defective nucleotide excision repair in Xpc mutant mice and its association with cancer predisposition. Mutat Res, 459, 99-108.

32. Hollander, M.C., Philburn, R.T., Patterson, A.D., Velasco-Miguel, S., Friedberg, E.C., Linnoila, R.I. and Fornace, A.J., Jr. (2005) Deletion of XPC leads to lung tumors in mice and is associated with early events in human lung carcinogenesis. Proc Natl Acad Sci U S A, 102, 13200-13205.

33. Cheo, D.L., Burns, D.K., Meira, L.B., Houle, J.F. and Friedberg, E.C. (1999) Mutational inactivation of the xeroderma pigmentosum group $\mathrm{C}$ gene confers predisposition to 2-acetylaminofluorene-induced liver and lung cancer and to spontaneous testicular cancer in Trp53-/- mice. Cancer Res, 59, 771-775.

34. Hoogervorst, E.M., van Oostrom, C.T., Beems, R.B., van Benthem, J., van den Berg, J., van Kreijl, C.F., Vos, J.G., de Vries, A. and van Steeg, H. (2005) 2-AAF-induced tumor development in nucleotide excision repair-deficient mice is associated with a defect in global genome repair but not with transcription coupled repair. DNA Repair (Amst), 4, 3-9.

35. Wickliffe, J.K., Galbert, L.A., Ammenheuser, M.M., Herring, S.M., Xie, J., Masters, O.E., 3rd, Friedberg, E.C., Lloyd, R.S. and Ward, J.B., Jr. (2006) 3,4-Epoxy-1-butene, a reactive metabolite of 1,3-butadiene, induces somatic mutations in Xpc-null mice. Environ Mol Mutagen, 47, 67-70.

36. Yauk, C.L., Fox, G.A., McCarry, B.E. and Quinn, J.S. (2000) Induced minisatellite germline mutations in herring gulls (Larus argentatus) living near steel mills. Mutat Res, 452, 211-218.

37. Somers, C.M., McCarry, B.E., Malek, F. and Quinn, J.S. (2004) Reduction of particulate air pollution lowers the risk of heritable mutations in mice. Science, 304, 1008-1010.

38. Adler, I.D. (1996) Comparison of the duration of spermatogenesis between male rodents and humans. Mutat Res, 352, 169-172.

39. Grootegoed, J.A., Siep, M. and Baarends, W.M. (2000) Molecular and cellular mechanisms in spermatogenesis. Bailliere's best practice \& research, 14, 331-343.

40. Holstein, A.F., Schulze, W. and Davidoff, M. (2003) Understanding spermatogenesis is a prerequisite for treatment. Reprod Biol Endocrinol, 1, 107.

41. Hecht, N.B. (1990) Regulation of 'haploid expressed genes' in male germ cells. Journal of reproduction and fertility, 88, 679-693.

42. Olsen, A.K., Lindeman, B., Wiger, R., Duale, N. and Brunborg, G. (2005) How do male germ cells handle DNA damage? Toxicol Appl Pharmacol, 207, 521-531.

43. Ehmcke, J., Wistuba, J. and Schlatt, S. (2006) Spermatogonial stem cells: questions, models and perspectives. Hum Reprod Update, 12, 275-282.

44. Russell L.D., E.R., Sinha Hikim A.P., Clegg E.D. (1990) Mammalian Spermatogenesis. In: Histological and Histopathological Evaluation of the testis. Cache River Press, Clearwater, USA.

45. Georgellis, A., Toppari, J., Veromaa, T., Rydstrm, J. and Parvinen, M. (1990) Inhibition of meiotic divisions of rat spermatocytes in vitro by polycyclic aromatic hydrocarbons. Mutation research, 231, 125135.

46. Watanabe, S. and Kamiguchi, Y. (2001) Chromosome analysis of human spermatozoa following in vitro exposure to cyclophosphamide, benzo(a)pyrene and $\mathrm{N}$-nitrosodimethylamine in the presence of rat liver S9. Mutat Res, 491, 57-63.

47. Kamiguchi, Y. and Tateno, H. (2002) Radiation- and chemical-induced structural chromosome aberrations in human spermatozoa. Mutat Res, 504, 183-191.

48. Revel, A., Raanani, H., Younglai, E., Xu, J., Han, R., Savouret, J.F. and Casper, R.F. (2001) Resveratrol, a natural aryl hydrocarbon receptor antagonist, protects sperm from DNA damage and apoptosis caused by benzo(a)pyrene. Reprod Toxicol, 15, 479-486. 
49. Ramesh, A., Inyang, F., Lunstra, D., Niaz, M., Kopsombut, P., Jones, K., Hood, D., Hills, E. and Archibong, A. (2008) Alteration of fertility endpoints in adult male F-344 rats by subchronic exposure to inhaled benzo(a)pyrene. Experimental and Toxicologic Pathology, 60, 269-280.

50. Inyang, F., Ramesh, A., Kopsombut, P., Niaz, M., Hood, D., Nyanda, A. and Archibong, A. (2003) Disruption of testicular steroidogenesis and epididymal function by inhaled benzo(a)pyrene. Reproductive Toxicology, 17, 527-537.

51. Polyzos, A., Schmid, T.E., Pina-Guzman, B., Quintanilla-Vega, B. and Marchetti, F. (2009) Differential sensitivity of male germ cells to mainstream and sidestream tobacco smoke in the mouse. Toxicol Appl Pharmacol, 237, 298-305.

52. Kapawa, A., Giannakis, D., Tsoukanelis, K., Kanakas, N., Baltogiannis, D., Agapitos, E., Loutradis, D., Miyagawa, I. and Sofikitis, N. (2004) Effects of paternal cigarette smoking on testicular function, sperm fertilizing capacity, embryonic development, and blastocyst capacity for implantation in rats. Andrologia, 36, 57-68.

53. Yauk, C.L., Berndt, M.L., Williams, A., Rowan-Carroll, A., Douglas, G.R. and Stampfli, M.R. (2007) Mainstream tobacco smoke causes paternal germ-line DNA mutation. Cancer Res, 67, 5103-5106.

54. Fraga, C.G., Motchnik, P.A., Wyrobek, A.J., Rempel, D.M. and Ames, B.N. (1996) Smoking and low antioxidant levels increase oxidative damage to sperm DNA. Mutation research, 351, 199-203.

55. Potts, R.J., Newbury, C.J., Smith, G., Notarianni, L.J. and Jefferies, T.M. (1999) Sperm chromatin damage associated with male smoking. Mutation research, 423, 103-111.

56. Zenzes, M.T., Bielecki, R. and Reed, T.E. (1999) Detection of benzo(a)pyrene diol epoxide-DNA adducts in sperm of men exposed to cigarette smoke. Fertil Steril, 72, 330-335.

57. Robbins, W.A., Vine, M.F., Truong, K.Y. and Everson, R.B. (1997) Use of fluorescence in situ hybridization (FISH) to assess effects of smoking, caffeine, and alcohol on aneuploidy load in sperm of healthy men. Environmental and molecular mutagenesis, 30, 175-183.

58. Rubes, J., Lowe, X., Moore, D., Perreault, S., Slott, V., Evenson, D., Selevan, S.G. and Wyrobek, A.J. (1998) Smoking cigarettes is associated with increased sperm disomy in teenage men. Fertility and sterility, 70, 715-723.

59. Ramlau-Hansen, C.H., Thulstrup, A.M., Aggerholm, A.S., Jensen, M.S., Toft, G. and Bonde, J.P. (2007) Is smoking a risk factor for decreased semen quality? A cross-sectional analysis. Human Reproduction, 22, 188-196. 



\section{Chapter 2}

REVIEW

\section{New methods for assessing male germ line mutations in humans and genetic risks in their offspring}

Mutagenesis 2008; 23(4): 241-247

Nicole Verhofstad Joost O. Linschooten Jan van Benthem Yuri E. Dubrova Harry van Steeg Frederik J. van Schooten Roger W.L. Godschalk 


\section{Abstract}

Germ line mutations resulting from chemical or radiation exposure are a particular problem in toxicology as they affect not only the exposed generation, but an infinite number of generations thereafter. Established methods to show that these mutations occur in an F1 or subsequent population require the use of a large number of progeny for statistical significance. Consequently, many thousands of animals have been used in the past. Such a use is no longer considered desirable and is also very expensive. Several new molecular techniques (including analysis of tandem repeats and randomly amplified polymorphic DNA) now provide alternative methods of assessment, which also allow the quantification of individual mutations in individual sperm cells. These can also be applied to human offspring, making extrapolation obsolete. The downside of these methods is that they effectively determine the mutation rate in certain regions of DNA and the relevance of these to diseases, particularly cancer, is not always apparent. Therefore it must be assumed that an increase in mutation rates in these selected regions correlates with altered phenotype. However, disease types linked to changes in tandem repeat length indicate that these may act as relevant markers for the development of phenotypes. Further research and evaluation is required to more closely link changes in DNA with altered phenotype and validate the use of tandem repeats and randomly amplified polymorphic DNA in transgenerational genotoxicity testing. This paper introduces and compares recently developed methods to assess mutations in sperm due to stem cell damage. 


\section{Introduction}

New methods are needed to detect germ line mutations induced by exposures to genotoxins in humans. Too little is known about how genotoxic compounds induce mutations in human germ cells and the subsequent transmission of these to offspring. Transmittable genetic damage in humans has been studied in populations exposed to radiation [1], whereas germ line mutations induced by environmental pollutants have only been studied in animals. Most of the mutations transmitted to offspring had a paternal origin [2-5]. A similar result might be expected in humans although a direct relationship between mutations in human sperm and a genetic disease induced in the progeny has not been reported yet [6].

A parallelogram approach developed by Sobels [7] and extended by Adler [8] has been used until now to extrapolate measurable effects in rodent germ cells, their progeny and human germ cells in vitro to estimate the genetic risks in humans in vivo (figure 1). This approach uses classical methods, such as the morphological specific locus (MSL) test and the dominant lethal test. These tests have low sensitivity, use large numbers of progeny to obtain the recommended sample size, and are very time consuming and expensive. Recently developed germ cell mutagenicity tests seem to have rendered this parallelogram approach obsolete, since these new tests can detect mutations in human germ cells and offspring, and are suitable for studying genetic risks in human populations. A recent review by Singer et al. [9] compared classical approaches (e.g. MSL and heritable translocation assay) with new methodologies (e.g. expanded simple tandem repeats (ESTRs) mutation assay and the gene mutation test in transgenic rodents) but too little data was available to compare the performances of these tests in detail.

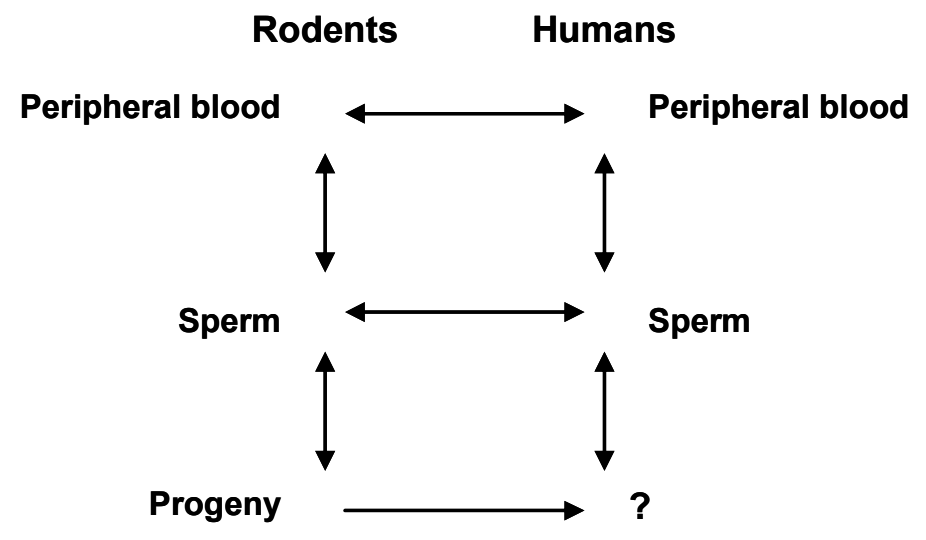

Figure 1. A parallelogram approach to estimate the genetic risk in humans (adapted from Adler [8]). $\leftrightarrow$ measured, $\rightarrow$ estimated.

Of these new techniques, only the analysis of tandem repeat sequences seems suitable for testing in humans. We will therefore discuss this assay in greater detail together with randomly amplified polymorphic DNA PCR (RAPD-PCR), an assay that could be used to quickly screen exposed humans for the transmission of mutations to 
their offspring. Although these new methods seem to have a high sensitivity, they have yet to be validated and only a few laboratories are equipped to perform the analysis of tandem repeat sequences.

Germ cell tests play a decisive role in classifying and labelling chemicals for genotoxicity. To minimize animal use, tests that detect effects in germ cells should be performed first. However, if quantification of these effects is required, assays for mutations in the offspring are essential. In the guidance document for genotoxicity under REACH, the new EU policy for authorization of new and existing chemicals, a test that determines changes in hypervariable tandem repetitive regions is stated as an alternative to classical tests. As this test also allows the measurement of heritable damage in humans, it is a recommended alternative.

\section{Germ line mutagenicity tests}

\section{Randomly amplified polymorphic DNA PCR}

RAPD-PCR was first described by Williams et al. and is based on the amplification of random unknown DNA segments with a single primer of arbitrary nucleotide sequence [10]. RAPD-PCR can be used to detect genomic alterations without prior information about the loci. Multiple fragments are generated in a single reaction that can be visualized after gel electrophoresis (figure 2A). Any genomic alteration (point mutations, structural rearrangements, deletions, insertions, etc.) may change the place where the primer anneals, resulting in different profiles (figure 2B and C). For germ cell mutagenicity testing, the patterns obtained from the mother and father can be compared with those from the offspring. Differences between the patterns may indicate a genomic alteration if 1) the DNA fragment is only visible in the pattern of the child, 2) the DNA fragment is present in the pattern of the father and/or the mother, but absent in the pattern of the child, or 3) bands are increased or decreased in intensity. However, PCR products that disappear or change in intensity should be interpreted with care, because of the possibility of heterozygosity in the parents. Other PCR-based techniques have also been developed, like DNA amplification fingerprinting (DAF) and arbitrarily primed PCR (AP-PCR) [11, 12]. However, these have yet to be used for germ line mutation detection.

RAPD-PCR might detect single base changes in genomic DNA [10], although genomic rearrangements are probably detected the most [13]. As RAPD-PCR only detects genomic alterations in or close to a priming site, the use of multiple primers may increase the sensitivity of this method. Moreover, the sensitivity of the test could be improved by using a more accurate method described by Valentini et al. for the separation and detection of multiple amplified fragments [14]. In toxicological exposure experiments to assess population-genetic effects this method successfully detected genomic alterations induced by benzo(a)pyrene $(\mathrm{B}[\mathrm{a}] \mathrm{P})$, copper, mitomycin $\mathrm{C}$, UV radiation and X-rays [15-18]. Theoretically, all routes of exposure in which toxicants may affect the genetic structure can be analysed. Experimental studies usually require several hundred offspring for the powerful detection of germ line alterations using approximately 5 to 10 RAPD primers.

RAPD-PCR has several advantages: 1) it is relatively inexpensive and rapid, 2) it yields information on a large number of loci, 3) the same primers can be used for genomic analysis in all species, including humans, and 4) it can be performed with relatively small sample sizes. However, there are also several drawbacks: 1) the 
results are considered to be qualitative and indicative, and should be further corroborated by cloning, sequencing and probing techniques, 2) the nature of the genomic change observed can not be assessed from the sequence of the RAPD-PCR product, 3) the technique may not screen the genome as randomly as expected, and 4) both nuclear and mitochondrial DNA may be amplified during PCR. Amplification of mitochondrial DNA may complicate the interpretation of RAPD fingerprints as it is not a Mendelian marker, but only inheritable from the mother [19]. Reproducibility of RAPD profiles is another potential pitfall [20]. However, this can be overcome by using appropriate PCR conditions and by cleaving DNA with restriction enzymes prior to the amplification [21].

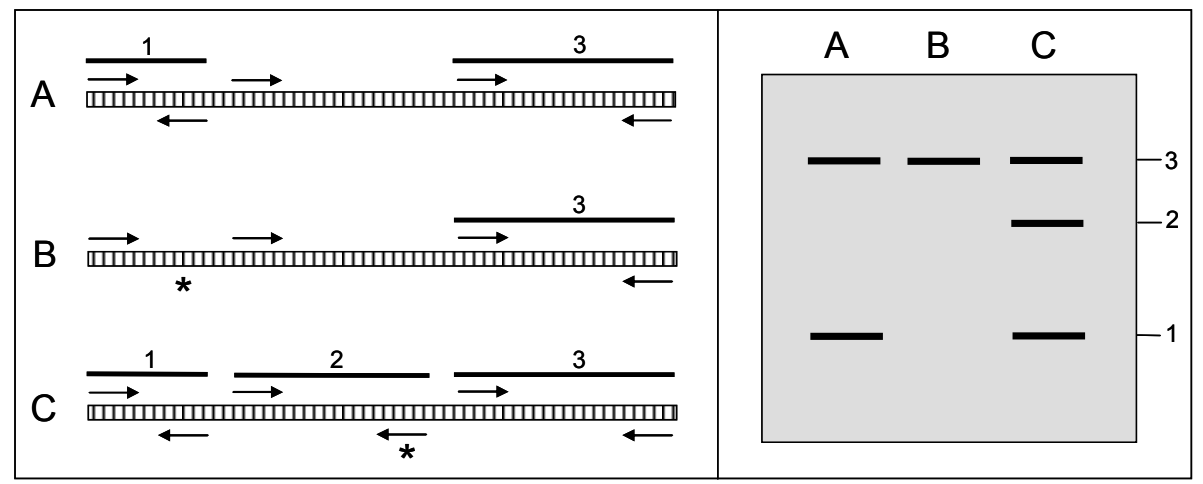

Figure 2. Simplified overview of the RAPD-PCR principle: A. A single random primer is able to bind at several sites in the DNA (indicated by arrows) and produces fragments of different lengths upon PCR (products 1 and 3 ), which can subsequently be detected after gel electrophoresis (panel on the right). B. If a mutation is introduced at a site at which a primer binds, this binding site is lost (indicated by *) under stringent conditions, and so the PCR product (product 1) cannot be formed. C. Mutations can also lead to the introduction of new binding sites for the primer (indicated by *), leading to the formation of a new PCR product (product 2). Situations $\mathbf{B}$ and $\mathbf{C}$ can involve a range of genomic alterations such as deletions, insertions and chromosomal rearrangements. If the distance between two primers due to a genomic alteration is too large for effective amplification during PCR, the PCR product will also be lost. However, a deletion may result in primers that are close enough to allow amplification.

So far, RAPD-PCR has mainly been used in ecotoxicological studies, for example, to detect genomic alterations in Daphnia magna exposed to $B[a] P[13,22]$. Weinberg et al. [23] have used the method in humans and they detected a seven-fold increase in mutation frequencies in blood from children of families conceived after parental exposure to radiation from the Chernobyl accident, compared to children conceived before parental exposure. They concluded that exposure to low dose radiation induces genetic changes in the germ line. Although the finding of a sevenfold increase in mutation rate has been questioned by Jeffreys and Dubrova [24] and mutants have not been validated, the study nevertheless raises major concerns regarding radiation-induced heritable genetic effects.

In conclusion, RAPD-PCR seems to be a promising method for the analysis of germ line mutations in offspring. For human studies, however, PCR conditions and RAPD-PCR methods should be optimized to yield reproducible DNA fingerprints, and several verification methods should be used to validate and confirm results [13]. 
Although the findings obtained by RAPD-PCR can only be regarded as indicative at present, the method can still be used as an effective screening tool in studying germ line mutagenesis.

\section{DNA fingerprinting of tandem repetitive DNA sequences}

Part of the genome consists of tandem repetitive sequences, which are known to be unstable and predominantly non-coding DNA. These sequences can be divided into microsatellites, minisatellites and ESTRs based on sequence size and number of repeats (table 1). Yauk [25] provides further information on the differences between minisatellites and ESTRs with respect to their structure and mutational mechanisms.

Minisatellites and ESTRs can be sensitive tools for monitoring germ line mutations after mutagenic exposure, since both exhibit high mutation rates. This facilitates the assessment of induced mutations in a relatively small number of samples following environmentally relevant exposure [26]. The DNA is digested with restriction enzymes and subsequently electrophoresed, before being hybridized with probes that are complementary to hypervariable loci. This gives a unique pattern of fragments (DNA fingerprint) (figure 3). The use of multiple probes can increase the probability of detecting mutations, when comparing the patterns between parents and their offspring (each band should also be present in one of the parents). Therefore this is a statistically powerful technique that reduces the time needed and costs involved to quantify the number of germ line mutations.

Table 1. Structural differences of tandem repetitive sequences

\begin{tabular}{lccc}
\hline Tandem repetitive sequences & Sequence size $(\mathbf{n t})$ & Number of repeats & Total size \\
\hline Microsatellites & $2-5$ & $1-100$ & - \\
Minisatellites & $5-100$ & Up to 6000 & Up to $30 \mathrm{~kb}$ \\
ESTRs & $4-6$ & Up to 4000 & Up to $16 \mathrm{~kb}$ \\
\hline
\end{tabular}

The structure of tandem repetitive sequences can be classified according to sequence size and number of repeats. nt, nucleotides.

Recent experiments have shown that it is possible with minisatellites and ESTRs to detect an increase in germ line mutations in humans and animals exposed to radioactive or chemical pollutants in their natural environment [2-5]. Multi-locus DNA fingerprinting has also demonstrated significantly elevated mutation rates in the offspring of humans inhabiting the radioactive polluted areas of Belarus near Chernobyl, when compared to control families from the United Kingdom. Moreover, a significant radiation-dose effect relationship was observed [1,27].

These studies demonstrate that the analysis of tandem repetitive sequences could be a sensitive method for the detection of germ line mutations transmitted to the next generation and caused by long-term and/or low dose environmental exposure. However, very little is currently known about germ line mutations induced at hypervariable tandem repeat sequences by specific chemicals. Two mono-functional alkylating agents, ethylnitrosourea (ENU) and isopropyl methanesulphonate (iPMS), and the anticancer drug etoposide have already been investigated and led to elevated ESTR mutation rates in the germ line of male mice [28]. Although these results demonstrate that tandem repeat sequences can be used to monitor germ line muta- 
tion induction, the effects of exposure to environmental or dietary mutagens other than radiation on germ line mutation induction at tandem repeat loci in rodents and humans clearly merits further evaluation.

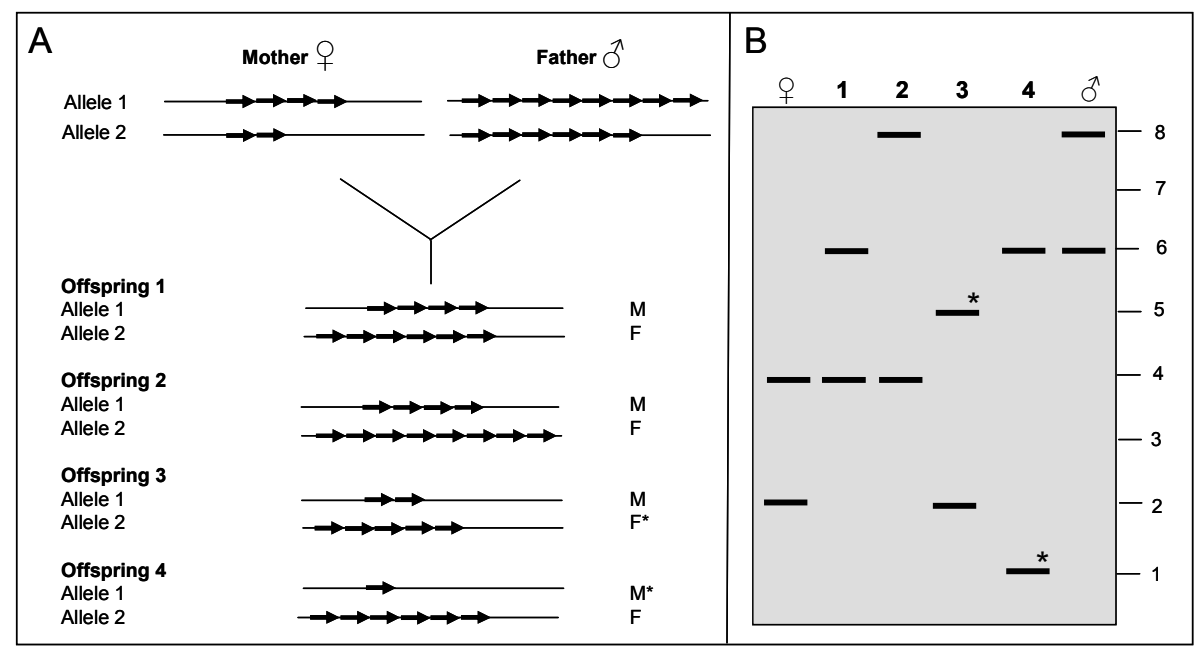

Figure 3. Simplified overview of tandem repeat mutation analysis. Children always inherit one tandem repeat allele from their mother and one from their father. Changes in allele size indicate a deletion or insertion of one or more repeat units. A. Offspring 1 has inherited allele 1 from the mother and allele 2 from the father and no changes in allele size are detectable. There are also no changes detectable in offspring 2, who inherited another allele from the father. Offspring 3 has inherited allele 1 from the mother and allele 2 from the father. However, a change in repeat size of the allele inherited from the father (allele 2) has occurred, which indicates a deletion of one repeat unit. In offspring 4, a change in repeat size of allele 1 has occurred. A deletion of one repeat unit is visible in the allele inherited from the mother. B. Changes in allele size are visible after hybridization of digested and electrophoresed DNA, which gives a pattern of tandem repeat fragments unique for a person.

\section{Small-pool PCR}

Small-pool PCR (SP-PCR), which is derived from DNA fingerprinting of minisatellites, can also be used as a germ cell mutagenicity test [29-31]. However, in contrast to DNA fingerprinting, the tandem repeats are amplified by PCR using allele-specific PCR primers directed at the polymorphic sites in minisatellite regions. This allows the analysis of mutant alleles in individual gametes. Consequently this method can be used to map minisatellite length polymorphisms directly in the germ cell DNA [29-31]. SP-PCR uses amplification of small aliquots of sperm DNA to screen thousands of sperm cells from an individual in one PCR reaction to detect changes in the repeat size of unstable minisatellite loci. Mutations detected by SP-PCR as products of altered length are counted and the rate of mutation expressed as a given number of events found in a given estimated number of sperm equivalents [32].

Quantitative SP-PCR methods were found to be appropriate for investigating the effects of chemotherapeutic mutagens and radiation on minisatellite mutation rates in human sperm [32-35]. The advantage of this approach is that relatively small increases in mutation rate can be detected in individual samples, which makes it a 
sensitive method. However, this technique also has several limitations that are predominantly related to interpretation of the data. First, this technique may potentially underestimate the true number of expansion events, since PCR is known to favour the amplification of the smaller allele. Second, the variants detected in this assay may be PCR artefacts rather than variants in repeat size. Third, SP-PCR is less precise in controlling for the number of cell equivalents analysed. Consequently, considerable care should be taken in accurately diluting and pipetting the DNA samples for SP-PCR in order to minimize variation, as the number of cells in each pool is the denominator in determining the rates of change. Furthermore, the efficiency of amplification of all the cell equivalents within a pool may be less than $100 \%$ [36].

In conclusion, SP-PCR seems less appropriate as a mutagenicity test than standard DNA fingerprinting of minisatellites and ESTRs. The disadvantages of this technique are mainly related to the use of PCR amplification, which causes misinterpretation of the results by PCR artefacts.

\section{Single-molecule PCR}

In addition to SP-PCR, single molecule PCR (SM-PCR) has been developed as a method for detecting new mutations in both the germ line and somatic tissues [35]. This method has been used to quantify the in vivo mutation frequency at the Ms6-hm locus in somatic and germ cells, and to determine whether mutation induction by environmental exposure and ionizing radiation can be detected in pedigrees as well as directly in sperm DNA [35, 37]. This is an important addition to the pedigree approach for tandem repeat analysis, because mutations in sperm are not necessarily transferred to the offspring and vice versa mutations in the offspring do not necessarily originate from the gametes, but can be induced during early embryogenesis. For this SM-PCR method, DNA samples are digested outside the ESTR array and distal to the PCR primer sites prior to amplification, to render genomic DNA fully soluble prior to dilution. Digested DNA is serially diluted and amplified with flanking primers [38]. PCR products are analysed by electrophoresis followed by hybridization with specific probes. The approximate number of amplifiable ESTR molecules in each dilution is estimated by Poisson analysis of the number of positive and negative reactions for ESTR-PCR products. Subsequently, a new set of PCR reactions is seeded with each containing a mean of approximately one amplifiable ESTR molecule. PCR products are subsequently separated on an agarose gel, followed by hybridization and scoring of the allele lengths. A band shift of at least $1 \mathrm{~mm}$ relative to the internal size marker indicates a mutation; smaller changes can not be scored reliably [35].

SM-PCR has several advantages. First, experimental time might be reduced because mating and birth is unnecessary (it has been shown in laboratory mice that mutation rates in the offspring were indistinguishable from the rates in sperm DNA [35]). Second, SM-PCR was found to be useful for studying mutation induction at low dose exposures [35] and the majority of mutations were small changes in repeat copy number. These advantages allow a more thorough investigation of chemicals with different modes of action. Furthermore, using SM-PCR circumvents the requirement of sub-cloning. Yauk et al. [35] showed that SM-PCR can provide robust estimates of the frequency of ESTR mutations in somatic and sperm cells of irradiated and control male mice.

In addition to the limited number of in vivo results, in vitro studies have also shown that SM-PCR is a useful method for detecting mutations. Polyzos et al. [37, 
39] described the same method for the in vitro detection of de novo mutations in cultures of embryonic cells and noted that cells treated with ENU, B[a]P and etoposide showed a significant increase of the mutation frequency compared to untreated cells. They also indicated a similarity in mutation response between embryonic fibroblasts in culture, and somatic and germ cells in vivo at the ESTR locus [39].

In conclusion, SM-PCR methods are appropriate for the detection of germ line mutations at the ESTR locus Ms6-hm. The reduction in time and costs make this method particularly suitable for screening large numbers of agents. A similar approach developed for minisatellites would be very useful for studying mutation frequencies in humans, but such methods are currently lacking.

\section{Do differences between rodent and human spermatogenesis affect germ line mutation induction?}

The advantage of the methods described above is that they can be used to detect germ line mutations in rodents and humans. This is essential because until recently extrapolation of animal data was necessary for assessing potential genetic risks in the human population. Nonetheless, extrapolation might still be very useful in certain situations. Human exposure to genotoxic chemicals usually involves chronic exposure to low doses, making it much more difficult to study mutagenicity during spermatogenesis. In theory, this could lead to a misinterpretation of the effects due to the differences in spermatogenesis between rodents and humans (reviewed by Ehmcke et al. [40], and summarized in figure 4). There are differences in type of stem cell and in mitotic expansion. Finally, it must also be remembered that the vulnerability of germ cells towards genotoxins is known to alter during spermatogenesis due to cell turnover, differentiation and changes in DNA repair activity [41].

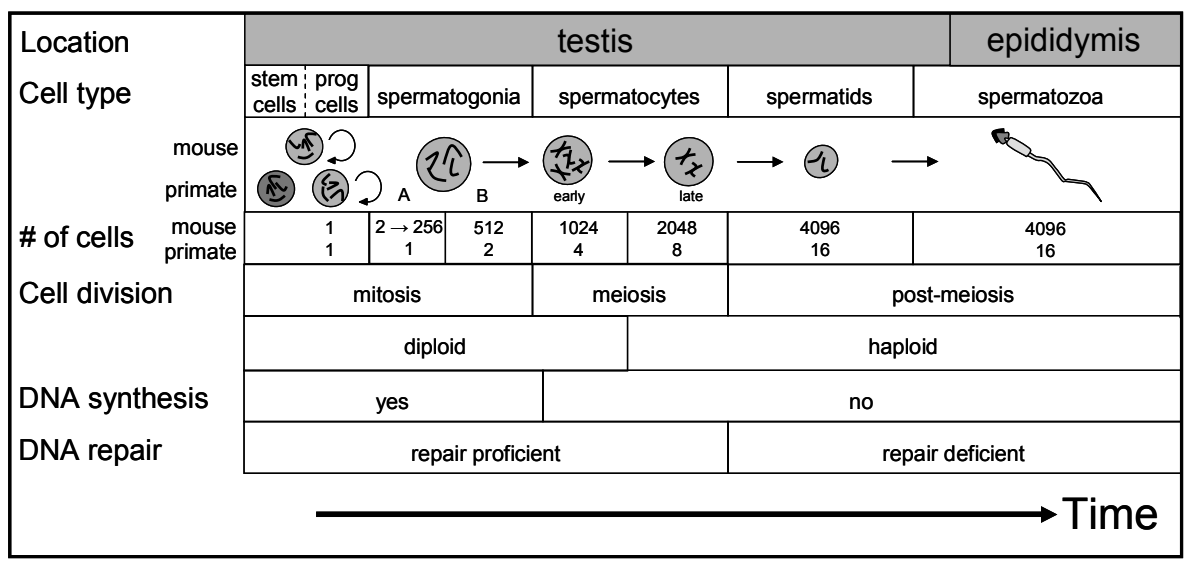

Figure 4. Schematic overview of spermatogenesis in mice and humans. This scheme shows the characteristics of different cell stages during spermatogenesis that are important for the formation of mutations in germ cells at different stages. Differences in spermatogenesis between mice and humans are predominantly at the level of stem/progenitor cells and the number of differentiating cells after mitotic expansion. prog, progenitor. 


\section{Analysis of germ line mutations: where do they come from and where do they take us?}

Both RAPD-PCR and the analysis of repetitive sequences might increase our understanding of how best to extrapolate from rodents to humans. However, important concerns are: 1) the mechanisms through which the mutations arise are unknown, and 2) their biological relevance for the health of offspring is not clear.

\section{Mechanisms leading to mutations}

Alterations in RAPD-PCR profiles may originate from genomic alterations, DNA lesions that block the polymerase and secondary structures within the PCR product [13]. Therefore, studying the origin of RAPD-PCR detectable mutations from a mechanistic viewpoint will be difficult, because multiple types of mutations can be involved. Gains or losses of tandem repeats are possibly easier to interpret, as the underlying mechanism might be the same. ESTR mutations have been observed after exposure to radiation but were also induced by chemical carcinogens that induce strand breaks or bulky DNA lesions [28, 37, 42]. Although this non-specific detection of mutations induced by different types of DNA damage might be advantageous for the sensitivity of the assays, it complicates the mechanistic interpretation of the data. Therefore, more dedicated in vitro and in vivo experiments are needed to provide a definitive characterization of the mechanistic basis for this type of mutation analyses. Moreover, these mutations may also be the consequence of genomic destabilization during early embryogenesis, which is supported by the observation that an increased number of mutations can arise in the maternal allele of the offspring of irradiated males and unexposed mothers [43]. Therefore, mutations in both sperm and offspring should be observed so that the two processes can be differentiated. There is evidence that indirect mechanisms are involved in the induction of tandem repeat mutations; for instance, recent findings indicate a potential role for epigenetic alterations [44]. Since the epigenome can be transferred to subsequent generations, this mechanism might also be relevant for exposed populations.

Transcriptomics could contribute to this mechanistic understanding of germ line mutagenesis by comparing gene expression in testes of exposed fathers. Despite the obvious difficulties in obtaining mRNA from human testes, gene-expression can be studied in mRNA obtained from ejaculates. The presence of mRNA in an ejaculate was discovered by Pessot et al. [45] and is thought to reflect gene expression during spermatogenesis [46]. Therefore pathways involved in the induction of tandem repeat mutations may also be identifiable in humans. Studies in humans seem to be necessary to avoid problems with inter-species extrapolation. However, variability in the susceptibility towards genotoxic compounds may complicate the interpretation of the data and so controlled studies with laboratory animals are still required. Moreover, the use of genetically modified animals may allow further elucidation of mechanisms in germ line mutagenesis.

\section{Biological significance of mutations detected}

It is almost impossible to predict the biological impact of germ line mutations for offspring health. In principle, the RAPD-PCR assay can scan the entire genome including coding DNA regions, which can be identified by cloning and sequencing the altered PCR products (new PCR products, or PCR products that disappeared due to 
exposure). However, most of the mutations will probably be found in non-coding DNA. No studies to date have linked an increased mutational load, as assessed by RAPD-PCR, to an actual phenotypic alteration. Furthermore, it is still unclear whether tandem repeat mutations reflect effects in coding regions or provide a measure of other heritable genomic outcomes. Although the tandem repeat loci do not confer any observed phenotypes, many tandem repeats are known to be related to transcribed genes and instability within these repetitive sequences has been shown to influence the function of these genes [47-50]. For example, expansions within tandem repeat sequences are associated with approximately 20 well-characterized developmental and degenerative diseases [47]. Nevertheless, mutations assessed by RAPD-PCR or tandem repeat analysis can be considered as biomarkers of adverse genetic events.

\section{Future perspectives}

The new approaches described are needed to test germ line mutagenicity in humans exposed to environmental and dietary mutagens [51]. Efforts need to be made to use new molecular techniques to overcome the limitations of classical tests with respect to time, costs and the number of animals needed for germ line mutagenicity testing. Further these tests should fit in a broad range of applications; genomic alterations should be measurable in humans, animals and their offspring, in multiple organs, and at different stages during spermatogenesis.

Table 2 provides an overview of the advantages and disadvantages of RAPDPCR and DNA fingerprinting of tandem repetitive DNA sequences compared to classical germ cell assays. The two new methods fulfil most of the demands, including their applicability in humans, but still require further technical validation. Too few experiments have been performed to confirm the suitability of these methods for detecting germ line mutations. In addition, not enough is known about how tandem repeat mutations are formed, and the type of mutations analysed by RAPD-PCR. Therefore, the biological consequences of these mutations for the offspring are unknown. However, the improved sensitivity, which results in the use of small sample sizes and consequently lower costs, means that these methods are promising for the testing of low doses of mutagens and long-term exposure to mutagens on germ line mutations and heritable effects.

Table 2. Comparison of the characteristics of germ cell assays

\begin{tabular}{lccc}
\hline Characteristics & DNA fingerprinting & RAPD-PCR & Classical tests \\
\hline Validation & - & - & + \\
Reproducibility & + & $+/-$ & + \\
Costs & + & ++ & - \\
Time & + & ++ & - \\
Number of animals required & + & + & - \\
Sensitivity & + & + & - \\
Applicable to humans & ++ & $+/-$ & - \\
Coding DNA & - & - & + \\
Phenotypic effects & - & - & + \\
Defined mechanism of mutation & - & - \\
\hline
\end{tabular}

'+' indicates favourable and '-' indicates unfavourable. 
DNA fingerprinting for repetitive sequences is the most promising new method for mutagenicity testing, while RAPD-PCR can be considered as a semi-quantitative screening method. Furthermore, DNA fingerprinting is a sensitive method for detecting germ line mutations in sperm, and for establishing whether these mutations can be transmitted to the progeny after long-term, low dose exposure to pollutants in experimental animals, free-living animals, and humans.

\section{Funding}

Cefic Long-Range Research Initiative (LRI) Innovative Science award 2004 (to R.G.); EU Integrated Project NEWGENERIS, 6th Framework Programme, Priority 5: Food Quality and Safety (FOOD-CT-2005 016320). 


\section{References}

1. Dubrova, Y.E., Nesterov, V.N., Krouchinsky, N.G., Ostapenko, V.A., Neumann, R., Neil, D.L. and Jeffreys, A.J. (1996) Human minisatellite mutation rate after the Chernobyl accident. Nature, 380, 683-686.

2. Yauk, C.L., Fox, G.A., McCarry, B.E. and Quinn, J.S. (2000) Induced minisatellite germline mutations in herring gulls (Larus argentatus) living near steel mills. Mutat Res, 452, 211-218.

3. Somers, C.M., Yauk, C.L., White, P.A., Parfett, C.L. and Quinn, J.S. (2002) Air pollution induces heritable DNA mutations. Proc Natl Acad Sci USA, 99, 15904-15907.

4. Yauk, C.L. and Quinn, J.S. (1996) Multilocus DNA fingerprinting reveals high rate of heritable genetic mutation in herring gulls nesting in an industrialized urban site. Proc Natl Acad Sci USA, 93, 1213712141.

5. Somers, C.M., McCarry, B.E., Malek, F. and Quinn, J.S. (2004) Reduction of particulate air pollution lowers the risk of heritable mutations in mice. Science, 304, 1008-1010.

6. Trasler, J.M. and Doerksen, T. (1999) Teratogen update: paternal exposures-reproductive risks. Teratology, 60, 161-172.

7. Sobels, F.H. (1989) Models and assumptions underlying genetic risk assessment. Mutat Res, 212, 7789.

8. Adler, I.D. (1996) Future research directions to study genetic damage in germ cells and estimate genetic risk. Environ Health Perspect, 104 Suppl 3, 619-624.

9. Singer, T.M., Lambert, I.B., Williams, A., Douglas, G.R. and Yauk, C.L. (2006) Detection of induced male germline mutation: correlations and comparisons between traditional germline mutation assays, transgenic rodent assays and expanded simple tandem repeat instability assays. Mutat Res, 598, 164-193.

10. Williams, J.G., Kubelik, A.R., Livak, K.J., Rafalski, J.A. and Tingey, S.V. (1990) DNA polymorphisms amplified by arbitrary primers are useful as genetic markers. Nucleic Acids Res, 18, 6531-6535.

11. Welsh, J. and McClelland, M. (1990) Fingerprinting genomes using PCR with arbitrary primers. Nucleic Acids Res, 18, 7213-7218.

12. Caetano-Anolles, G. (1993) Amplifying DNA with arbitrary oligonucleotide primers. PCR Methods Appl, 3, 85-94.

13. Atienzar, F.A. and Jha, A.N. (2006) The random amplified polymorphic DNA (RAPD) assay and related techniques applied to genotoxicity and carcinogenesis studies: a critical review. Mutat Res, 613, 76-102.

14. Valentini, A., Timperio, A.M., Cappuccio, I. and Zolla, L. (1996) Random amplified polymorphic DNA (RAPD) interpretation requires a sensitive method for the detection of amplified DNA. Electrophoresis, 17, 1553-1554.

15. Atienzar, F.A., Cheung, V.V., Jha, A.N. and Depledge, M.H. (2001) Fitness parameters and DNA effects are sensitive indicators of copper-induced toxicity in Daphnia magna. Toxicol Sci, 59, 241-250.

16. Becerril, C., Ferrero, M., Sanz, F. and Castano, A. (1999) Detection of mitomycin C-induced genetic damage in fish cells by use of RAPD. Mutagenesis, 14, 449-456.

17. Atienzar, F.A., Venier, P., Jha, A.N. and Depledge, M.H. (2002) Evaluation of the random amplified polymorphic DNA (RAPD) assay for the detection of DNA damage and mutations. Mutat Res, 521, 151163.

18. Jones, C. and Kortenkamp, A. (2000) RAPD library fingerprinting of bacterial and human DNA: applications in mutation detection. Teratog Carcinog Mutagen, 20, 49-63.

19. Russell, P.J.(2002) iGenetics. San Francisco: Pearson Education, Inc.

20. Benter, T., Papadopoulos, S., Pape, M., Manns, M. and Poliwoda, H. (1995) Optimization and reproducibility of random amplified polymorphic DNA in human. Anal Biochem, 230, 92-100.

21. Savva, D. (1998) Use of DNA fingerprinting to detect genotoxic effects. Ecotoxicol Environ Saf, 41, 103106.

22. Atienzar, F.A. and Jha, A.N. (2004) The random amplified polymorphic DNA (RAPD) assay to determine DNA alterations, repair and transgenerational effects in B(a)P exposed Daphnia magna. Mutat Res, 552, 125-140.

23. Weinberg, H.S., Korol, A.B., Kirzhner, V.M., Avivi, A., Fahima, T., Nevo, E., Shapiro, S., Rennert, G., Piatak, O., Stepanova, E.I. and Skvarskaja, E. (2001) Very high mutation rate in offspring of Chernobyl accident liquidators. Proc Biol Sci, 268, 1001-1005.

24. Jeffreys, A.J. and Dubrova, Y.E. (2001) Monitoring spontaneous and induced human mutation by RAPDPCR: a response to Weinberg et al. (2001). Proc Biol Sci, 268, 2493-2494.

25. Yauk, C.L. (2004) Advances in the application of germline tandem repeat instability for in situ monitoring. Mutat Res, 566, 169-182.

26. Jeffreys, A.J., Royle, N.J., Wilson, V. and Wong, Z. (1988) Spontaneous mutation rates to new length alleles at tandem-repetitive hypervariable loci in human DNA. Nature, 332, 278-281.

27. Dubrova, Y.E., Nesterov, V.N., Krouchinsky, N.G., Ostapenko, V.A., Vergnaud, G., Giraudeau, F., Buard, J. and Jeffreys, A.J. (1997) Further evidence for elevated human minisatellite mutation rate in Belarus eight years after the Chernobyl accident. Mutat Res, 381, 267-278. 
28. Vilarino-Guell, C., Smith, A.G. and Dubrova, Y.E. (2003) Germline mutation induction at mouse repeat DNA loci by chemical mutagens. Mutat Res, 526, 63-73.

29. Buard, J., Collick, A., Brown, J. and Jeffreys, A.J. (2000) Somatic versus germline mutation processes at minisatellite CEB1 (D2S90) in humans and transgenic mice. Genomics, 65, 95-103.

30. May, C.A., Jeffreys, A.J. and Armour, J.A. (1996) Mutation rate heterogeneity and the generation of allele diversity at the human minisatellite MS205 (D16S309). Hum Mol Genet, 5, 1823-1833.

31. Jeffreys, A.J., Tamaki, K., MacLeod, A., Monckton, D.G., Neil, D.L. and Armour, J.A. (1994) Complex gene conversion events in germline mutation at human minisatellites. Nat Genet, 6, 136-145.

32. Armour, J.A., Brinkworth, M.H. and Kamischke, A. (1999) Direct analysis by small-pool PCR of MS205 minisatellite mutation rates in sperm after mutagenic therapies. Mutat Res, 445, 73-80.

33. May, C.A., Tamaki, K., Neumann, R., Wilson, G., Zagars, G., Pollack, A., Dubrova, Y.E., Jeffreys, A.J. and Meistrich, M.L. (2000) Minisatellite mutation frequency in human sperm following radiotherapy. Mutat Res, 453, 67-75.

34. Zheng, N., Monckton, D.G., Wilson, G., Hagemeister, F., Chakraborty, R., Connor, T.H., Siciliano, M.J. and Meistrich, M.L. (2000) Frequency of minisatellite repeat number changes at the MS205 locus in human sperm before and after cancer chemotherapy. Environ Mol Mutagen, 36, 134-145.

35. Yauk, C.L., Dubrova, Y.E., Grant, G.R. and Jeffreys, A.J. (2002) A novel single molecule analysis of spontaneous and radiation-induced mutation at a mouse tandem repeat locus. Mutat Res, 500, 147-156.

36. Crawford, D.C., Wilson, B. and Sherman, S.L. (2000) Factors involved in the initial mutation of the fragile X CGG repeat as determined by sperm small pool PCR. Hum Mol Genet, 9, 2909-2918.

37. Polyzos, A., Parfett, C., Healy, C., Douglas, G.R. and Yauk, C.L. (2006) Instability of expanded simple tandem repeats is induced in cell culture by a variety of agents: N-Nitroso-N-ethylurea, benzo(a)pyrene, etoposide and okadaic acid. Mutat Res, 598, 73-84.

38. Jeffreys, A.J., Neumann, R. and Wilson, V. (1990) Repeat unit sequence variation in minisatellites: a novel source of DNA polymorphism for studying variation and mutation by single molecule analysis. Cell, 60, 473-485.

39. Polyzos, A., Parfett, C., Healy, C., Douglas, G. and Yauk, C. (2006) A single-molecule PCR approach to the measurement of induced expanded simple tandem repeat instability in vitro. Mutat Res, 594, 93-100.

40. Ehmcke, J., Wistuba, J. and Schlatt, S. (2006) Spermatogonial stem cells: questions, models and perspectives. Hum Reprod Update, 12, 275-282.

41. Adler, I.D. (1996) Comparison of the duration of spermatogenesis between male rodents and humans. Mutat Res, 352, 169-172.

42. Dubrova, Y.E. (2005) Radiation-induced mutation at tandem repeat DNA Loci in the mouse germline: spectra and doubling doses. Radiat Res, 163, 200-207.

43. Niwa, O. and Kominami, R. (2001) Untargeted mutation of the maternally derived mouse hypervariable minisatellite allele in F1 mice born to irradiated spermatozoa. Proc Natl Acad Sci USA, 98, 1705-1710.

44. Yauk, C., Polyzos, A., Rowan-Carroll, A., Somers, C.M., Godschalk, R.W., Van Schooten, F.J., Berndt, M.L., Pogribny, I.P., Koturbash, I., Williams, A., Douglas, G.R. and Kovalchuk, O. (2008) Germ-line mutations, DNA damage, and global hypermethylation in mice exposed to particulate air pollution in an urban/industrial location. Proc Natl Acad Sci U S A, 105, 605-610.

45. Pessot, C.A., Brito, M., Figueroa, J., Concha, II, Yanez, A. and Burzio, L.O. (1989) Presence of RNA in the sperm nucleus. Biochem Biophys Res Commun, 158, 272-278.

46. Ostermeier, G.C., Goodrich, R.J., Diamond, M.P., Dix, D.J. and Krawetz, S.A. (2005) Toward using stable spermatozoal RNAs for prognostic assessment of male factor fertility. Fertil Steril, 83, 1687-1694.

47. Gatchel, J.R. and Zoghbi, H.Y. (2005) Diseases of unstable repeat expansion: mechanisms and common principles. Nat Rev Genet, 6, 743-755.

48. Dubrova, Y.E., Jeffreys, A.J. and Malashenko, A.M. (1993) Mouse minisatellite mutations induced by ionizing radiation. Nat Genet, 5, 92-94.

49. Dubrova, Y.E., Plumb, M., Brown, J., Fennelly, J., Bois, P., Goodhead, D. and Jeffreys, A.J. (1998) Stage specificity, dose response, and doubling dose for mouse minisatellite germ-line mutation induced by acute radiation. Proc Natl Acad Sci USA, 95, 6251-6255.

50. Kelly, R., Gibbs, M., Collick, A. and Jeffreys, A.J. (1991) Spontaneous mutation at the hypervariable mouse minisatellite locus Ms6-hm: flanking DNA sequence and analysis of germline and early somatic mutation events. Proc Biol Sci, 245, 235-245.

51. Wyrobek, A.J., Mulvihill, J.J., Wassom, J.S., Malling, H.V., Shelby, M.D., Lewis, S.E., Witt, K.L., Preston, R.J., Perreault, S.D., Allen, J.W., Demarini, D.M., Woychik, R.P. and Bishop, J.B. (2007) Assessing human germ-cell mutagenesis in the Postgenome Era: a celebration of the legacy of William Lawson (Bill) Russell. Environ Mol Mutagen, 48, 71-95. 




\section{Chapter 3}

\section{DNA adduct kinetics in reproductive tissues of DNA repair proficient and deficient male mice after oral exposure to benzo(a)pyrene}

Environmental and Molecular Mutagenesis 2010; 51(2): 123-129

Nicole Verhofstad

Conny Th.M.van Oostrom

Jan van Benthem Frederik J. van Schooten

Harry van Steeg Roger W.L. Godschalk 


\section{Abstract}

Benzo(a)pyrene $(\mathrm{B}[\mathrm{a}] \mathrm{P})$ can induce somatic mutations, whereas its potential to induce germ cell mutations is unclear. There is circumstantial evidence that paternal exposure to $B[a] P$ can result in germ cell mutations. Since DNA adducts are thought to be a prerequisite for B[a]P induced mutations, we studied DNA adduct kinetics by ${ }^{32} \mathrm{P}$-postlabelling in sperm, testes and lung tissues of male mice after a single exposure to $B[a] P(13 \mathrm{mg} / \mathrm{kg}$ bw, by gavage). To investigate DNA adduct formation at different stages of spermatogenesis, mice were sacrificed at day $1,4,7,10,14,21,32$ and 42 after exposure. In addition, DNA repair deficient $\left(X_{p c}^{-1-}\right)$ mice were used to study the contribution of nucleotide excision repair in DNA damage removal. DNA adducts were detectable with highest levels in lung followed by sperm and testis. Maximum adduct levels in the lung and testis were observed at day 1 after exposure, while adduct levels in sperm reached maximum levels at approximately 1 week after exposure. Lung tissue and testis of $X p c^{-/-}$ mice contained significantly higher DNA adduct levels compared to wild type $(\mathrm{Wt})$ mice over the entire 42 day observation period $(p<0.05)$. Differences in adduct half-life between $X p c^{-1 /}$ and $\mathrm{Wt}$ mice were only observed in testis. In sperm, DNA adduct levels were significantly higher in $X p c^{-1-}$ mice than in Wt mice only at day 42 after exposure $(p=0.01)$. These results indicate that spermatogonia and testes are susceptible for the induction of DNA damage and rely on nucleotide excision repair for maintaining their genetic integrity. 


\section{Introduction}

Benzo(a)pyrene (B[a]P), a well-known polycyclic aromatic hydrocarbon (PAH), is formed during the incomplete combustion of organic material, such as coal, oil, wood and tobacco, making $\mathrm{B}[\mathrm{a}] \mathrm{P}$ a ubiquitous environmental and occupational pollutant. $\mathrm{B}[\mathrm{a}] \mathrm{P}$ is metabolized by cytochrome $\mathrm{P} 450$ enzymes into benzo(a)pyrene-diol-epoxide (BPDE), which has the potential to bind to DNA to form so-called BPDE-DNA adducts [1]. There is a clear role for these BPDE-DNA adducts in inducing somatic mutations [2], but the potential of $B[a] P$ related DNA damage to induce male germ cell mutations is unclear. BPDE-DNA adducts in mature sperm have been observed [3], but the evidence that these DNA lesions can induce gene mutations in gametes is only indirect [4-7]. Epidemiological studies have shown that paternal exposure to PAHs could increase the risk of childhood cancer in their offspring [8-11], but the associations are weak and need further studies to determine whether a causal relationship exists.

Although DNA damage is detectable in sperm cells, they can be protected during spermatogenesis from genotoxic exposures by a complex network of molecular defence mechanisms [12]. Firstly, DNA damage can be prevented by detoxification of $\mathrm{B}[\mathrm{a}] \mathrm{P}$ and scavenging of its reactive metabolites. Secondly, DNA damage can be repaired by DNA repair mechanisms. Nucleotide excision repair (NER) is considered to be the most relevant repair mechanism for bulky DNA adducts formed by reactive metabolites of B[a]P, such as BPDE. NER can detect and repair damage in both transcribed (i.e. transcription coupled repair (TCR)) and non-transcribed (i.e. global genome repair (GGR)) parts of the genome. GGR is especially involved in the recognition and removal of bulky DNA adducts, while TCR removes these lesions if they block RNA synthesis [13]. Finally, cells that are too heavily damaged can be eliminated by cell death to prevent accumulation of mutations [12]. It is still not clear whether these protective mechanisms sufficiently protect the integrity of germ cell DNA upon exposure to $B[a] P$, but failure of these defence mechanisms may lead to increased levels of DNA damage and possibly germ line mutations. Moreover, the vulnerability of germ cells to the persistence of DNA damage is known to change during spermatogenesis [14], and depends on DNA synthesis and cell proliferation in both the mitotic and meiotic stages. During these early stages, dividing sperm cells are still DNA repair proficient and seem to be well protected. In post-meiotic stages, spermatids lack DNA repair, and induced DNA damage may not be removed until after fertilization. Nonetheless, the main concern is the fixation of DNA damage into gene mutations in spermatogonial stem cells, because mutations in stem cells will persist throughout the reproductive life of the male. Figure 1 gives an overview of the above mentioned germ cell characteristics during the different stages of spermatogenesis.

In order to learn more about the formation and removal of DNA adducts in male germ cells and the impact of DNA repair processes, we studied DNA adduct kinetics in testes, spermatozoa and lung tissues (as a known target organ) of DNA repair deficient $X p c^{-/-}$and wild type (Wt) male mice at different stages of spermatogenesis. For that purpose, mice were acutely exposed to B[a]P and sacrificed at different time intervals after exposure. The contribution of GGR/NER to BPDE-DNA adduct removal was studied by comparing DNA adduct kinetics in both $\mathrm{Xpc}^{-/-}$and Wt mice. $\mathrm{XPC}$ is involved in GGR/NER, which is thought to be an important mechanism for 
BPDE-DNA adduct removal from the entire genome. We used $X p c^{-/-}$rather than $X p a^{-/-}$ mice, since it was previously shown that $X p a^{-/-}$mice are very sensitive to compounds that give bulky adducts, in contrast to $X p c^{-/-}$mice [15]. The observed toxicity was linked to absence of TCR/NER in Xpa ${ }^{-/-}$mice. To prevent unwanted toxicity, we decided to perform the studies in $X p c^{-/-}$mice, which have only a defect in GGR/NER.

\begin{tabular}{|l|c|c|c|c|c|c|}
\hline Location & \multicolumn{3}{|c|}{ testis } & epididymis \\
\hline Cell type & stem cells & spermatogonia & spermatocytes & spermatids & \multicolumn{2}{c|}{ spermatozoa } \\
\hline Duration (days) & 6 & 14 & 9 & 6 & $4-6$ \\
\hline Cell stage & mitotic & meiotic & \multicolumn{3}{|c|}{ nostmeiotic } \\
\hline DNA synthesis & \multicolumn{2}{|c|}{ yes } & & \multicolumn{2}{c|}{ deficient } \\
\hline DNA repair & \multicolumn{2}{|c|}{ proficient } & \\
\hline
\end{tabular}

Figure 1. Schematic overview of the cellular characteristics during spermatogenesis.

\section{Materials and Methods}

\section{Animal experiments}

Wild type male mice (C57BL/6) and $\mathrm{Xpc}^{-/-}$male mice (C57BL/6), as previously described [16, 17], were exposed to a single dose of $B[a] P(13 \mathrm{mg} / \mathrm{kg} \mathrm{bw})$ by oral gavage, and were sacrificed after 1, 4, 7, 10, 14, 21, 32 and 42 days. The dose of 13 $\mathrm{mg} / \mathrm{kg}$ bw has been used in previous studies and is appropriate to induce detectable DNA adducts levels [18]. We analyzed 3 to 13 mice per group, depending on the type of tissue and time point tested (indicated in figure $\mathbf{3}$ and $\mathbf{4}$, and table $\mathbf{1}$ ). The untreated control groups consisted of 3 to 5 mice sacrificed after 4,7 or 21 days. We collected testes, spermatozoa and lung tissues. Sperm cells were obtained from the epididymides as previously described [19]. Samples were snap frozen in liquid nitrogen and stored at $-80^{\circ} \mathrm{C}$ until DNA isolation. A separate group of $\mathrm{Wt}$ and $X p c^{-/-}$mice exposed to $\mathrm{B}[\mathrm{a}] \mathrm{P}$ was sacrificed after 42 days for histopathological analysis. One testis and one epididymis per mouse were embedded in formalin; the other ones were snap frozen and stored.

Mice were bred and housed under specific pathogen-free conditions in a 12-hour light-dark cycle at the animal facilities of the Netherlands Vaccine Institute (NVI, Bilthoven, the Netherlands), and received food and water ad libitum. Experiments were approved by the institute's Animal Ethics Committee and were carried out according to their guidelines.

\section{DNA isolation}

After lung tissues had been cut into small pieces and testes had been pulverized using mortar and tamper cooled in liquid nitrogen, both materials were lysed in $2 \mathrm{ml}$ lysis buffer (50 mM NaCl, $18.75 \mathrm{mM}$ EDTA, $15 \mathrm{mM}$ TrisHCl pH 8.5 and $0.5 \%$ SDS) and $30 \mu \mathrm{l}$ proteinase $\mathrm{K}$ [25 mg/ml], and incubated overnight at $55^{\circ} \mathrm{C}$. DNA was extracted sequentially with phenol: chloroform: isoamyl alcohol $(25: 24: 1, \mathrm{v} / \mathrm{v} / \mathrm{v})$ and chloroform: isoamyl alcohol $(24: 1, \mathrm{v} / \mathrm{v})$. DNA was precipitated with 2 volumes of cold 
$100 \%$ ethanol and $10 \% 3 \mathrm{M} \mathrm{NaAc}(\mathrm{pH} 5.2)$. Pelleted DNA was washed with $80 \%$ ethanol, dried under nitrogen and dissolved in $\mathrm{mQ}$-water.

Spermatozoa obtained from epididymal tissues were lysed in $100 \mu$ lysis buffer (200 mM NaCl, $20 \mathrm{mM}$ EDTA, $20 \mathrm{mM}$ TrisHCl pH 8.0, $80 \mathrm{mM}$ dithiothreitiol (DTT), $4 \%$ SDS and $250 \mu \mathrm{g} / \mathrm{ml}$ proteinase $\mathrm{K}$ ). DNA was isolated using DNeasy Blood \& Tissue kit (Qiagen, Venlo, the Netherlands) according to the manufacturer's protocol with slight modifications, starting with the addition of $200 \mu \mathrm{l}$ buffer AL (from kit) and $200 \mu \mathrm{l} 100 \%$ ethanol. Samples were mixed by vortexing and pipetted into the DNeasy spin column. After centrifugation at $6000 \times \mathrm{g}$ for 1 minute, $500 \mu \mathrm{l}$ buffer AW1 (from kit) was added. Samples were centrifuged again and $500 \mu \mathrm{l}$ buffer AW2 (from kit) was added to the column. Finally, samples were centrifuged for 3 minutes at $20.000 \times \mathrm{g}$ to dry the DNeasy membrane. DNA was eluted in $100 \mu \mathrm{mQ}$-water. Concentrations and purity of all samples were determined spectrophotometrically.

\section{DNA adduct measurement by ${ }^{32} \mathrm{P}$-postlabelling}

To determine BPDE-DNA adducts by ${ }^{32} \mathrm{P}$-postlabelling, $10 \mu \mathrm{g}$ DNA was digested using micrococcal endonuclease $(0.57 \mathrm{U} /$ sample, Sigma-Aldrich, Zwijndrecht, the Netherlands) and spleen phosphodiesterase $(4.75 \mu \mathrm{g} / \mathrm{sample}$, Sigma-Aldrich, Zwijndrecht, the Netherlands) for 4 hours at $37^{\circ} \mathrm{C}$. Subsequently, samples were treated with nuclease P1 $(3.25 \mu \mathrm{g} / \mathrm{sample}$, MP Biomedicals, Eindhoven, the Netherlands) for 30 minutes at $37^{\circ} \mathrm{C}$ in a total volume of $12.5 \mu \mathrm{l}$. The largest fraction of the modified nucleotides $(\mathrm{nt})(10.5 \mu \mathrm{l})$ was labelled with $\left[\mathrm{\gamma}^{-}{ }^{32} \mathrm{P}\right]-\mathrm{ATP}(50 \mu \mathrm{Ci} / \mathrm{sample}, \mathrm{MP}$ Biomedicals, Eindhoven, the Netherlands) by incubation with T4-polynucleotide kinase (11.5 U/sample, Fermentas, St. Leon-Rot, Germany) for 30 minutes at $37^{\circ} \mathrm{C}$. Radiolabelled adduct nucleotide bisphosphates were separated by thin-layer chromatography on polyethyleneimine (PEI) cellulose sheets (Macherey-Nagel, Düren, Germany) in the following solvents: $\mathrm{D} 1,1 \mathrm{M} \mathrm{NaH}_{2} \mathrm{PO}_{4} \mathrm{pH}$ 6.5; D2, 8.5 M urea, $5.3 \mathrm{M}$ lithium formate $\mathrm{pH} 3.5$; and $\mathrm{D} 3,1.2 \mathrm{M}$ lithium chloride, $0.5 \mathrm{M}$ Tris, $8.5 \mathrm{M}$ urea $\mathrm{pH}$ 8.0. In each experiment 3 standards of $\left[{ }^{3} \mathrm{H}\right] \mathrm{BPDE}$ modified DNA with known modification levels ( 1 per $10^{7}, 10^{8}$ and $10^{9} \mathrm{nt}$ ) were run in parallel for quantification purposes, and $\mathrm{mQ}$-water was used as a negative control. DNA adduct levels were quantified by using FujiFilm imaging system FLA-3000, BASReader software and Advanced Image Data Analyzer (AIDA) software (all from Raytest, Tilburg, the Netherlands), with a detection limit of $<1$ adduct per $10^{9} \mathrm{nt}$ per individual DNA adduct spot. A small fraction of the digest $(2 \mu \mathrm{l})$ was used to determine the final amount of DNA in the assay and was added to $36.3 \mu \mathrm{l} \mathrm{mQ}$-water. Tris $\mathrm{HCl}(\mathrm{pH}$ 7.4) and alkaline phosphatase $(0.01 \mathrm{U} / \mu \mathrm{l}$, Sigma-Aldrich, Zwijndrecht, the Netherlands) were added to the samples after which samples were incubated at $37^{\circ} \mathrm{C}$ for 45 minutes. Nucleosides were subsequently separated and detected by HPLC-UV using $10 \%$ aqueous methanol containing $94 \mathrm{mM} \mathrm{KH}_{2} \mathrm{PO}_{4}, 13 \mathrm{mM} \mathrm{K}_{2} \mathrm{HPO}_{4}, 26 \mathrm{mM} \mathrm{KCl}$ and $0.5 \mathrm{mM}$ EDTA. The peak area of dG was used to correct for differences in DNA content between samples.

\section{Statistics}

Results are presented as mean \pm standard error of the mean (SEM). Half of the detection limit $\left(0.05\right.$ per $\left.10^{8} \mathrm{nt}\right)$ was assigned to samples with undetectable adduct levels. Half-lives of DNA adducts during the first week after exposure were estimated based on an exponential decay curve with leveling-off to a symptotic value (i.e. steady state levels observed 42 days after exposure) using the formula $y=[(a-$ 
c) $\left./ 2^{t / b}\right]+c$. In this formula, $a=$ adduct level 1 day after exposure, $b=$ half-life in days, $c=$ leveling-off value for large $t$ (i.e. adduct level 42 days after exposure), $y=$ adduct level 7 days after exposure, and $t=$ time (days). The non-parametric Mann-Whitney U-test was used to analyze differences in DNA adduct levels between $\mathrm{Xpc}^{-/}$and $\mathrm{Wt}$ male mice in the various tissues per individual time point. To examine overall differences between $\mathrm{Xpc}^{--}$and Wt mice, we used the non-parametric Wilcoxon Signed Ranks Test for paired analysis (average adduct levels per time point were analyzed as pairs). The relations between DNA adduct levels in the various tissues were assessed by Pearson correlation. SPSS v.15.0 was used for statistical analysis. A difference was considered significant at $p<0.05$.

\section{Results}

\section{Microscopic examination of testes and epididymides}

Formalin-fixed, paraffin-wax embedded and haematoxylin and eosin stained slides were examined microscopically for testes and epididymides obtained 42 days after exposure. There were no obvious indications of toxicity to the germinal tissue. Still, minor changes were observed in the testes, including a low grade of focal tubular atrophy and interstitial (Leydig) cell hyperplasia. In the epididymides cellular debris was occasionally observed in addition to the normal spermatocytic content. However, these changes are not abnormal for rodents and belong to the spontaneous background morphology.

\section{Qualitative results of adduct analysis in $\mathrm{B}[\mathrm{a}] \mathrm{P}$ exposed $\mathrm{Xpc}^{-\mathrm{I}_{-}}$and Wt mice}

No differences were observed in DNA adduct patterns between $X p c^{-/-}$and $\mathrm{Wt}$ mice. The predominant DNA adduct spot co-migrated with the BPDE-DNA adduct standard (figure 2). Occasionally, a second DNA adduct spot was observed and migrated more slowly than the BPDE-DNA adduct standard in both chromatographic directions. This $B[a] P$ related DNA adduct was not used for the analysis of DNA adduct kinetics, since this spot was not detected in all samples and did not correspond to the BPDE-DNA adduct standard. No DNA adducts were detected in samples of unexposed $\mathrm{Xpc}^{-/-}$or Wt mice.

\section{Quantitative results of adduct analysis in lung tissues of $\mathrm{B}[\mathrm{a}] \mathrm{P}$ exposed $X p c^{-/-}$and Wt mice}

In lung tissues, we were able to detect a gradual decline of DNA adduct levels from day 1 (35.1 \pm 7.2 adducts per $10^{8} \mathrm{nt}$ in $X p c^{-/-}$mice and $26.1 \pm 12.4$ adducts per $10^{8} \mathrm{nt}$ in Wt mice) until 14 days after exposure $\left(10.7 \pm 4.8\right.$ adducts per $10^{8} \mathrm{nt}$ in $X p c^{-/-}$ mice and $4.4 \pm 1.0$ adducts per $10^{8} \mathrm{nt}$ in Wt mice). After 14 days, DNA adducts seemed to reach a plateau at approximately one third of the initial DNA adduct level. Overall DNA adduct levels were higher in $X p c^{-/-}$mice compared to Wt mice ( $p=$ 0.028 ) (figure 3 ). The estimated half-life of DNA adducts did not differ significantly between $X p c^{-/-}$and $\mathrm{Wt}$ mice (1.5 days and 2.5 days, respectively). 


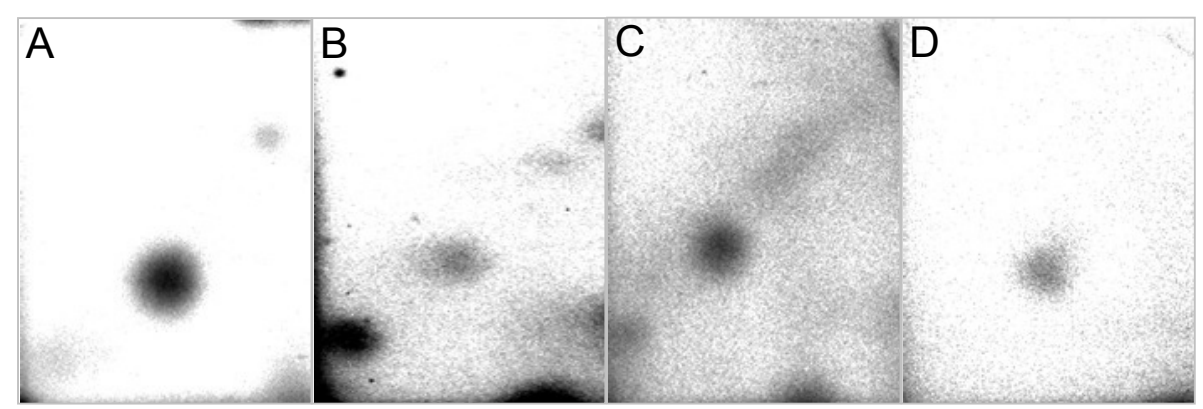

Figure 2. DNA adduct spots detected by ${ }^{32} \mathrm{P}$-postlabelling. A. DNA adduct spot in lung tissue of $X p c^{-/-}$mouse. B. DNA adduct spot in testis of $X p c^{-/-}$mouse. C. DNA adduct spot in sperm of Wt mouse. D. BPDE-DNA adduct standard $\left(1 \times 10^{-8}\right)$.

\section{Quantitative results of adduct analysis in testes of B[a]P exposed $X p c^{-1-}$ and Wt mice}

DNA adduct levels in testes were approximately 10 -fold lower than in lung tissues (compare figure 3 and 4 ). Although similar adduct levels were observed in testes of exposed $X p c^{-/-}$and Wt mice at day 1 after exposure $(2.8 \pm 1.7$ adducts per $10^{8} \mathrm{nt}$ in $X p c^{-/-}$mice and $2.5 \pm 1.3$ adducts per $10^{8} \mathrm{nt}$ in Wt mice), the decrease of adduct levels over time differed, with estimated half-lives of 13.2 days and 2.9 days between day 1 and 7 in $X p c^{-/-}$and Wt mice, respectively. This difference was most obvious between day 1 and 4, when DNA adduct levels declined by one third in $X p c^{--}$ mice and almost $75 \%$ in Wt mice. Similar to lung tissues, DNA adduct levels in testes were overall higher in $X p c^{-/-}$mice than in Wt mice $(p=0.043)$. DNA adducts in testes at 42 days after exposure were close to the limit of detection $(0.2 \pm 0.04$ adducts per $10^{8} \mathrm{nt}$ in $\mathrm{Xpc}^{-/-}$mice and $0.1 \pm 0.1$ adducts per $10^{8} \mathrm{nt}$ in Wt mice) (figure 4), and did not show a steady-state level as was observed in lung. We observed a good correlation between the DNA adduct levels in lung tissues and testes of Wt mice $(R=0.915$, $p<0.001)$ and no correlation in $X p c^{-/-}$mice $(R=0.245, p=0.327)$.

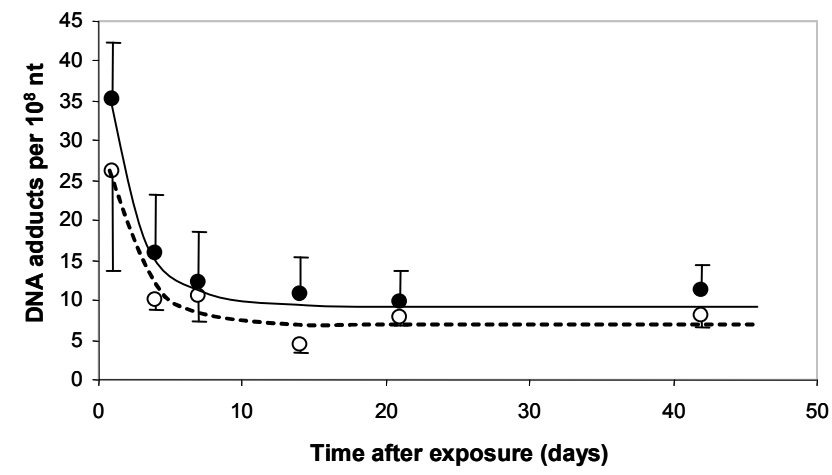

Figure 3. DNA adduct levels in lung tissues of exposed Wt (- - - - ) and $X p c^{-/-}$ $(-\bullet)$ male mice $(n=3)$. 


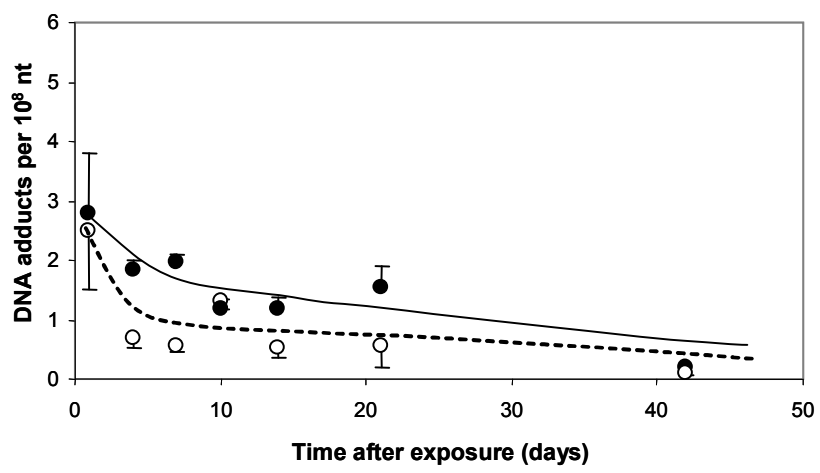

Figure 4. DNA adduct levels in testes of exposed Wt (- -०- -) and $X p c^{-/-}(-\bullet-)$ male mice $(n=5$, except at day $42 n=3)$.

\section{Discussion}

Determining DNA adduct kinetics after acute exposure in mature spermatozoa derived from epididymides will help to elucidate susceptible time-windows in spermatogenesis for DNA damage by $\mathrm{B}[\mathrm{a}] \mathrm{P}$. The current knowledge of spermatogenesis in mice enables the collection of sperm cells that were at a certain position and stage of maturation at the actual time of exposure (table 1). For instance, sperm cells collected from the epididymides 42 days after exposure were in a spermatogonial stage at the time of exposure. Spermatogonia have the capacity to repair DNA damage, but this capacity is lost after meiosis [12]. Other processes that can lower average DNA adduct levels, besides DNA repair, are cell turnover [20] and cell death. By comparing the reduction of DNA adducts in $X p c^{-/-}$and Wt mice, it is possible to determine the contribution of DNA repair to the removal of DNA adducts in different stages of spermatogenesis.

DNA adduct levels measured in spermatozoa in the first week (day 1 and 4) after exposure will represent DNA damage in mature sperm cells of which most were already present in the epididymides at the time of exposure (stage: epididymal spermatozoa). DNA adduct levels at these time points did not differ between $\mathrm{Xpc}^{-/}$and Wt mice, which is logical because they both lack the ability to remove DNA damage in the period between exposure and collection. Moreover, these spermatozoa did not divide, and it is important to note that at this stage DNA damage is present until after fertilization [21]. Mutations may be induced after DNA replication resumes which, of course, holds for all DNA adducts present in any mature spermatozoa. In the second week after exposure (day 7 and 10), spermatozoa present in the testes and/or seminiferous tubules, at the time of exposure, entered the epididymides. In theory, these sperm cells (stage: testicular spermatozoa) did not divide and lack the ability to actively remove DNA adducts between the time of exposure and collection. Indeed, no clear difference was observed between cells obtained from $\mathrm{Xpc}^{-/-}$and $\mathrm{Wt}$ mice. However, we did observe increased DNA adduct levels in both $X p c^{-/-}$and Wt mice in the second week as compared to the first week. This suggests that the spermatozoa entering the epididymides in the second week contained higher DNA adduct levels and were possibly more exposed. Sperm cells are assumed to be metabolically inactive and, therefore, these cells must have received the active metabolites of $B[a] P$ 
from their surrounding tissues, which differed for spermatozoa obtained in the first week (stage: epididymal spermatozoa) and second week (stage: testicular spermatozoa) after exposure. In the following three weeks (day 14, 21 and 32), DNA adduct levels decreased in both $\mathrm{Xpc}^{-/-}$and $\mathrm{Wt}$ mice to levels observed in the first week.

Table 1. Overview of sperm DNA adduct levels in relation to spermatogenesis stages

\begin{tabular}{|c|c|c|c|c|c|c|}
\hline \multirow{2}{*}{$\begin{array}{l}\text { Days } \\
\text { after } \\
\text { exposure }\end{array}$} & \multirow[t]{2}{*}{$\begin{array}{c}\text { Cell stage } \\
\text { at time of exposure }\end{array}$} & \multirow[t]{2}{*}{$\begin{array}{l}\text { Repair } \\
\text { capacity }\end{array}$} & \multirow[t]{2}{*}{$\begin{array}{c}\text { Position at time } \\
\text { of exposure }\end{array}$} & \multirow[t]{2}{*}{$\mathbf{n}$} & \multicolumn{2}{|c|}{$\begin{array}{l}\text { DNA adducts per } 10^{8} \mathrm{nt} \\
\text { (Mean } \pm \text { SEM) }\end{array}$} \\
\hline & & & & & Wt & $X p c^{-1-}$ \\
\hline 1 & Epididymal spermatozoa & Deficient & Epididymis & 8 & $1.77 \pm 0.96$ & $2.20 \pm 0.89$ \\
\hline 4 & Epididymal spermatozoa & Deficient & Epididymis & 8 & $2.16 \pm 0.87$ & $1.63 \pm 0.55$ \\
\hline 7 & Testicular spermatozoa & Deficient & Testis & 13 & $3.81 \pm 0.97$ & $5.54 \pm 1.37$ \\
\hline 10 & $\begin{array}{c}\text { Testicular spermatozoa/ } \\
\text { Spermatids }\end{array}$ & Deficient & Testis & 5 & $4.54 \pm 1.80$ & $2.14 \pm 1.48$ \\
\hline 14 & Spermatids & $\begin{array}{l}\text { Deficient/ } \\
\text { proficient }\end{array}$ & Testis & 8 & $2.09 \pm 0.50$ & $3.28 \pm 0.96$ \\
\hline 21 & Late spermatocytes & Proficient & Testis & 13 & $1.27 \pm 0.56$ & $1.41 \pm 0.43$ \\
\hline 32 & Early spermatocytes & Proficient & Testis & 5 & $2.35 \pm 0.52$ & $2.61 \pm 0.40$ \\
\hline $42^{*}$ & Spermatogonial stem cells & Proficient & Testis & 8 & $0.38 \pm 0.25$ & $3.17 \pm 1.12^{*}$ \\
\hline
\end{tabular}

The table gives an overview of the days after exposure and the corresponding cell stage, repair capacity and position of the sperm cells. Also the number of samples tested per genotype $(n)$ and corresponding adduct levels are given per time point for $\mathrm{Wt}$ and $X p c^{-/-}$mice. $\mathrm{n}$, number of samples tested per genotype. nt, nucleotides. * significantly different from Wt mice $(p=0.01)$.

As the time between exposure and collection of spermatozoa increases, more mature sperm cells that were exposed in the testes (stage: spermatids and spermatocytes) enter the epididymides. Simultaneously, sperm cells exposed in the epididymides are removed by mechanisms (e.g. phagocytosis) that have not been fully characterized [22, 23]. Sperm cells entering the epididymides at three weeks would have been in an early stage of spermatogenesis at the time of exposure (stage: spermatids/spermatocytes), and would have had the opportunity to divide in the meantime. As a result, DNA replication would dilute DNA adducts and lower total DNA adduct levels, with an associated risk of inducing mutations. Despite adduct dilution, DNA adducts were still detectable after 6 weeks in sperm, with significantly higher levels in $X p c^{-/-}$than in Wt mice. At 6 weeks, DNA adducts were measured in spermatozoa that would have developed from exposed spermatogonial stem cells or that would have been in an early mitotic stage of spermatogenesis at the time of exposure. In 42 days, spermatogonia would have had the chance to divide multiple times and to recover from the damage by DNA repair. Therefore, the difference in DNA adduct levels of $X p c^{-/-}$and Wt mice indicates that initial DNA damage in spermatogonia was relatively high, and that accurate DNA repair mechanisms are an important factor in maintaining the integrity of the genome in spermatogonia.

In testes we found peak DNA adduct levels in $X_{p c}^{-/-}$and Wt mice at day one after exposure, but the DNA adduct levels were approximately 10 times lower than the levels observed in lung tissue, which is considered to be a target organ for B[a]P induced mutagenicity. The difference between the adduct levels in testes and lung tissue was found previously [24]. It is possible that $\mathrm{B}[\mathrm{a}] \mathrm{P}$ does not reach the testes 
as well as lung tissue after exposure by oral gavage, and/or that testes may contain lower concentrations of enzymes converting $\mathrm{B}[\mathrm{a}] \mathrm{P}$ into DNA binding derivatives. For example, it has been noted that CYP1A1 is not significantly induced in testes after exposure to B[a]P [25]. The time-dependent decline in adduct levels in testes can in theory be the result of 4 processes: 1. cell turnover, 2. DNA repair, 3. apoptosis and necrosis, and 4. removal of spermatozoa carrying DNA adducts out of the testes into the epididymides. Regarding 1 and 2, we indeed noticed a faster decline in DNA adduct levels in Wt mice (half-life: 2.9 days) than the DNA repair deficient mice (halflife: 13.2 days) in the first week, indicating that there is, in addition to cell turnover, a role for DNA repair in removing DNA adducts from the testes. Regarding 3, there is evidence that exposure to $\mathrm{B}[\mathrm{a}] \mathrm{P}$ can result in apoptosis and necrosis of germ cells present in the testes, especially of spermatogonia [25], resulting in a loss of DNA adducts. Our data confirm that spermatogonia are particularly sensitive for B[a]P induced genotoxicity. However, histopathological examination of testes in our study did not reveal any signs of cytotoxicity in $\mathrm{Xpc}^{-/-}$or Wt mice. Regarding 4, DNA adduct levels in testes can be reduced by migration of damaged spermatozoa from testes into the epididymides. This damage would show up in epididymal spermatozoa with a delay. Indeed, a peak in testes was observed at day 1 whereas highest adduct levels in sperm were found at 7 to 10 days after exposure. Moreover, DNA adducts in sperm collected at 42 days after exposure were significantly higher in $\mathrm{Xpc}^{-/-}$mice than in Wt mice, which can be related to the longer half-life of adducts seen in testes.

DNA adduct levels in lung of $\mathrm{Xpc}^{-/-}$mice were overall higher than the adduct levels in lung of Wt mice over the whole 42 days observation period, but no significantly different levels were found at single time points. Thus, GGR/NER has only a minor influence on the DNA adduct levels and kinetics in lung tissue. In addition, the gradual decline of DNA adduct levels in the first few days did not differ between the genotypes, which indicates that GGR/NER is not an efficient repair mechanism for the removal of $\mathrm{B}[\mathrm{a}] \mathrm{P}$ induced DNA adducts in lung tissue, as was previously suggested [26]. The reduction of adduct levels found in lung tissues of these mice is possibly due to other DNA repair mechanisms and cell turnover. Van Schooten et al. reported a similar decline of BPDE-DNA adducts in lung tissues of acutely exposed mice, and showed that the removal of the DNA adducts paralleled cell turnover [20]. We also showed that DNA adduct levels in lung tissues reached a plateau at 14 days until the end of the experiment. Previous studies already reported a similar pattern and an unexplained long-term persistence of DNA adduct levels after a single dose of B[a]P and other carcinogens in lung tissues [27, 28]. Although cell turnover seems to play a role in the removal in the first two weeks after exposure, the plateau suggests that a subset of lung cells carrying DNA damage is not dividing. The adduct kinetics in lung tissues were clearly distinct from those in testes and mature sperm, and may be relevant for determining the effects of $\mathrm{B}[\mathrm{a}] \mathrm{P}$ on DNA integrity, and subsequent mutagenicity. It has already been shown that the total area under the curve, rather than absolute adduct levels, is more important for determining the carcinogenicity of PAHs [29]. For that reason, lung tissues may be more susceptible for the induction of mutations than testes. Interestingly, the deficiency of $X p c$ increases the area under the curve in testis as compared to Wt mice, suggesting that Xpc deficiency may make the germ line more susceptible to B[a]P.

From our data it can be concluded that spermatogonia and testes are susceptible for the induction of DNA damage by $B[a] P$ and that GGR/NER is an important factor 
in protecting the DNA of these tissues. If DNA damage is not removed, this might lead to the formation of mutations in the germ line, or DNA damage may persist in sperm cells until after fertilization, thus affecting the developing embryo [30]. Further studies should elucidate whether GGR/NER works efficiently to protect the inherited DNA against mutation induction.

\section{Acknowledgements}

The authors thank E.C. Friedberg for providing the $\mathrm{Xpc}^{-/-}$mice, and the animal technicians of the animal facilities of the Netherlands Vaccine Institute (NVI, the Netherlands) for their skilful assistance during this study. This project was partly funded by the Cefic Long-Range Research Initiative Innovative Science award given to R.W.L.G. in 2004. Further, part of the study was supported by the European Network of Excellence (NoE) "Environmental cancer, nutrition and individual susceptibility" (ECNIS), sixth Framework Programme (FP6), FOOD-CT-2005-513943. 


\section{References}

1. Sims, P., Grover, P.L., Swaisland, A., Pal, K. and Hewer, A. (1974) Metabolic activation of benzo(a)pyrene proceeds by a diol-epoxide. Nature, 252, 326-328.

2. Denissenko, M.F., Pao, A., Tang, M. and Pfeifer, G.P. (1996) Preferential formation of benzo[a]pyrene adducts at lung cancer mutational hotspots in P53. Science, 274, 430-432.

3. Zenzes, M.T., Bielecki, R. and Reed, T.E. (1999) Detection of benzo(a)pyrene diol epoxide-DNA adducts in sperm of men exposed to cigarette smoke. Fertil Steril, 72, 330-335.

4. Somers, C.M., Yauk, C.L., White, P.A., Parfett, C.L. and Quinn, J.S. (2002) Air pollution induces heritable DNA mutations. Proc Natl Acad Sci U S A, 99, 15904-15907.

5. Vilarino-Guell, C., Smith, A.G. and Dubrova, Y.E. (2003) Germline mutation induction at mouse repeat DNA loci by chemical mutagens. Mutat Res, 526, 63-73.

6. Yauk, C.L., Fox, G.A., McCarry, B.E. and Quinn, J.S. (2000) Induced minisatellite germline mutations in herring gulls (Larus argentatus) living near steel mills. Mutat Res, 452, 211-218.

7. Yauk, C.L. and Quinn, J.S. (1996) Multilocus DNA fingerprinting reveals high rate of heritable genetic mutation in herring gulls nesting in an industrialized urban site. Proc Natl Acad Sci U S A, 93, 1213712141.

8. Cordier, S., Lefeuvre, B., Filippini, G., Peris-Bonet, R., Farinotti, M., Lovicu, G. and Mandereau, L. (1997) Parental occupation, occupational exposure to solvents and polycyclic aromatic hydrocarbons and risk of childhood brain tumours (Italy, France, Spain). Cancer Causes Control, 8, 688-697.

9. Cordier, S., Monfort, C., Filippini, G., Preston-Martin, S., Lubin, F., Mueller, B.A., Holly, E.A., PerisBonet, R., McCredie, M., Choi, W., Little, J. and Arslan, A. (2004) Parental exposure to polycyclic aromatic hydrocarbons and the risk of childhood brain tumors: The SEARCH International Childhood Brain Tumor Study. Am J Epidemiol, 159, 1109-1116.

10. Boffetta, P., Tredaniel, J. and Greco, A. (2000) Risk of childhood cancer and adult lung cancer after childhood exposure to passive smoke: A meta-analysis. Environ Health Perspect, 108, 73-82.

11. Ji, B.T., Shu, X.O., Linet, M.S., Zheng, W., Wacholder, S., Gao, Y.T., Ying, D.M. and Jin, F. (1997) Paternal cigarette smoking and the risk of childhood cancer among offspring of nonsmoking mothers. $J$ Natl Cancer Inst, 89, 238-244.

12. Olsen, A.K., Lindeman, B., Wiger, R., Duale, N. and Brunborg, G. (2005) How do male germ cells handle DNA damage? Toxicol Appl Pharmacol, 207, 521-531.

13. Gillet, L.C. and Scharer, O.D. (2006) Molecular mechanisms of mammalian global genome nucleotide excision repair. Chem Rev, 106, 253-276.

14. Adler, I.D. (1996) Comparison of the duration of spermatogenesis between male rodents and humans. Mutat Res, 352, 169-172.

15. Klein, J.C., Beems, R.B., Zwart, P.E., Hamzink, M., Zomer, G., van Steeg, H. and van Kreijl, C.F. (2001) Intestinal toxicity and carcinogenic potential of the food mutagen 2-amino-1-methyl-6-phenylimidazo[4,5b]pyridine (PhIP) in DNA repair deficient XPA-/- mice. Carcinogenesis, 22, 619-626.

16. Hoogervorst, E.M., van Oostrom, C.T., Beems, R.B., van Benthem, J., van den Berg, J., van Kreij, C.F., Vos, J.G., de Vries, A. and van Steeg, H. (2005) 2-AAF-induced tumour development in nucleotide excision repair-deficient mice is associated with a defect in global genome repair but not with transcription coupled repair. DNA Repair (Amst), 4, 3-9.

17. Cheo, D.L., Ruven, H.J., Meira, L.B., Hammer, R.E., Burns, D.K., Tappe, N.J., van Zeeland, A.A., Mullenders, L.H. and Friedberg, E.C. (1997) Characterization of defective nucleotide excision repair in $X P C$ mutant mice. Mutat Res, 374, 1-9.

18. de Vries, A., Dolle, M.E., Broekhof, J.L., Muller, J.J., Kroese, E.D., van Kreijl, C.F., Capel, P.J., Vijg, J. and van Steeg, H. (1997) Induction of DNA adducts and mutations in spleen, liver and lung of XPAdeficient//acZ transgenic mice after oral treatment with benzo[a]pyrene: correlation with tumour development. Carcinogenesis, 18, 2327-2332.

19. Lowe, X.R., de Stoppelaar, J.M., Bishop, J., Cassel, M., Hoebee, B., Moore, D., 2nd and Wyrobek, A.J. (1998) Epididymal sperm aneuploidies in three strains of rats detected by multicolor fluorescence in situ hybridization. Environ Mol Mutagen, 31, 125-132.

20. van Schooten, F.J., Hillebrand, M.J., Scherer, E., den Engelse, L. and Kriek, E. (1991) Immunocytochemical visualization of DNA adducts in mouse tissues and human white blood cells following treatment with benzo[a]pyrene or its diol epoxide. A quantitative approach. Carcinogenesis, 12, 427-433.

21. Zenzes, M.T., Puy, L.A., Bielecki, R. and Reed, T.E. (1999) Detection of benzo[a]pyrene diol epoxideDNA adducts in embryos from smoking couples: evidence for transmission by spermatozoa. Mol Hum Reprod, 5, 125-131.

22. Jones, R. (2004) Sperm survival versus degradation in the Mammalian epididymis: a hypothesis. Biol Reprod, 71, 1405-1411.

23. Cosentino, M.J. and Cockett, A.T. (1986) Structure and function of the epididymis. Urol Res, 14, 229240 . 
24. Yauk, C., Polyzos, A., Rowan-Carroll, A., Somers, C.M., Godschalk, R.W., Van Schooten, F.J., Berndt, M.L., Pogribny, I.P., Koturbash, I., Williams, A., Douglas, G.R. and Kovalchuk, O. (2008) Germ-line mutations, DNA damage, and global hypermethylation in mice exposed to particulate air pollution in an urban/industrial location. Proc Natl Acad Sci U S A, 105, 605-610.

25. Revel, A., Raanani, H., Younglai, E., Xu, J., Han, R., Savouret, J.F. and Casper, R.F. (2001) Resveratrol, a natural aryl hydrocarbon receptor antagonist, protects sperm from DNA damage and apoptosis caused by benzo(a)pyrene. Reprod Toxicol, 15, 479-486.

26. Stowers, S.J. and Anderson, M.W. (1985) Formation and persistence of benzo(a)pyrene metaboliteDNA adducts. Environ Health Perspect, 62, 31-39.

27. Bieler, C.A., Cornelius, M.G., Stiborova, M., Arlt, V.M., Wiessler, M., Phillips, D.H. and Schmeiser, H.H. (2007) Formation and persistence of DNA adducts formed by the carcinogenic air pollutant 3nitrobenzanthrone in target and non-target organs after intratracheal instillation in rats. Carcinogenesis, 28, 1117-1121.

28. Godschalk, R.W., Moonen, E.J., Schilderman, P.A., Broekmans, W.M., Kleinjans, J.C. and Van Schooten, F.J. (2000) Exposure-route-dependent DNA adduct formation by polycyclic aromatic hydrocarbons. Carcinogenesis, 21, 87-92.

29. Ross, J.A., Nelson, G.B., Wilson, K.H., Rabinowitz, J.R., Galati, A., Stoner, G.D., Nesnow, S. and Mass, M.J. (1995) Adenomas induced by polycyclic aromatic hydrocarbons in strain A/J mouse lung correlate with time-integrated DNA adduct levels. Cancer Res, 55, 1039-1044.

30. Zenzes, M.T. (2000) Smoking and reproduction: gene damage to human gametes and embryos. Hum Reprod Update, 6, 122-131. 



\section{Chapter 4}

\section{Benzo(a)pyrene induces similar gene expression changes in testis of DNA repair proficient and deficient mice}

BMC Genomics 2010; 11(1): 333

Nicole Verhofstad

Jeroen L.A. Pennings

Conny Th.M. van Oostrom Jan van Benthem

Frederik J. van Schooten

Harry van Steeg

Roger W.L. Godschalk 
Abstract

Background: Benzo[a]pyrene $(\mathrm{B}[\mathrm{a}] \mathrm{P})$ exposure induces DNA adducts at all stages of spermatogenesis and in testis, and removal of these lesions is less efficient in nucleotide excision repair deficient $X p c^{-/-}$mice than in wild type mice. In this study, we investigated by using microarray technology whether compromised DNA repair in $X p c^{-1-}$ mice may lead to a transcriptional reaction of the testis to cope with increased levels of $B[a] P$ induced DNA damage.

Results: Two-way ANOVA revealed only 4 genes differentially expressed between wild type and $\mathrm{Xpc}^{-1-}$ mice, and 984 genes between testes of $\mathrm{B}[\mathrm{a}] \mathrm{P}$ treated and untreated mice irrespective of the mouse genotype. However, the level in which these $\mathrm{B}[\mathrm{a}] \mathrm{P}$ regulated genes are expressed differs between $\mathrm{Wt}$ and $X p c^{-1-}$ mice $(p=0.000000141)$, and were predominantly involved in the regulation of cell cycle, translation, chromatin structure and spermatogenesis, indicating a general stress response. In addition, analysis of cell cycle phase dependent gene expression revealed that expression of genes involved in G1-S and G2-M phase arrest was increased after $\mathrm{B}[\mathrm{a}] \mathrm{P}$ exposure in both genotypes. A slightly higher induction of average gene expression was observed at the G2-M checkpoint in $X p c^{-1-}$ mice, but this did not reach statistical significance $(P=0.086)$. Other processes that were expected to have changed by exposure, like apoptosis and DNA repair, were not found to be modulated at the level of gene expression.

Conclusions: Gene expression in testis of untreated $\mathrm{Xpc}^{-1-}$ and wild type mice were very similar, with only 4 genes differentially expressed. Exposure to benzo(a)pyrene affected the expression of genes that are involved in cell cycle regulation in both genotypes, indicating that the presence of unrepaired DNA damage in testis blocks cell proliferation to protect DNA integrity in both DNA repair proficient and deficient animals. 


\section{Background}

Exposure to chemicals like benzo(a)pyrene $(\mathrm{B}[\mathrm{a}] \mathrm{P})$ can lead to structural changes in DNA and as a consequence to the development of diseases with a genetic basis [1]. Changes in the DNA sequence can be induced by exposure to chemicals during life, but may also be inherited via mutations in the spermatogonial stem cells; in that way increasing the risk of developing abnormalities or diseases in the offspring $[2,3]$. The mutagenic potential of $\mathrm{B}[\mathrm{a}] \mathrm{P}$ in male germ cells, however, has still not been fully established. B[a]P related DNA damage was observed at all stages of spermatogenesis and in testis [4,5], but it is largely unknown how germ cells deal with DNA damage to protect their genetic material, and to prevent the accumulation of mutations in the germ line.

Spermatogenesis is carefully controlled to produce mature spermatozoa from spermatogonial stem cells in three major stages; the mitotic stage, the meiotic stage and the maturation stage. Germ cells are susceptible for the induction of mutations during mitotic and meiotic divisions, because cell turnover is a prerequisite for fixation of DNA damage into mutations. However, it is likely that several processes prevent the occurrence of gene mutations in male germ cells; for example, DNA damage can be removed by DNA repair mechanisms, of which nucleotide excision repair (NER) is considered to be the most relevant repair mechanism for bulky DNA adducts formed by reactive metabolites of $B[a] P$. Two NER mechanisms have been described: global genome repair (GGR) eliminates bulky DNA lesions in the entire genome, whereas transcription coupled repair (TCR) specifically removes lesions that block RNA synthesis [6]. In a previous study, we observed that GGR/NER plays an important role in the removal of $B[a] P$ induced DNA adducts in the testis, especially in the first week after exposure [5]. B[a]P-induced DNA adduct levels in the testis were significantly different between $\mathrm{Wt}$ and $X p c^{-/-}$mice, especially at 4 days after a single exposure to $\mathrm{B}[\mathrm{a}] \mathrm{P}\left(0.69 \pm 0.16\right.$ and $1.84 \pm 0.70$ adducts per $10^{8}$ nucleotides in $\mathrm{Wt}$ and $X p c^{-/-}$mice, respectively). Therefore, in an attempt to reveal the responses in the testis to this damage, we investigated by using microarrays the changes in gene expression induced by $\mathrm{B}[\mathrm{a}] \mathrm{P}$ in testis from $\mathrm{Wt}$ and $X p c^{-/-}$male mice, 4 days after exposure to $\mathrm{B}[\mathrm{a}] \mathrm{P}$. Since $X p c^{-/-}$mice lack one of the most important protective mechanisms against $\mathrm{B}[\mathrm{a}] \mathrm{P}$ induced DNA damage, we expected a different (adaptive) transcriptional response in these mice as compared to their Wt counterparts.

\section{Methods}

\section{Animal experiments}

Male wild type (C57BL/6) and $X p c^{-/-}$mice (C57BL/6), as previously described [7, 8], were exposed to a single dose of $B[a] P(13 \mathrm{mg} / \mathrm{kg} \mathrm{bw})$ by oral gavage, and were sacrificed 4 days after exposure. All groups consisted of 5 mice. The dose of 13 $\mathrm{mg} / \mathrm{kg}$ bw has been used in previous studies and is appropriate to induce detectable DNA adduct levels [9]. The control groups received the solvent sunflower oil and were also sacrificed at day 4 after exposure. Testes were snap frozen in liquid nitrogen and stored at $-80^{\circ} \mathrm{C}$ until analysis. Mice were bred and housed under specific pathogen-free conditions in a 12-hour light-dark cycle at the animal facilities of the Netherlands Vaccine Institute (NVI, Bilthoven, the Netherlands), and received food 
and water ad libitum. Experiments were approved by the institute's Animal Ethics Committee and were carried out according to their guidelines.

\section{RNA isolation and purification}

After testes had been pulverized using mortar and tamper cooled in liquid nitrogen, TRIzol ${ }^{\circledR}$ Reagent (Invitrogen, Breda, the Netherlands) was added to the material and RNA was isolated using an RNeasy Mini Kit (Qiagen, Venlo, the Netherlands) with DNase treatment according to the manufacturer's protocol with minor modifications. RNA quantity was determined spectrophotometrically and RNA purity was assessed on an Agilent 2100 Bioanalyzer (Agilent Technologies, Amstelveen, the Netherlands). All samples were pure and free of RNA degradation.

\section{RNA labelling and hybridization on microarrays}

Cyanine labelled cRNA was generated by using the Two-Color Microarray-Based Gene Expression Analysis kit from Agilent Technologies according to the manufacturer's protocol. All samples were labelled with Cy5, and 3 samples of unexposed $\mathrm{Wt}$ mice were labelled with Cy3, pooled and used as a reference sample. On the basis of dye incorporation rates, appropriate amounts of Cy5 and Cy3 labelled samples (10 pmol each) were simultaneously hybridized on Agilent 22K Mouse microarrays (Agilent Technologies). After hybridization, slides were washed and dried with $\mathrm{N}_{2}$ gas before scanning.

\section{Image analysis}

Slides were scanned on a GenePix ${ }^{\circledR}$ 4000B Microarray Scanner (Molecular Devices, Sunnyvale, CA, USA). Cy5 and Cy 3 were excited at wavelengths of 635 and $532 \mathrm{~nm}$, respectively. Laser power was set to $100 \%$. The photo multiplier was set to a saturation tolerance of $0.02 \%$ to minimize background and saturated spots. The images obtained (resolution 5 micron, 16 bit tiff images) were processed with Imagene 8.0.1 software (Biodiscovery, El Segundo, CA, USA) to measure mean signal intensities for spots and local backgrounds.

\section{Quality control}

Quality control was performed on raw data by means of a scatter plot and MAplot as well as a normal probability plot to assess signal distribution. Positive (landmark) and negative (blank) spots were used for quality control but not included in further analyses. Microarray spot signal data were normalized in R using a four-step approach of (1) natural log-transformation, (2) quantile normalization of all scans, (3) correction of the sample spot signal for the corresponding reference spot signal and (4) averaging data from replicate spots. Normalized data were visualized by Principal Component Analysis (PCA) for additional quality control. The gene expression data discussed in this publication have been deposited in NCBl's Gene Expression Omnibus [10] and are accessible through GEO Series accession number GSE17979 (http://www.ncbi.nlm.nih.gov/geo/query/acc.cgi?acc=GSE17979).

\section{Data analysis}

Significance of differences in gene expression between genotype and/or treatment groups was calculated by a Two-Way ANOVA, where genes with a false discovery rate (FDR) below $5 \%$ were selected as differentially expressed. Differentially 
expressed genes were clustered (based on Euclidian Distance and Ward linkage) using GeneMaths (Applied Maths, St-Martens-Latem, Belgium). By using the DAVID/EASE (http://david.abcc.ncifcrf.gov) web application, functional annotation and Gene Ontology (GO) term enrichment were determined for three different gene sets, namely $\mathrm{B}[\mathrm{a}] \mathrm{P}$ induced genes, $\mathrm{B}[\mathrm{a}] \mathrm{P}$ suppressed genes and all regulated genes together (FDR < 0.1) [11, 12].

Pathway enrichment among $\mathrm{B}[\mathrm{a}] \mathrm{P}$ regulated genes was further used to identify regulated genes within a pathway, and to compare the average gene expression ratios of $\mathrm{B}[\mathrm{a}] \mathrm{P}$ treated $v s$. control groups between the two genotypes. Pathways with related terms for cell cycle, translation, chromatin structure and spermatogenesis, which were already found to be enriched among the up regulated genes, were combined to form 4 groups of genes that were used for this comparison.

For visualization of cell cycle phase activity, the average gene expression for suitable gene sets was calculated. Sets used were based on either GO functional annotation or on genes found specifically expressed in a particular cell cycle phase by both Bar-Joseph et al. [13] and Whitfield et al. [14], but only used for calculation if they contained at least 4 genes. Setwise average gene expression levels for each experimental group were expressed relative to the Wt control mice, for which the level was set at 1.

\section{Quantitative Real-Time PCR}

For qPCR of 4 selected genes (ASf1b, Cit, Ect2 and Psip1) and reference gene Hprt1, cDNA was synthesized using the iScript cDNA Synthesis kit (Bio-Rad, Veenendaal, the Netherlands) according to the manufacturer's protocol, starting with $0.5 \mu \mathrm{g}$ of RNA. QPCR was performed on a MyiQ ${ }^{\mathrm{TM}}$ Single-Color Real-Time PCR detection system (Bio-Rad) using the $\mathrm{iQ}^{\mathrm{TM}} \mathrm{SYBR}^{\circledR}$ Green Supermix (Bio-Rad) according to the manufacturer's protocol with minor modifications, $5 \mu \mathrm{l}$ of 10 times diluted cDNA and $0.3 \mu \mathrm{M}$ primers in a total volume of $25 \mu \mathrm{l}$. Samples were amplified under the following conditions: $95^{\circ} \mathrm{C}$ for 3 minutes, followed by 40 cycles at $95^{\circ} \mathrm{C}$ for 15 seconds and $60^{\circ} \mathrm{C}$ for 45 seconds. PCR was checked for a-specific products by performing a melting curve analysis $\left(65^{\circ} \mathrm{C}-95^{\circ} \mathrm{C}\right)$. Data were analyzed using the My$\mathrm{iQ}^{\mathrm{TM}}$ Software system (Bio-Rad) and were expressed as average gene expression ratios as compared to controls.

\section{Results}

\section{Gene expression profiling}

Two-way ANOVA revealed 984 regulated genes that were differentially expressed between treated and untreated mice (FDR 5\%), of which 638 genes were increased and 346 genes were decreased by B[a]P exposure. Only 4 genes (Xpc, $\mathrm{Cm} / 2$, D6Mm5e and 2610209M04Rik) were differentially expressed between unexposed Wt and unexposed $X p c^{-/-}$mice (FDR 5\%), and they are all located at the same site of chromosome 6 . Of these 4 genes, $X p c, C m / 2$ and $D 6 M m 5 e$ were decreased in expression in $\mathrm{Xpc}^{-/-}$mice as compared to the Wt mice, with higher gene expression levels of $\mathrm{Cm} / 2$ and $D 6 M m 5 e$ than the very low levels of $X p c$. On the other hand, $2610209 M 04 R i k$ was increased in $X p c^{-/-}$mice. This confirms the absence of a functional $X p c$ gene in the $X p c^{--/}$genotype, and shows that closely linked genes have 
significantly altered expression patterns. Finally, our results show that there is only a modest difference between the gene expression patterns in testis of $\mathrm{B}[\mathrm{a}] \mathrm{P}$ treated $\mathrm{Wt}$ and $\mathrm{Xpc}^{-/-}$mice. Nonetheless, a paired T-test showed that the level in which these $\mathrm{B}[\mathrm{a}] \mathrm{P}$ regulated genes are expressed differs between $\mathrm{Wt}$ and $X p c^{-/-}$mice $(\mathrm{p}=$ $0.000000141)$. The clustering of the combined hits is presented in figure 1.

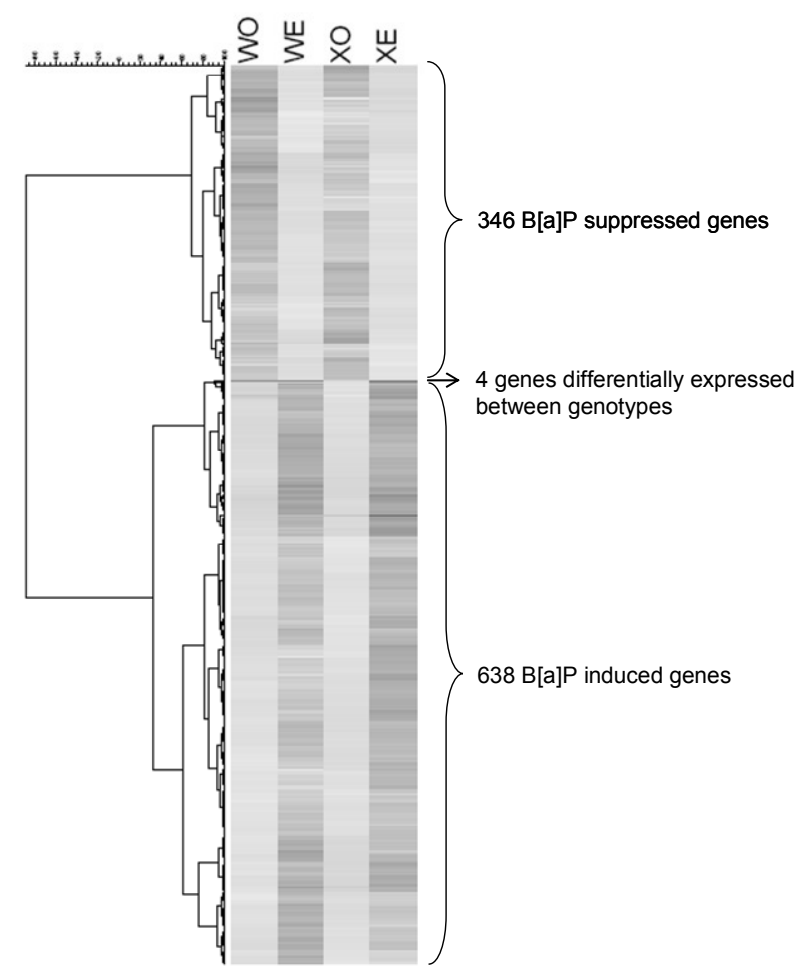

Figure 1. Cluster analysis of differentially expressed genes. Differentially expressed genes were clustered based on Euclidian Distance and Ward linkage using GeneMaths. WO, Wt control. WE, Wt exposed. XO, Xpc-/control. XE, Xpc ${ }^{-/-}$exposed.

\section{Analysis of pathway regulation}

The list of the 638 genes that were induced by B[a]P suggested, by using DAVID/EASE, a significant enrichment for several Gene Ontology (GO) biological processes and Swiss-Prot_Protein Information Resource (SP_PIR) terms, such as 'cell division' ( $p=0.000000082$ ), 'mitosis' ( $p=0.00000037$ ), 'chromosome segregation' $(p=0.000085)$ and 'spermatogenesis' $(p=0.00024)$ (additional file $\left.1^{\ddagger}\right)$. The 346 genes that were down regulated by $B[a] P$ exposure also showed an enrichment for several pathways, including 'oxidative phosphorylation' $(p=0.0011)$ (additional file $\left.2^{\ddagger}\right)$. In addition, two GO terms for the cellular components mitochondrial part $(p=$ 
0.001 ) and mitochondrion $(p=0.0011)$, were enriched among $B[a] P$ suppressed genes, which is in line with the inhibition of the oxidative phosphorylation process.

The combined list of B[a]P (both up and down) regulated genes showed an enrichment of $110 \mathrm{GO}$ and SP_PIR terms (additional file $3^{\ddagger}$ ), including cell cycle, translation, chromatin structure and spermatogenesis, which we already found to be enriched among the up regulated genes only. Therefore, we used these 4 processes to further select genes and to subsequently compare the two genotypes regarding their gene expression ratios between B[a]P treated vs. control groups. An overview of the gene expression ratio distribution is given in table 1 . Forty-six differentially regulated genes were involved in the cell cycle (table 2), of which 20 genes were induced to a higher extent in $\mathrm{Xpc}^{-/-}$mice, whereas only 12 of these genes were expressed to a higher extent in Wt mice. Regarding the genes that were inhibited in their expression, 6 genes were more suppressed in $X p c^{-/-}$mice, and 8 genes in Wt mice as compared to animals of the other genotype. In addition, we found 37 genes that are involved in the chromatin structure (additional file $4^{\ddagger}$ ), of which 20 genes were more induced in $\mathrm{Xpc}^{-/-}$mice, and 8 genes in Wt mice. Only 8 chromatin structure related genes were more suppressed in Wt mice, as compared to 1 gene in $\mathrm{Xpc}^{-/-}$mice. Among the spermatogenesis related genes (additional file $5^{\ddagger}$ ), we only found differences between $\mathrm{Wt}$ and $\mathrm{Xpc}^{-/-}$animals among the $\mathrm{B}[\mathrm{a}] \mathrm{P}$ suppressed genes; nine genes were more suppressed in Wt mice compared to 1 gene in $\mathrm{Xpc}^{-/-}$mice as compared to animals of the other genotype. Taken together, these results indicate that gene expression differences between $\mathrm{Wt}$ and $\mathrm{Xpc}^{-/-}$mice are small, and that the induction of genes involved in cell division regulating processes was stronger in $\mathrm{Xpc}^{-/-}$than in $\mathrm{Wt}$ mice. We did not find relevant differences in average gene expression ratios between $\mathrm{Xpc}^{--}$and Wt mice among translation related genes, that are given in additional file $6^{\ddagger}$.

Among the $110 \mathrm{GO}$ and SP_PIR terms that were obtained from the combined list of $\mathrm{B}[\mathrm{a}] \mathrm{P}$ (both up and down) regulated genes, we again found a few mitochondria related terms, such as the cellular components 'mitochondrial part', 'mitochondrial envelope' and 'mitochondrial membrane', and the SP_PIR Keyword 'mitochondrion'. Furthermore, we found the SP_PIR keyword 'chaperone', which involves genes that are known to be activated during a stress response.

Table 1. Comparison of gene expression ratios

\begin{tabular}{lccccc}
\hline Pathway & Total \# of genes & Uw & Ux & Dw & Dx \\
\hline Cell cycle & 46 & 12 & 20 & 8 & 6 \\
Chromatin structure & 37 & 8 & 20 & 8 & 1 \\
Translation & 59 & 18 & 22 & 7 & 12 \\
Spermatogenesis & 32 & 10 & 12 & 9 & 1 \\
\hline
\end{tabular}

Average gene expression ratios for genes involved in significantly regulated pathways are compared between $\mathrm{Wt}$ and $\mathrm{Xpc}^{-/-}$mice. The table shows the number of genes that are up or down regulated to a higher extent after $\mathrm{B}[\mathrm{a}] \mathrm{P}$ exposure in either genotype. Uw, up regulated to a higher extent in Wt mice. Ux, up regulated to a higher extent in $\mathrm{Xpc}^{-/-}$mice. Dw, down regulated to a greater extent in Wt mice. Dx, down regulated to a greater extent in $\mathrm{Xpc}^{-/-}$mice. 
Table 2. Differentially regulated genes regarding the cell cycle process after B[a]P exposure

\begin{tabular}{|c|c|c|c|}
\hline Symbol & Gene Name & $\mathbf{W t}$ & $X p c^{-1-}$ \\
\hline Bin3 & bridging integrator 3 & 1.13 & 1.31 \\
\hline Brca2 & breast cancer 2 & -1.35 & -1.34 \\
\hline Brms1 & breast cancer metastasis-suppressor 1 & -1.18 & -1.34 \\
\hline Calr & calreticulin & -1.26 & -1.31 \\
\hline Ccnb2 & cyclin B2 & -1.24 & -1.16 \\
\hline Ccng2 & cyclin G2 & 1.23 & 1.32 \\
\hline Ccnk & cyclin $\mathrm{K}$ & 1.21 & 1.23 \\
\hline Cdc25c & cell division cycle 25 homolog C (S. cerevisiae) & -1.09 & -1.30 \\
\hline Cdc27 & cell division cycle 27 homolog (S. cerevisiae) & 1.41 & 1.31 \\
\hline Cdc42 & cell division cycle 42 homolog (S. cerevisiae) & 1.34 & 1.50 \\
\hline Cdca1 & cell division cycle associated 1 & 1.24 & 1.50 \\
\hline Cdca5 & cell division cycle associated 5 & 1.18 & 1.30 \\
\hline Cdca8 & cell division cycle associated 8 & -1.24 & -1.11 \\
\hline Cdk5rap3 & CDK5 regulatory subunit associated protein 3 & -1.24 & -1.23 \\
\hline Cetn1 & centrin 1 & 1.46 & 1.31 \\
\hline Cit & citron & 1.20 & 1.35 \\
\hline Cks2 & CDC28 protein kinase regulatory subunit 2 & 1.29 & 1.36 \\
\hline Cul3 & cullin 3 & 1.28 & 1.18 \\
\hline Dhcr24 & 24-dehydrocholesterol reductase & 1.50 & 1.43 \\
\hline Dnajc2 & DnaJ (Hsp40) homolog, subfamily C, member 2 & -1.42 & -1.23 \\
\hline Fzr1 & fizzy/cell division cycle 20 related 1 (Drosophila) & 1.44 & 1.39 \\
\hline Gspt1 & G1 to $S$ phase transition 1 & 1.37 & 1.31 \\
\hline Hells & helicase, lymphoid specific & 1.43 & 1.46 \\
\hline Incenp & inner centromere protein & 1.17 & 1.29 \\
\hline Kif20a & kinesin family member $20 \mathrm{~A}$ & 1.54 & 1.41 \\
\hline Macf1 & microtubule-actin crosslinking factor 1 & 1.16 & 1.49 \\
\hline Mad2I2 & MAD2 mitotic arrest deficient-like 2 (yeast) & 1.19 & 1.27 \\
\hline Mphosph6 & M phase phosphoprotein 6 & 1.30 & 1.26 \\
\hline Mtus1 & mitochondrial tumor suppressor 1 & -1.22 & -1.19 \\
\hline Nasp & nuclear autoantigenic sperm protein (histone-binding) & 1.34 & 1.38 \\
\hline Nek4 & NIMA (never in mitosis gene a)-related expressed kinase 4 & 1.31 & 1.37 \\
\hline Pin1 & protein (peptidyl-prolyl cis/trans isomerase) NIMA-interacting 1 & 1.31 & 1.26 \\
\hline Ppp3ca & protein phosphatase 3 , catalytic subunit, alpha isoform & -1.19 & -1.22 \\
\hline Pten & phosphatase and tensin homolog & 1.32 & 1.31 \\
\hline Rad17 & RAD17 homolog (S. pombe) & 1.22 & 1.27 \\
\hline Ranbp1 & RAN binding protein 1 & -1.24 & -1.23 \\
\hline Rbm5 & RNA binding motif protein 5 & 1.34 & 1.39 \\
\hline Sgol1 & shugoshin-like 1 (S. pombe) & 1.26 & 1.20 \\
\hline Smarcb1 & $\begin{array}{l}\text { SWI/SNF related, matrix associated, actin dependent regulator of chroma- } \\
\text { tin, subfamily b, member } 1\end{array}$ & 1.27 & 1.33 \\
\hline Sycp3 & synaptonemal complex protein 3 & 1.34 & 1.30 \\
\hline Tacc3 & transforming, acidic coiled-coil containing protein 3 & 1.31 & 1.34 \\
\hline Tipin & timeless interacting protein & -1.22 & -1.24 \\
\hline Trrap & transformation/transcription domain-associated protein & -1.26 & -1.22 \\
\hline Tubb6 & tubulin, beta 6 & -1.33 & -1.44 \\
\hline Ube2i & ubiquitin-conjugating enzyme E2I & 1.17 & 1.30 \\
\hline Zw10 & ZW10 homolog (Drosophila), centromere/kinetochore protein & 1.23 & 1.30 \\
\hline
\end{tabular}

Forty-six differentially regulated genes regarding the cell cycle process. Results are presented as average gene expression ratios between exposed and control samples. 


\section{Cell cycle phase activity}

The setwise average gene expression levels of cell cycle related gene sets were calculated for sets of genes related to specific cell cycle phases, in order to study cell cycle phase activity (figure 2). The sets used were based on GO functional annotation for the complete cell cycle or genes found specifically expressed in a particular cell cycle phase, reported by both Bar-Joseph et al. [13] and Whitfield et al. [14]. Average gene expression levels of all cell cycle genes were lower in $\mathrm{Xpc}^{-/-}$mice than in Wt mice $(p=0.024)$ in the absence of exposure to B[a]P. However, after B[a]P exposure gene expression levels of the same cell cycle related genes were increased to comparable levels in both genotypes. When focusing on specific cell cycle phases, we observed that the average gene expression levels of genes within the cell cycle transition between $\mathrm{G} 1$ and $\mathrm{S}$ was similar in $\mathrm{Wt}$ and $X p c^{-/-}$control mice, and again increased after $B[a] P$ exposure to equal levels $(p=0.937)$. On the other hand, the average level of expression of genes involved in the G2-M phase transition was initially lower in $\mathrm{Xpc}^{-/-}$control mice compared to the Wt control mice, and gene expression levels were increased by $\mathrm{B}[\mathrm{a}] \mathrm{P}$ exposure to a higher extent in $\mathrm{Xpc}^{-/-}$mice compared to the $\mathrm{Wt}$ mice. Table 3 shows the gene expression ratios of the 18 genes involved in the G2-M phase transition, indicating that 11 out of these 18 genes were more induced in $X p c^{-/-}$mice after $\mathrm{B}[\mathrm{a}] \mathrm{P}$ exposure as compared to $\mathrm{Wt}$ mice $(\mathrm{p}=$ 0.086). Although these differences between $\mathrm{Wt}$ and $X p c^{-/-}$mice are not significant, they are consistent since the majority of genes respond into the same direction, and represent an observed trend towards a more pronounced response to B[a]P in Xpc $c^{-1-}$ mice. Within the M-G1 phase, we observed a low impact of $B[a] P$ exposure in both genotypes, as compared to the other cell cycle phases. Also within this cell cycle phase, the response to $\mathrm{B}[\mathrm{a}] \mathrm{P}$ was more pronounced in $\mathrm{Xpc}^{-/-}$mice than in $\mathrm{Wt}$ mice, although this was based on the expression of 4 genes only $(p=0.300)$.

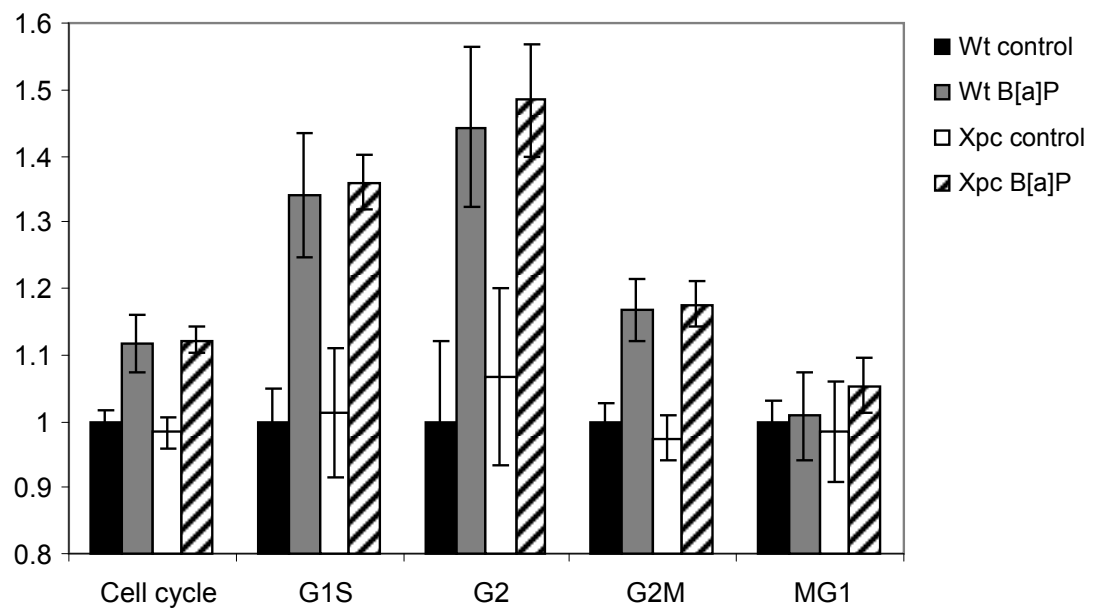

Figure 2. Average gene expression levels of cell cycle related gene sets. The setwise average expression levels of genes involved in cell cycle regulation and regulation during specific phases of the cell cycle. Error bars presented are based on the expression levels of individual mice. The average expression level of Wt control mice is set at 1 . 
Table 3. Differentially regulated genes involved in G2-M phase transition

\begin{tabular}{|c|c|c|c|}
\hline Symbol & Gene Name & $\mathbf{W t}$ & $X p c^{-/-}$ \\
\hline$\overline{\mathrm{Arl}^{*}}$ & ADP-ribosylation factor-like 4 & 1.15 & 1.20 \\
\hline Asf $1 b^{*}$ & ASF1 anti-silencing function 1 homolog B & 1.24 & 1.25 \\
\hline Ccnb2 & cyclin B2 & -1.24 & -1.16 \\
\hline Cdc25c & cell division cycle 25 homolog C (S. cerevisiae) & -1.09 & -1.30 \\
\hline Cdc42ep4 & CDC42 effector protein (Rho GTPase binding) 4 & 1.33 & 1.29 \\
\hline Cdca8 & cell division cycle associated 8 & -1.24 & -1.11 \\
\hline $\mathrm{Cit}^{*}$ & citron & 1.20 & 1.35 \\
\hline $\mathrm{Cks}^{*}$ & CDC28 protein kinase regulatory subunit 2 & 1.29 & 1.36 \\
\hline Ect2* & ect2 oncogene & 1.25 & 1.45 \\
\hline Got1 & glutamate oxaloacetate transaminase 1 , soluble & 1.24 & 1.24 \\
\hline Gpsm2* & G-protein signalling modulator 2 (AGS3-like) & 1.23 & 1.33 \\
\hline Kpna2 & karyopherin (importin) alpha 2 & 1.35 & 1.30 \\
\hline Map3k6* & mitogen-activated protein kinase kinase kinase 6 & 1.25 & 1.35 \\
\hline Psip1* & PC4 and SFRS1 interacting protein 1 & 1.17 & 1.30 \\
\hline Rrm1* & ribonucleotide reductase $\mathrm{M} 1$ & 1.18 & 1.22 \\
\hline Tacc3* $^{*}$ & transforming, acidic coiled-coil containing protein 3 & 1.31 & 1.34 \\
\hline Tdp1 & tyrosyl-DNA phosphodiesterase 1 & 1.28 & 1.21 \\
\hline Tubd1* & tubulin, delta 1 & 1.26 & 1.30 \\
\hline
\end{tabular}

Gene expression ratios are presented of 18 differentially regulated genes involved in G2-M phase transition based on microarray results. These 18 genes, of which 3 were down regulated and 15 were up regulated after $\mathrm{B}[\mathrm{a}] \mathrm{P}$ exposure, showed a trend towards a more pronounced induction in $\mathrm{Xpc}^{-/-}$mice as compared to Wt mice $(p=0.086)$. However, a less extensive down regulation is not the same as a greater induction. Therefore, an additional $p$-value was calculated for the 15 up regulated genes, showing that 11 (indicated with *) out of these 15 up regulated genes are more induced in $X p c^{-/-}$than in Wt mice $(p=0.024)$.

\section{Validation with quantitative Real-Time PCR}

Quantitative Real-Time PCR (qPCR) was performed on 4 selected genes that are involved in the G2-M phase transition to validate the gene expression changes in Wt vs. Xpc ${ }^{-/-}$mice after B[a]P exposure. Three genes (Cit, Ect2 and Psip1) were selected because their average gene expression ratios were most different between $\mathrm{Wt}$ and $X p c^{-/-}$mice based on the microarray results, and Asf1b was selected as a control because of the small difference between $\mathrm{Wt}$ and $X p c^{-/-}$mice. After gene expression changes were normalised to the Hprt1 reference, qPCR data of the 3 strongly differentially expressed genes indeed showed a higher induction of gene expression after B[a]P exposure in $X p c^{-/-}$mice (ratios are 1.15 vs. 1.18, 1.00 vs. 1.05 and 1.00 vs. 1.04 for Cit, Ect2 and Psip1, in Wt and $X p c^{-1-}$ mice, respectively). However, the effect of $\mathrm{B}[\mathrm{a}] \mathrm{P}$ exposure was smaller on basis of the $\mathrm{QPCR}$ expression data. QPCR data of Asf1b showed a down regulation after B[a]P exposure in both $\mathrm{Wt}$ and $X_{p c}{ }^{-/}$mice (ratios are 0.94 and 0.98 , respectively), and did therefore, not confirm the microarray results. Overall, 3 out of 4 selected genes confirmed the microarray re- 
sults found within the G2-M phase, showing that B[a]P induces marginally higher gene expression changes in $\mathrm{Xpc}^{-/-}$than in Wt mice.

\section{Discussion}

$\mathrm{B}[\mathrm{a}] \mathrm{P}$ exposure leads to the formation of DNA adducts in testis and sperm of exposed male mice and humans [4, 5]. These pro-mutagenic DNA adducts are usually removed by DNA repair mechanisms to prevent the accumulation of mutations. In a previous study, we found that there is a difference in DNA adduct removal between $\mathrm{Wt}$ and $X p c^{-/-}$mouse testes [5]. In the first week after exposure to B[a]P, we observed more DNA adducts in testis of $X p c^{-/-}$mice, and a slower decline of DNA adducts over time. In addition, we showed that spermatogonial stem cells rely on NER for the complete removal of DNA adducts during spermatogenesis [5]. This suggests that GGR/NER plays an important role in mice in protecting the testis and sperm cells from DNA damage by $B[a] P$. In the present study, we used a microarray approach to study whether these differences in DNA adduct removal between $\mathrm{Wt}$ and $\mathrm{Xpc} \mathrm{c}^{--}$mice are accompanied by differences in gene expression, thereby elucidating adaptive responses towards the induction of heritable DNA damage in testis. We chose to analyze gene expression after 4 days, since at that time point DNA adduct levels differed more between $\mathrm{Wt}$ and $X p c^{-/-}$mice compared to day 1 , and still differed at day 7 [5].

Two-way ANOVA indicated that there are only minor expression differences between $\mathrm{Xpc}^{-/-}$and $\mathrm{Wt}$ mice. No more than 4 genes $(\mathrm{Xpc}, \mathrm{Cm} / 2, \mathrm{D} 6 \mathrm{Mm} 5 \mathrm{e}$ and 2610209 M04Rik) located in a $10 \mathrm{MB}$ locus on chromosome 6 , were differentially expressed between the two genotypes. Although the expression levels of $\mathrm{Cm} / 2$, $D 6 M m 5 e$ and 2610209M04Rik were higher as compared to the very low levels of $X p c$, the fact that these genes are located in proximity to the $X p c$ gene on chromosome 6 suggests that mutating the $X p c$ gene has changed the genomic or regulatory structure at that particular site and therefore the expression of these 3 genes. Another explanation could be that these 3 genes are of an Ola129 genetic background, which is used to create the $X p c$ mutant, and are for some unknown reason differently expressed [8].

The main differences were found between the B[a]P exposed and control mice, regardless of genotype. After B[a]P exposure, 984 genes were differentially regulated and these were enriched for genes involved in cell cycle, translation (ribosomes), chromatin structure and spermatogenesis. Besides these pathways, other more general processes were found to be affected (additional file $3^{\ddagger}$ ). Regulated processes regarding mitochondrial function (energy metabolism), chaperones, and the aforementioned changes in cell cycle seem to indicate a general stress response after exposure to $\mathrm{B}[\mathrm{a}] \mathrm{P}$ in testes of both genotypes. In addition, the altered expression of mitochondria related genes is indicative for changes in the oxidative phosphorylation; this process was also found to be affected among the B[a]P down regulated genes, and the genes for several ATP synthase subunits, NADH dehydrogenase (ubiquinone) subunits, cytochrome $\mathrm{c}$ and cytochrome $\mathrm{c}$ oxidase were differentially regulated (additional file $7^{\ddagger}$ ). Therefore, the motility and the fertilizing capacity of the sperm cells might have been affected, since mitochondria in sperm are responsible for the energy supply required to propel the flagellum [15]. A change in mitochondrial activity, which leads to less potent sperm cells, may therefore be part of the protec- 
tive mechanisms against DNA damage in the testis and sperm cells. Indeed, litter sizes of female mice that were fertilized by $\mathrm{B}[\mathrm{a}] \mathrm{P}$ exposed $\mathrm{Xpc^{-/- }}$ male mice were found to be smaller (data not shown).

$\mathrm{B}[\mathrm{a}] \mathrm{P}$ is a well-known mutagen and carcinogen, and mostly studied for its capacity to form bulky DNA adducts, which are mainly repaired by NER. By changing the NER capacity in $X p c^{--}$mice, we expected to find additional mechanisms affected by $\mathrm{B}[\mathrm{a}] \mathrm{P}$ exposure that could possibly protect the testis and male germ cells against the formation of heritable DNA damage, as a backup for the lack of GGR/NER. However, pathways involving DNA repair (other than NER) or apoptosis were not significantly enriched among our regulated genes. Nonetheless, we did find 16 differentially regulated genes that are involved in DNA repair (GO:0006281 DNA repair) (table 4), and at least 9 out of these 16 genes are related to repair of double strand breaks and/or homologous recombination. This suggests that exposure to $\mathrm{B}[\mathrm{a}] \mathrm{P}$ may cause double strand breaks, for instance by the collapse of the replication fork in replicating cells. Indeed, the number of $\mathrm{YH} 2 \mathrm{AX}$ foci, which is a hallmark for double strand break formation, was reported to be increased by exposure to B[a]P [16]. Although the pathway involving apoptosis was not significantly enriched among our regulated genes, we found 32 apoptosis-related genes to be differentially expressed after B[a]P exposure (table 5). In testes, apoptosis is a common process to discard excessive germ cells, or to remove severely damaged germ cells [17]. From our data it is hard to conclude whether apoptosis is elicited by B[a]P exposure, since we found only a small number of differentially expressed genes after $\mathrm{B}[\mathrm{a}] \mathrm{P}$ exposure and both pro-apoptotic and anti-apoptotic signals were found. For example, cytochrome c (Cycs) was up regulated after exposure in both $\mathrm{Wt}$ and $X p c^{-/-}$mice, which could be indicative for the initiation of the intrinsic apoptotic pathway. On the other hand, the expression of the anti-apoptotic gene Faim (Fas apoptotic inhibitory molecule) was also up regulated after B[a]P exposure, indicating an inhibitory effect on the apoptotic pathway [18]. Several aspects should be considered for the interpretation of transcriptional data regarding the regulation of apoptosis after $\mathrm{B}[\mathrm{a}] \mathrm{P}$ exposure; 1) the large number of apoptotic cells in normal testis will make it difficult to measure subtle changes in the apoptotic response after a single $\mathrm{B}[\mathrm{a}] \mathrm{P}$ exposure, 2) the apoptotic response after $\mathrm{B}[\mathrm{a}] \mathrm{P}$ exposure is an acute response that is probably hard to assess 4 days after exposure, and 3 ) the activation of the different caspases leading to fragmentation of DNA occurs by cleavage of procaspases already stored in the cell, a process that is unlikely to be found at the transcriptional level [19]. It should be noted that this last point may also hold true for other processes such as DNA repair, which also relies on activation and transport of already existing proteins.

To have a better understanding of the changes in cell cycle regulation, we compared setwise average expression levels of genes related to specific cell cycle phases between the 4 experimental groups. Genes involved in the $\mathrm{G} 1$ to $S$ phase transition and the $\mathrm{G} 2$ to $\mathrm{M}$ phase transition were induced in animals of both genotypes after B[a]P exposure, suggesting that cells may accumulate in both $\mathrm{G} 1$ and $\mathrm{G} 2$. Cell cycle arrest after B[a]P exposure was previously found, using MCF-7 (human breast carcinoma) and HepG2 (human hepatocarcinoma) cells, and identified altered expression of genes that affect cell cycle regulation [20]. Moreover, cell cycle phases assessed by FACS analysis indeed showed an accumulation of cells in the G1 and G2 phase after B[a]P exposure [20]. It has also been shown that benzo[a]pyrene-7,8dihydrodiol (BPD) and benzo(a)pyrene-diol-epoxide (BPDE), both metabolites of 
$B[a] P$, can induce a G2/M accumulation [21]. All these data are in line with our findings in testis of $\mathrm{B}[\mathrm{a}] \mathrm{P}$ exposed male mice.

Table 4. Differentially regulated genes concerning DNA repair

\begin{tabular}{|c|c|c|c|}
\hline Symbol & Gene Name & $\mathbf{W t}$ & $X p c^{-1-}$ \\
\hline 5830483C08Rik & riken cDNA 5830483c08 gene & 1.13 & 1.17 \\
\hline Als4 & amyotrophic lateral sclerosis 4 homolog (human) & 1.28 & 1.44 \\
\hline Asf1a & asf1 anti-silencing function 1 homolog a (s. cerevisiae) & -1.34 & -1.24 \\
\hline Brca2* $^{*}$ & breast cancer 2 & -1.35 & -1.34 \\
\hline Cry1 & cryptochrome 1 (photolyase-like) & 1.19 & 1.29 \\
\hline Cspg6* & chondroitin sulfate proteoglycan 6 & 1.39 & 1.40 \\
\hline Fbxo18 & f-box protein 18 & 1.13 & 1.26 \\
\hline Hmgn1 & high mobility group nucleosomal binding domain 1 & 1.36 & 1.36 \\
\hline $\mathrm{Mpg}^{*}$ & n-methylpurine-DNA glycosylase & 1.38 & 1.36 \\
\hline Polg & polymerase (DNA directed), gamma & 1.36 & 1.42 \\
\hline $\operatorname{Rad} 17^{*}$ & rad17 homolog (s. pombe) & 1.22 & 1.27 \\
\hline Rad52* & rad52 homolog (s. cerevisiae) & -1.21 & -1.16 \\
\hline Ssrp1* & structure specific recognition protein 1 & 1.13 & 1.30 \\
\hline Tdp1* & tyrosyl-DNA phosphodiesterase 1 & 1.28 & 1.21 \\
\hline$X p c$ & xeroderma pigmentosum, complementation group $\mathrm{C}$ & -1.07 & -1.11 \\
\hline $\operatorname{Xrcc}^{*}$ & $\begin{array}{l}\text { x-ray repair complementing defective repair in Chinese hamster } \\
\text { cells } 2\end{array}$ & -1.28 & -1.16 \\
\hline $\operatorname{Xrcc5}^{*}$ & $\begin{array}{l}\text { x-ray repair complementing defective repair in Chinese hamster } \\
\text { cells } 5\end{array}$ & 1.23 & 1.35 \\
\hline
\end{tabular}

Sixteen differentially regulated genes concerning DNA repair. Results are presented as average gene expression ratios between exposed and control samples. *genes associated with double strand breaks and/or homologous recombination.

The B[a]P induced G1-S arrest did not differ between Wt and $X p c^{-/-}$mice $(p=$ $0.937)$. However, expression of G2-M phase genes showed a trend towards a higher induction of these genes in testes of $X p c^{-/-}$mice after $B[a] P$ exposure $(p=0.086)$. Therefore, the expression ratios of $4 \mathrm{G} 2-\mathrm{M}$ phase genes were validated by qPCR, and results of 3 out of these 4 genes confirmed that $B[a] P$ induces slightly higher gene expression changes in $\mathrm{Xpc}^{-{ }_{-}-}$mice than in Wt mice. However, the level of induction by $\mathrm{B}[\mathrm{a}] \mathrm{P}$ exposure was higher on basis of microarray analysis, than by qPCR analysis. QPCR could not confirm the induction of Asf1b gene expression by B[a]P as shown by microarray analysis, although the difference in gene expression ratios between $\mathrm{Wt}$ and $X p c^{-/-}$mice remained small. Such a small difference in reaction may be explained by the fact that $\mathrm{Xpc}^{-/-}$mice are less capable of removing $\mathrm{B}[\mathrm{a}] \mathrm{P}$ induced damage in testis [5], and therefore more damaged cells are arrested (instead of a stronger reaction in each individual cell). This was also observed in a study using UVB irradiated Xpc-deficient epidermal cells [22]; Xpc-deficient cells were blocked in the late $S$ phase due to incomplete DNA replication at sites of damaged DNA [22]. As 
a result, the regulation of the $\mathrm{G} 2$ phase genes might differ slightly between $X p c^{-/-}$and Wt mice, as found in this study.

Table 5. Differentially regulated genes concerning apoptosis

\begin{tabular}{|c|c|c|c|}
\hline Symbol & Gene Name & $\mathbf{W t}$ & $X p c^{-/-}$ \\
\hline 1700003F12Rik & riken cDNA 1700003 f12 gene & 1.44 & 1.45 \\
\hline Atp7a & atpase, cu++ transporting, alpha polypeptide & 1.15 & 1.29 \\
\hline Bag1 & bcl2-associated athanogene 1 & 1.49 & 1.42 \\
\hline Bag4 & bcl2-associated athanogene 4 & -1.26 & -1.25 \\
\hline Brca2 & breast cancer 2 & -1.35 & -1.34 \\
\hline Cycs & cytochrome c, somatic & 1.21 & 1.37 \\
\hline Dap & death-associated protein & 1.31 & 1.25 \\
\hline Dhcr24 & 24-dehydrocholesterol reductase & 1.50 & 1.43 \\
\hline Dpf2 & $\mathrm{d} 4$, zinc and double phd fingers family 2 & 1.31 & 1.17 \\
\hline Faim & fas apoptotic inhibitory molecule & 1.21 & 1.20 \\
\hline Hells & helicase, Iymphoid specific & 1.43 & 1.46 \\
\hline Hras1 & harvey rat sarcoma virus oncogene 1 & 1.20 & 1.15 \\
\hline Klrb1c & killer cell lectin-like receptor subfamily b member $1 \mathrm{c}$ & -1.09 & -1.18 \\
\hline Opa1 & optic atrophy 1 homolog (human) & -1.34 & -1.17 \\
\hline $\mathrm{P} 2 \mathrm{rx} 1$ & purinergic receptor $\mathrm{p} 2 \mathrm{x}$, ligand-gated ion channel, 1 & 1.10 & 1.17 \\
\hline Pdcd5 & programmed cell death 5 & -1.22 & -1.23 \\
\hline Pim1 & proviral integration site 1 & -1.17 & -1.17 \\
\hline Proc & protein c & 1.26 & 1.22 \\
\hline Pten & phosphatase and tensin homolog & 1.32 & 1.31 \\
\hline Purb & purine rich element binding protein $b$ & 1.16 & 1.30 \\
\hline Qars & glutaminyl-trna synthetase & 1.20 & 1.35 \\
\hline Rragc & ras-related gtp binding $\mathrm{c}$ & 1.29 & 1.25 \\
\hline Rybp & ring1 and yy1 binding protein & 1.18 & 1.37 \\
\hline Sh3kbp1 & sh3-domain kinase binding protein 1 & -1.37 & -1.39 \\
\hline Smndc1 & survival motor neuron domain containing 1 & 1.21 & 1.35 \\
\hline Sra1 & steroid receptor rna activator 1 & 1.26 & 1.23 \\
\hline Sycp3 & synaptonemal complex protein 3 & 1.34 & 1.30 \\
\hline Tax1bp1 & tax1 (human t-cell leukemia virus type i) binding protein 1 & 1.25 & 1.08 \\
\hline Tnfrsf4 & tumor necrosis factor receptor superfamily, member 4 & 1.30 & 1.11 \\
\hline Uaca & uveal autoantigen with coiled-coil domains and ankyrin repeats & 1.24 & 1.29 \\
\hline Uaca & uveal autoantigen with coiled-coil domains and ankyrin repeats & 1.14 & 1.21 \\
\hline Zdhhc16 & zinc finger, dhhc domain containing 16 & 1.25 & 1.36 \\
\hline
\end{tabular}

Thirty-two differentially regulated genes concerning apoptosis. Results are presented as average gene expression ratios between exposed and control samples. 
Unrepaired DNA damage blocks the cell cycle. However, specialized Y-family DNA polymerases are capable of extending replication beyond lesions in an errorfree or error-prone way [22]. For example the expression of DNA polymerase $\mathrm{k}(P o / k)$ is under the control of the $\mathrm{B}[\mathrm{a}] \mathrm{P}$ activated arylhydrocarbon receptor $(\mathrm{AhR})$, and more highly expressed in testes than in other tissues [23, 24]. It bypasses BPDE- $N^{2}-d G$ in an efficient and mostly error-free way [24]. If we assume that DNA repair deficient $\mathrm{Xpc}^{-/}$cells that are present in testes (such as Sertoli cells, Leydig cells and developing sperm cells), in contrast to DNA repair proficient Wt cells, are blocked in the late $S$ phase due to unrepaired damage, then this damage could be passed in an errorfree way with progression of the cell cycle and spermatogenesis, but without the actual removal of the blocking lesion. Although Polk was not present among the differentially expressed genes by using Two-Way ANOVA, we found, however, that the expression of Polk was significantly higher in $X p c^{-/-}$than in Wt mice after $B[a] P$ exposure as assessed by a simple T-test $(p=0.038)$. However, this differential expression between $\mathrm{Wt}$ and $\mathrm{Xpc}^{-/-}$mice after $\mathrm{B}[\mathrm{a}] \mathrm{P}$ exposure was found only after correction for the slight initial expression differences found in their unexposed counterparts. Progression of the cell cycle and spermatogenesis, without the actual removal of the DNA lesion is in line with the differences in DNA damage kinetics between $X p c^{-/-}$ and Wt mice found in our previous study [5]. Therefore, we suggest that $X p c^{-/-}$mice are not per se more sensitive to mutation induction in the testis than Wt mice after $\mathrm{B}[\mathrm{a}] \mathrm{P}$ exposure, and thereby could have equal risks for heritable gene mutations. However, future studies analyzing mutation induction should elucidate the mutagenic potency of $\mathrm{B}[\mathrm{a}] \mathrm{P}$ in this reproductive organ.

\section{Conclusions}

From this study, we can conclude that gene expression in testis of untreated $X p c^{-1-}$ and Wt mice are similar, and this is also the case after exposure to B[a]P. B[a]P exposure, which formed a substantial amount of DNA damage, differentially regulated 984 genes that were enriched for cell cycle, translation, chromatin structure and spermatogenesis. Overall, $\mathrm{B}[\mathrm{a}] \mathrm{P}$-induced gene expression changes in $\mathrm{Xpc}^{-/-}$mice differed from their exposed wild type counterparts $(p=0.000000141)$, which was also found for stage specific cell cycle gene sets. These gene expression changes in testis may represent a cell cycle block due to the presence of unrepaired damage. Specialized DNA polymerases that are highly expressed in testis may still bypass $\mathrm{B}[\mathrm{a}] \mathrm{P}$ induced DNA damage in an error-free way, and cell cycle/ spermatogenesis can thus progress in the presence of DNA lesions.

\section{Acknowledgements}

The authors thank E.C. Friedberg for providing the $X p c^{-/-}$mice, the animal technicians of the animal facilities of the Netherlands Vaccine Institute (NVI, Bilthoven, the Netherlands) for their skilful assistance during this study, Marcel van Herwijnen and Ralph Gottschalk for their help with the microarray experiments, and Daniëlle Pachen for carrying out the Real-Time PCR experiments. This study was partly funded by the Cefic Long-range Research Initiative's (LRI) Innovative Science award 2004, and the European Network of Excellence (NoE) "Environmental cancer, nutrition and individual susceptibility" (ECNIS), sixth Framework Programme (FP6), FOOD-CT-2005-513943. 


\section{References}

1. Denissenko, M.F., Pao, A., Tang, M. and Pfeifer, G.P. (1996) Preferential formation of benzo[a]pyrene adducts at lung cancer mutational hotspots in P53. Science, 274, 430-432.

2. Somers, C.M., Yauk, C.L., White, P.A., Parfett, C.L. and Quinn, J.S. (2002) Air pollution induces heritable DNA mutations. Proc Natl Acad Sci USA, 99, 15904-15907.

3. Vilarino-Guell, C., Smith, A.G. and Dubrova, Y.E. (2003) Germline mutation induction at mouse repeat DNA loci by chemical mutagens. Mutat Res, 526, 63-73.

4. Zenzes, M.T., Bielecki, R. and Reed, T.E. (1999) Detection of benzo(a)pyrene diol epoxide-DNA adducts in sperm of men exposed to cigarette smoke. Fertil Steril, 72, 330-335.

5. Verhofstad, N., van Oostrom, C.T., van Benthem, J., van Schooten, F.J., van Steeg, H. and Godschalk, R.W. (2009) DNA adduct kinetics in reproductive tissues of DNA repair proficient and deficient male mice after oral exposure to benzo(a)pyrene. Environ Mol Mutagen,

6. Gillet, L.C. and Scharer, O.D. (2006) Molecular mechanisms of mammalian global genome nucleotide excision repair. Chem Rev, 106, 253-276.

7. Hoogervorst, E.M., van Oostrom, C.T., Beems, R.B., van Benthem, J., van den Berg, J., van Kreijl, C.F., Vos, J.G., de Vries, A. and van Steeg, H. (2005) 2-AAF-induced tumor development in nucleotide excision repair-deficient mice is associated with a defect in global genome repair but not with transcription coupled repair. DNA Repair (Amst), 4, 3-9.

8. Cheo, D.L., Ruven, H.J., Meira, L.B., Hammer, R.E., Burns, D.K., Tappe, N.J., van Zeeland, A.A., Mullenders, L.H. and Friedberg, E.C. (1997) Characterization of defective nucleotide excision repair in XPC mutant mice. Mutat Res, 374, 1-9.

9. de Vries, A., Dolle, M.E., Broekhof, J.L., Muller, J.J., Kroese, E.D., van Kreijl, C.F., Capel, P.J., Vijg, J. and van Steeg, H. (1997) Induction of DNA adducts and mutations in spleen, liver and lung of XPAdeficient/lac $Z$ transgenic mice after oral treatment with benzo[a]pyrene: correlation with tumour development. Carcinogenesis, 18, 2327-2332.

10. Edgar, R., Domrachev, M. and Lash, A.E. (2002) Gene Expression Omnibus: NCBI gene expression and hybridization array data repository. Nucleic Acids Res, 30, 207-210.

11. Dennis, G., Jr., Sherman, B.T., Hosack, D.A., Yang, J., Gao, W., Lane, H.C. and Lempicki, R.A. (2003) DAVID: Database for Annotation, Visualization, and Integrated Discovery. Genome Biol, 4, P3.

12. Huang, D.W., Sherman, B.T. and Lempicki, R.A. (2009) Systematic and integrative analysis of large gene lists using DAVID bioinformatics resources. Nature protocols, 4, 44-57.

13. Bar-Joseph, Z., Siegfried, Z., Brandeis, M., Brors, B., Lu, Y., Eils, R., Dynlacht, B.D. and Simon, I. (2008) Genome-wide transcriptional analysis of the human cell cycle identifies genes differentially regulated in normal and cancer cells. Proc Natl Acad Sci U S A, 105, 955-960.

14. Whitfield, M.L., Sherlock, G., Saldanha, A.J., Murray, J.I., Ball, C.A., Alexander, K.E., Matese, J.C., Perou, C.M., Hurt, M.M., Brown, P.O. and Botstein, D. (2002) Identification of genes periodically expressed in the human cell cycle and their expression in tumors. Mol Biol Cell, 13, 1977-2000.

15. Kao, S.H., Chao, H.T. and Wei, Y.H. (1998) Multiple deletions of mitochondrial DNA are associated with the decline of motility and fertility of human spermatozoa. Mol Hum Reprod, 4, 657-666.

16. Zhou, C., Li, Z., Diao, H., Yu, Y., Zhu, W., Dai, Y., Chen, F.F. and Yang, J. (2006) DNA damage evaluated by gammaH2AX foci formation by a selective group of chemical/physical stressors. Mutat Res, 604 , 8-18.

17. Tripathi, R., Mishra, D.P. and Shaha, C. (2009) Male germ cell development: turning on the apoptotic pathways. Journal of reproductive immunology, 83, 31-35.

18. Huo, J., Xu, S., Guo, K., Zeng, Q. and Lam, K.P. (2009) Genetic deletion of faim reveals its role in modulating C-FLIP expression during CD95-mediated apoptosis of lymphocytes and hepatocytes. Cell death and differentiation, 16, 1062-1070.

19. Boatright, K.M. and Salvesen, G.S. (2003) Mechanisms of caspase activation. Current opinion in cell biology, 15, 725-731.

20. Hockley, S.L., Arlt, V.M., Brewer, D., Giddings, I. and Phillips, D.H. (2006) Time- and concentrationdependent changes in gene expression induced by benzo(a)pyrene in two human cell lines, MCF-7 and HepG2. BMC Genomics, 7, 260.

21. Caino, M.C., Oliva, J.L., Jiang, H., Penning, T.M. and Kazanietz, M.G. (2007) Benzo[a]pyrene-7,8dihydrodiol promotes checkpoint activation and G2/M arrest in human bronchoalveolar carcinoma H358 cells. Mol Pharmacol, 71, 744-750.

22. van Oosten, M., Stout, G.J., Backendorf, C., Rebel, H., de Wind, N., Darroudi, F., van Kranen, H.J., de Gruijl, F.R. and Mullenders, L.H. (2005) Mismatch repair protein Msh2 contributes to UVB-induced cell cycle arrest in epidermal and cultured mouse keratinocytes. DNA Repair (Amst), 4, 81-89.

23. Gerlach, V.L., Aravind, L., Gotway, G., Schultz, R.A., Koonin, E.V. and Friedberg, E.C. (1999) Human and mouse homologs of Escherichia coli DinB (DNA polymerase IV), members of the UmuC/DinB superfamily. Proc Natl Acad Sci U S A, 96, 11922-11927. 
24. Ogi, T., Mimura, J., Hikida, M., Fujimoto, H., Fujii-Kuriyama, Y. and Ohmori, H. (2001) Expression of human and mouse genes encoding polkappa: testis-specific developmental regulation and AhRdependent inducible transcription. Genes Cells, 6, 943-953.

\section{${ }^{\ddagger}$ Additional files}

The additional files can be viewed at http://www.biomedcentral.com/1471-2164/11/333.

Additional file 1. Processes enriched among $B[a] P$ induced genes

The data presented are terms enriched among the $\mathrm{B}[\mathrm{a}] \mathrm{P}$ induced gene list by DAVID/EASE with a FDR $<0.1$.

Additional file 2. Processes enriched among B[a]P suppressed genes The data presented are terms enriched among the B[a]P suppressed gene list by DAVID/EASE with a FDR $<0.1$.

Additional file 3. Processes affected by B[a]P exposure in mouse testis The data presented are terms enriched among the B[a]P modulated gene list by DAVID/EASE with a FDR $<0.1$.

Additional file 4. Differentially regulated genes after $\mathrm{B}[\mathrm{a}] \mathrm{P}$ exposure involved in Chromatin structure

Thirty-seven differentially regulated genes involved in Chromatin structure. Results are presented as average gene expression ratios between exposed and control samples.

Additional file 5. Differentially regulated genes after $\mathrm{B}[\mathrm{a}] \mathrm{P}$ exposure regulating Spermatogenesis

Thirty-two differentially regulated genes involved in Spermatogenesis. Results are presented as average gene expression ratios between exposed and control samples.

Additional file 6. Differentially regulated genes after B[a]P exposure involved in Translation Ninety-five differentially regulated genes involved in Translation. Results are presented as average gene expression ratios between exposed and control samples.

Additional file 7. Differentially regulated genes after $\mathrm{B}[\mathrm{a}] \mathrm{P}$ exposure involved in Mitochondrial function

Fifty-one differentially regulated genes involved in mitochondrial function. Results are presented as average gene expression ratios between exposed and control samples. "genes involved in oxidative phosphorylation. 



\section{Chapter 5}

\section{Evaluation of benzo(a)pyrene-induced gene mutations in male germ cells}

Accepted for publication in Toxicological Sciences

Nicole Verhofstad

Conny Th.M. van Oostrom

Edwin Zwart

Lou M. Maas

Jan van Benthem

Frederik J. van Schooten

Harry van Steeg

Roger W.L. Godschalk 


\section{Abstract}

Polycyclic aromatic hydrocarbons (PAHs) are mutagenic in somatic cells, while it remains unclear whether PAHs induce mutations in male germ cells, subsequently increasing health risks in offspring. Although results from the classical specific locus test are negative or inconclusive, recent studies with environmentally exposed animals suggest that PAHs are mutagenic in sperm cells. Therefore, we studied whether benzo(a)pyrene was able to induce gene mutations in testis and sperm cells of wild type (Wt) and $X p c^{-1-}$ mice containing the pUR288 lacZ reporter gene. Mice were exposed to benzo(a)pyrene (13 mg/kg bw, 3 times per week) during 1, 4 or 6 weeks and sacrificed 6 weeks after the final exposure to obtain mutations in sperm derived from benzo(a)pyrene-exposed spermatogonial stem cells. The lacZ gene mutation assay was used to assess mutant frequencies in spleen, testis and mature sperm, and ${ }^{32} \mathrm{P}$-postlabelling was used for the detection of DNA adducts in testis. Successful exposure was confirmed by a doserelated higher mutant frequency in spleen of $\mathrm{Xpc}^{-/-}$mice as compared to Wt mice. Mutant frequencies were also increased in all ethyl nitrosourea (ENU) exposed samples, which were used as positive control. Although benzo(a)pyrene-related DNA adducts were detected in testis, mutant frequencies were not increased. On the other hand, benzo(a)pyrene increased mutant frequencies in sperm of Wt mice, but not in $X p c^{-/-}$mice, after 6 weeks exposure. Therefore, we conclude that benzo(a)pyrene can induce gene mutations in spermatogonial cells of mice, but it remains to be elucidated whether these mutations can be transmitted to offspring. 


\section{Introduction}

The integrity of our genome is constantly endangered by exposure to genotoxic chemical compounds present in the environment such as polycyclic aromatic hydrocarbons (PAHs), which are formed during the incomplete combustion of organic material. PAHs have been found in air, water and food, making exposure unavoidable. Many PAHs, of which benzo(a)pyrene $(\mathrm{B}[\mathrm{a}] \mathrm{P})$ is the one that has been studied most extensively, are known to be mutagenic in somatic cells. Results from the classical specific locus test for visible markers (SLT) were negative or inconclusive for detecting heritable point mutations after $\mathrm{B}[\mathrm{a}] \mathrm{P}$ exposure in male mice [1], however $\mathrm{B}[\mathrm{a}] \mathrm{P}$ was effective in inducing dominant lethal mutations in postmeiotic germ cells [2]. Besides, there is indirect evidence from environmentally exposed sentinel animals that PAHs are also mutagenic in male germ cells [3-6], potentially leading to health risks in the offspring.

After intake via diverse routes, $B[a] P$ is metabolized into reactive compounds, including benzo(a)pyrene-diol-epoxide (BPDE), that is able to bind to DNA and to form bulky DNA adducts. BPDE-DNA adducts are associated with the induction of mutations and the development of cancer [7]. Furthermore, $\mathrm{B}[\mathrm{a}] \mathrm{P}$ exposure may give rise to abnormal sperm [8] and is associated with a decline in sperm count [9], possibly because of its DNA damaging properties in spermatogonial stem cells [10]. Moreover, epidemiological studies showed that paternal exposure to organic solvents that may contain PAHs, increase the risk for childhood brain tumours in their offspring [11, 12]. On the other hand, in a meta-analysis it was concluded that there is only a weak association between paternal exposure to tobacco smoke (which contains PAHs) and several types of childhood cancer [13].

The unclear relationship between exposure to PAHs and the induction of germ line mutations may be related to the protection against genotoxic insults by molecular defence mechanisms during spermatogenesis [14]. Firstly, chemical compounds are detoxified and scavenged to prevent the formation of DNA damage in the target tissue. Secondly, if DNA damage is at hand, DNA repair mechanisms remove the damage and prevent the induction of mutations. Nucleotide excision repair (NER) can detect and remove damage in both transcribed (i.e. transcription coupled repair $(T C R)$ ) and non-transcribed (i.e. global genome repair (GGR)) parts of the genome [15]. GGR is involved in the recognition and removal of bulky DNA adducts, while TCR removes DNA lesions that block RNA synthesis. GGR is initiated by XPCHR23B after the recognition of a helix distortion, for instance caused by a BPDE-DNA adduct [15]. It has been shown that NER is limited in testicular cells, spermatocytes and round spermatids of rats [14]. Still though, we previously showed that the germ line relies on GGR/NER to remove a large portion of the B[a]P induced DNA damage by comparing DNA adduct kinetics in testis and sperm cells of wild type $(\mathrm{Wt})$ and GGR deficient $X p c^{-/-}$mice [10]. Thirdly, continuous exposure to chemical compounds may lead to an accumulation of genetic damage when DNA repair mechanisms become saturated. Heavily damaged cells may then be eliminated by apoptosis and necrosis [14] and may thus protect the male germ line for cells that have accumulated DNA mutations. All together, if these defence mechanisms fail to eliminate DNA damage, it will sustain and lead to a higher chance of accumulating gene mutations. Therefore, it is still not clear whether B[a]P poses a risk for germ cell mutagenesis, or 
whether these protective mechanisms sufficiently protect the integrity of germ cell DNA.

In the present study, we used $\mathrm{Wt}$ and $X p c^{-/-}$male mice containing the pUR288 lacZ reporter gene to assess the susceptibility for gene mutations in testis and sperm cells caused by exposure to $\mathrm{B}[\mathrm{a}] \mathrm{P} . \mathrm{Xpc}^{-/-}$mice are known to be more sensitive for the induction of mutations and tumour development [16]. As such, the $\mathrm{Xpc}^{-/-}$mouse model is ideal to study mutation induction in tissues with lower background mutant frequencies and gives the opportunity to see whether DNA repair processes (especially GGR/NER) are involved in the protection of testis and stem cells against severe DNA damage.

\section{Materials and Methods}

\section{Animal experiments}

Wild type male mice (C57BL/6) and $\mathrm{Xpc}^{-/-}$male mice (C57BL/6), between 8 and 12 weeks old and containing the pUR288 lacZ reporter gene [17, 18], were subchronically exposed to B[a]P (3 times per week, $13 \mathrm{mg} / \mathrm{kg}$ bw dissolved in $100 \mu \mathrm{l}$ sunflower oil) by oral gavage. $X p c^{-/-}$mice were exposed during 1, 4 and 6 weeks, and $\mathrm{Wt}$ mice during 6 weeks only (6 mice per genotype, per exposure time) because we did not expect to observe higher mutant frequencies after shorter exposure times in testis and sperm cells. Unexposed control mice (6 mice per genotype) received 100 $\mu \mathrm{l}$ sunflower oil 3 times per week during 6 weeks and a group of positive control mice (6 mice per genotype) received i.p. $100 \mathrm{mg} / \mathrm{kg}$ bw ethyl nitrosourea (ENU) once per week during 4 weeks (ENU is a known rodent germ line mutagen). Wt mice were sacrificed 6 weeks after the final exposure to ensure mutation fixation in spermatogonial stem cells, and to obtain sperm cells from the epididymides representing the stage of spermatogonia (please note that it takes 6 weeks for sperm cells to reach the epididymides after the mitotic division of a spermatogonial stem cell). Unexposed control and 6 weeks $B[a] P$ exposed $X p c^{-/-}$mice were crossed with Wt female mice $(\mathrm{Balb} / \mathrm{C}) 6$ weeks after the final exposure to obtain offspring and to determine litter sizes. Male mice were sacrificed after successful fertilization. One $X p c^{-/-}$mouse exposed to ENU did not survive the experiment. Spleen (target organ for B[a]P induced mutations), testis and mature sperm cells were collected. Sperm cells were obtained from the epididymides as described by Lowe et al. [19]. Samples were snap frozen in liquid nitrogen and stored at $-80^{\circ} \mathrm{C}$.

Mice were bred and maintained under specific pathogen-free conditions in a 12hr light-dark cycle at the animal facilities of the Netherlands Vaccine Institute (NVI, Bilthoven, the Netherlands) and received food and water ad libitum. Experiments were approved by the institute's Animal Ethics Committee and were carried out according to their guidelines.

\section{DNA isolation}

Spleen and whole testis were rapidly homogenized in $9 \mathrm{ml}$ lysis buffer $(10 \mathrm{mM}$ TrisHCl pH 8.0, $150 \mathrm{mM} \mathrm{NaCl}, 10 \mathrm{mM}$ EDTA $\mathrm{pH}$ 8.0), and SDS, proteinase $\mathrm{K}$ and RNase A were added to final concentrations of $1 \%, 0.5 \mathrm{mg} / \mathrm{ml}$ and $120 \mu \mathrm{g} / \mathrm{ml}$, respectively. Samples were lysed overnight in a $56^{\circ} \mathrm{C}$ shaking water bath. Total genomic DNA was extracted twice with 1 volume of phenol: chloroform: isoamyl alcohol 
$(25: 24: 1, v / v / v)$ by gently mixing for $10 \mathrm{~min}$. One-fifth volume of $8 \mathrm{M} \mathrm{KAc}$ was added to the aqueous phase and samples were extracted with 1 volume of chloroform by gently mixing for $10 \mathrm{~min}$. Approximately $10 \mathrm{ml}$ of extracted DNA was precipitated with two volumes of pure ethanol and transferred to $1 \mathrm{ml}$ of $70 \%$ ethanol. Pelleted DNA was washed with $0.5 \mathrm{ml} 70 \%$ ethanol and air-dried after the removal of excess ethanol. DNA was solubilised in $350 \mu \mathrm{l}$ TE buffer (10 mM Tris HCl pH 7.5, $1 \mathrm{mM}$ EDTA).

Sperm cells obtained from epididymal tissue were lysed overnight in a $56^{\circ} \mathrm{C}$ shaking water bath in $500 \mu \mathrm{l}$ lysis buffer $(0.2 \times$ SSC, $1 \%$ SDS, $1 \mathrm{M} \beta-$ mercaptoethanol, $200 \mu \mathrm{g} / \mathrm{ml}$ proteinase $\mathrm{K}$ ). DNA was extracted with 1 volume of phenol: chloroform: isoamyl alcohol (25:24:1, v/v/v) and subsequently, with 1 volume of chloroform: isoamyl alcohol (24:1). DNA samples were precipitated with $50 \mu \mathrm{l} 3 \mathrm{M}$ $\mathrm{NaAc}(\mathrm{pH} 4.9)$ and $1 \mathrm{ml}$ pure ethanol during $1 \mathrm{hr}$ at $-80^{\circ} \mathrm{C}$. Pelleted DNA was washed with $70 \%$ ethanol and air-dried after the removal of excess ethanol. DNA was solubilised in $58 \mu \mathrm{l}$ TE buffer. Concentrations and purity of sperm DNA samples were determined using a NanoDrop.

\section{DNA adduct measurement by ${ }^{32} \mathrm{P}$-postlabelling}

DNA adducts were measured in testis of $\mathrm{B}[\mathrm{a}] \mathrm{P}$ exposed $\mathrm{Wt}$ and $X p c^{-/}$mice, which were sacrificed 6 weeks after the final exposure. To determine BPDE-DNA adducts by ${ }^{32} \mathrm{P}$-postlabelling, $10 \mu \mathrm{g}$ DNA was digested using micrococcal endonuclease (0.57 U/sample, Sigma-Aldrich, Zwijndrecht, the Netherlands) and spleen phosphodiesterase $\left(4.75 \mu \mathrm{g} / \mathrm{sample}\right.$, Sigma-Aldrich) for $4 \mathrm{hrs}$ at $37^{\circ} \mathrm{C}$. Subsequently, samples were treated with nuclease P1 $(3.25 \mu \mathrm{g} / \mathrm{sample}$, MP Biomedicals, Eindhoven, the Netherlands) for $30 \mathrm{~min}$ at $37^{\circ} \mathrm{C}$ in a total volume of $12.5 \mu \mathrm{l}$. The largest fraction of the modified nucleotides $(n t)(10.5 \mu \mathrm{l})$ was labelled with $\left[\mathrm{Y}^{-}{ }^{32} \mathrm{P}\right]-\mathrm{ATP}$ (50 $\mu \mathrm{Ci} /$ sample, MP Biomedicals, Eindhoven, the Netherlands) by incubation with T4polynucleotide kinase (11.5 U/sample, Fermentas, St. Leon-Rot, Germany) for 30 min at $37^{\circ} \mathrm{C}$. Radiolabelled adduct nucleotide bisphosphates were separated by thinlayer chromatography on polyethyleneimine (PEI) cellulose sheets (Macherey-Nagel, Düren, Germany) in the following solvents: $\mathrm{D} 1,1 \mathrm{M} \mathrm{NaH}_{2} \mathrm{PO}_{4} \mathrm{pH}$ 6.5; D2, 8.5 M urea, $5.3 \mathrm{M}$ lithium formate $\mathrm{pH} 3.5$; and $\mathrm{D} 3,1.2 \mathrm{M}$ lithium chloride, $0.5 \mathrm{M}$ Tris, $8.5 \mathrm{M}$ urea $\mathrm{pH}$ 8.0. In each experiment 3 standards of $\left[{ }^{3} \mathrm{H}\right] \mathrm{BPDE}$ modified DNA with known modification levels ( 1 per $10^{7}, 10^{8}$ and $10^{9} \mathrm{nt}$ ) were run in parallel for quantification purposes, and $\mathrm{mQ}$-water was used as a negative control. DNA adduct levels were quantified by using FujiFilm imaging system FLA-3000, BASReader software and Advanced Image Data Analyzer (AIDA) software (all from Raytest, Tilburg, the Netherlands), with a detection limit of $<1$ adduct per $10^{9}$ nt per individual DNA adduct spot. A small fraction of the digest $(2 \mu \mathrm{l})$ was diluted in $36.3 \mu \mathrm{l}$ of $\mathrm{mQ}$-water and was used to determine the amount of DNA in the assay by HPLC-UV. Tris HCl $(\mathrm{pH} \mathrm{7.4)}$ and alkaline phosphatase $(0.01 \mathrm{U} / \mu \mathrm{l}$, Sigma-Aldrich) were added to the samples after which samples were incubated at $37^{\circ} \mathrm{C}$ for $45 \mathrm{~min}$. Nucleosides were subsequently separated and detected by reversed phase HPLC-UV detection using $10 \%$ aqueous methanol containing $94 \mathrm{mM} \mathrm{KH}_{2} \mathrm{PO}_{4}, 13 \mathrm{mM} \mathrm{K}_{2} \mathrm{HPO}_{4}, 26 \mathrm{mM} \mathrm{KCl}$ and $0.5 \mathrm{mM}$ EDTA as mobile phase. The peak area of $d G$ was used to correct for differences in DNA content between samples. 


\section{LacZ gene mutation assay}

Mutant frequencies were determined as described previously by Dollé et al. [20]. Briefly, total DNA was digested by HindIII and pUR288 plasmids were rescued from total DNA by magnetic beads coated with the lacZ-lacl fusion protein. Plasmids were subsequently transfected into electrocompetent $E$. coli $C$ (lacZ-/galE-). A fraction $(0.1 \%)$ of the cell culture was plated on non-selective 5 -bromo-4-chloro-3-indolyl- $\beta$-Dgalactoside (X-gal) plates to determine the rescue efficiency. The remainder of the cell culture was plated on selective phenyl- $\beta$-D-galactoside (P-gal) plates to select for lacZ mutants. Mutant frequencies were calculated by dividing the number of mutants by the total number of rescued colonies (at least 100) times the dilution factor.

\section{Statistics}

Results are presented as mean \pm standard error of the mean (SEM). The nonparametric Mann-Whitney U-test was used to analyze differences in mutant frequencies between $\mathrm{Wt}$ and $\mathrm{Xpc}^{-/-}$mice per individual time point, and the different time points as compared to control within a genotype. The relations between mutant frequencies found in testis and litter sizes in $\mathrm{Xpc}^{-/-}$mice were assessed by Pearson correlation. SPSS v. 15.0 was used for statistical analysis. A difference was considered significant at $p<0.05$.

\section{Results}

\section{DNA adducts in testis}

DNA adducts were measured in testis by ${ }^{32} \mathrm{P}$-postlabelling to indicate the presence of pre-mutagenic lesions after $\mathrm{B}[\mathrm{a}] \mathrm{P}$ exposure. The chromatograms showed in all $\mathrm{B}[\mathrm{a}] \mathrm{P}$ exposed samples, one detectable spot that migrated at the same position as the known BPDE-dG adduct standard (figure 1). Although the animals were not exposed to $B[a] P$ for the past 6 weeks, an effect of exposure duration was still observed in $X p c^{-/-}$mice; no detectable DNA adducts in unexposed mice, $1.5 \pm 0.3$ adducts per $10^{8} \mathrm{nt}$ after 1 week of exposure, and adducts accumulated to $2.6 \pm 1.0$ adducts per $10^{8} \mathrm{nt}$ after 4 weeks of exposure ( 1 week vs. 4 weeks $p=0.12$ ). However, DNA adduct levels did not increase further after 6 weeks of exposure in $X p c^{-/-}$ mice $\left(2.2 \pm 0.5\right.$ adducts per $\left.10^{8} \mathrm{nt}\right)$, and were not significantly different between $\mathrm{Wt}$ and $X p c^{-/-}$animals after 6 weeks of exposure. It should be noted that exposure was followed by 6 weeks of recovery and a portion of the DNA adducts may have been removed in this period, as we previously observed that almost all DNA adducts in testis were removed within a period of 6 weeks after a single exposure to B[a]P (13 $\mathrm{mg} / \mathrm{kg} \mathrm{bw}$ ) [10]. Nonetheless, DNA adducts were still clearly detectable which indicates that testis and the germ line encountered pre-mutagenic BPDE-DNA lesions.

\section{LacZ mutant frequencies are increased in spleen}

To check for a successful exposure of male mice to B[a]P and subsequent mutation detection by the lacZ gene mutation assay, mutant frequencies were determined in spleen, since spleen is known to accumulate mutations over time by subchronic $\mathrm{B}[\mathrm{a}] \mathrm{P}$ exposure (figure 2A) [16, 21]. Unexposed control mice showed low mutant frequencies in Wt and $X p c^{-/-}$genotypes. In addition, we observed a dose-response relationship in $X p c^{-/-}$mice, and an increase of mutant frequencies in Wt mice $(p=$ 
0.04 as compared to control mice). At 6 weeks of exposure, mutant frequencies were significantly higher in $X p c^{-/-}$than in Wt mice $(p=0.016)$. ENU exposure induced the highest mutant frequencies, with comparable levels in Wt and $X p c^{-/-}$mice.

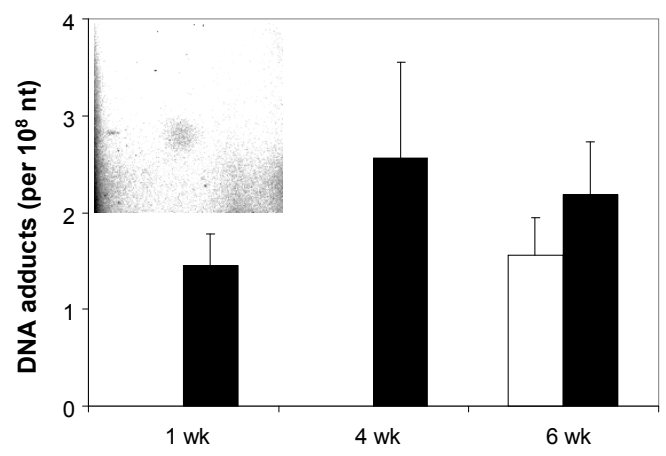

Figure 1. DNA adduct levels in testis. DNA adducts were measured by ${ }^{32} \mathrm{P}$-postlabelling in testes of $\mathrm{Wt}(\square)$ and $\mathrm{Xpc}^{-/-}$(घ) mice. Mice were exposed to $\mathrm{B}[\mathrm{a}] \mathrm{P}$ during 1,4 , or 6 weeks and sacrificed at least 6 weeks after the final exposure. DNA adducts were significantly increased as compared to control, but there were no significant differences between the different exposure groups.

\section{Effects of B[a]P exposure on lacZ mutant frequencies in testis and sperm}

Mutant frequencies in testis were analyzed as a first indication of possible heritable DNA damage after B[a]P exposure. As in spleen, we observed low mutant frequencies in testis of both unexposed control groups, and a significant induction of mutant frequencies after 4 weeks ENU exposure in Wt and $X p c^{--/}$mice $(p=0.004$ and $p=0.006$ for $\mathrm{Wt}$ and $X p c^{-/-}$mice, respectively). However, we did not find an increase of mutant frequencies after $\mathrm{B}[\mathrm{a}] \mathrm{P}$ exposure in both genotypes, not even after 6 weeks exposure time (figure 2B). A lack of mutation induction in whole testis is however not necessarily representative for the male germ cells, because testis contains many other types of cells (e.g. Leydig and Sertoli cells) which can 'dilute' the effect in sperm cells. The volumetric composition of the testis is $56 \%$ of germ cells [22], of which a part is haploid, showing that DNA of germ cells is only partly contributing to the mutant frequencies in whole testis.

Mutant frequencies were therefore also measured in sperm derived from $B[a] P$ exposed stem cells; since we waited 6 weeks after the final exposure, mutants detected in sperm are thus a measurement for the number of mutants induced in spermatogonial cells. The results showed low mutant frequencies in unexposed control mice of both genotypes ( $\mathrm{N}=6$ in $\mathrm{Wt}$ and $\mathrm{N}=2$ in $X p c^{-/-}$mice), and showed increased mutant frequencies after ENU exposure $(p=0.011$ and $p=0.06$ for $\mathrm{Wt}(\mathrm{N}=4)$ and $X p c^{-/-}(N=4)$ mice, respectively). In contrast to the results in testis, we did find a significant 2.3-fold increase in mutant frequencies after 6 weeks $B$ [a]P exposure in mature sperm of Wt mice $(\mathrm{N}=4, \mathrm{p}=0.019$, figure $2 \mathrm{C})$. On the other hand, no increase in mutant frequencies was found in $X p c^{-/-}$mice after $B[a] P$ exposure $(N=6,5$ 
and 4 for 1, 4 and 6 weeks exposure, respectively). It was unexpected that mutant frequencies were unaltered in sperm of $\mathrm{Xpc}^{-/-}$mice, while mutant frequencies were increased in sperm of Wt mice, since $X p c^{-/-}$mice were thought to be more sensitive for the induction of mutations. Mutant frequencies in $X p c^{-/-}$mice were almost tripled after ENU exposure as compared to levels in unexposed mice, but this difference did not reach statistical significance, probably due to the low number of samples that were successful in the analysis ( $\mathrm{N}=2$ and 4 for unexposed and ENU exposed mice, respectively).

A

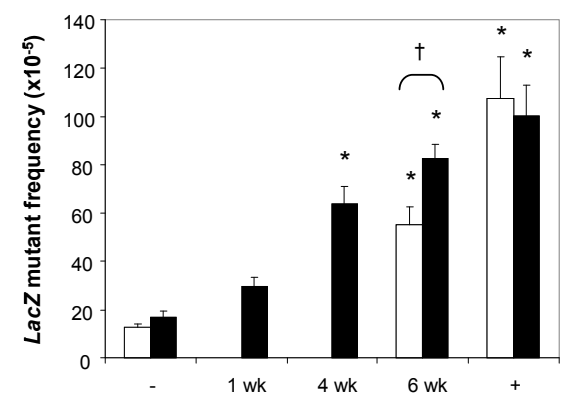

C

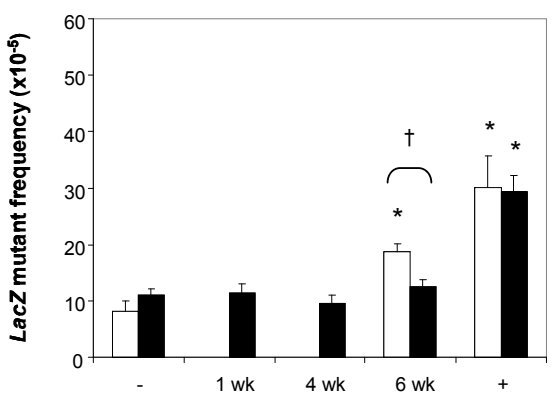

B

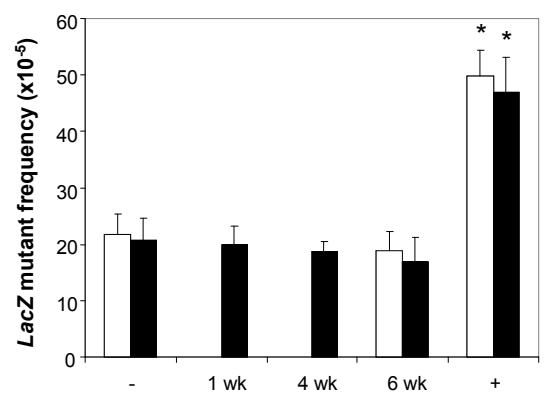

Figure 2. LacZ mutant frequencies were measured in spleen (A), testis (B) and mature sperm (C) of Wt ( $\square$ ) and $\mathrm{Xpc}^{-/-}$(घ) mice exposed to $\mathrm{B}[\mathrm{a}] \mathrm{P}(13 \mathrm{mg} / \mathrm{kg}$ bw, 3 times per week) during 1, 4 or 6 weeks. Note scale differences between figures. - Unexposed control group. + ENU exposed control group $(100 \mathrm{mg} / \mathrm{kg}$ bw, once per week, during 4 weeks). * Indicative of significant difference as compared to control $(p<0.05)$. $\dagger$ Indicative of significant difference between genotypes per individual time point.

\section{Litter sizes of $X p c^{-/-}$mice}

Since mutant frequencies were unexpectedly not increased in $X p c^{-/-}$mice, while mutant frequencies were in sperm of Wt mice, we argued that this may be due to enhanced cytotoxicity induced by subchronic $\mathrm{B}[\mathrm{a}] \mathrm{P}$ exposure. $\mathrm{Xpc^{-/- }}$ mice were crossed with female mice to test their reproductive capacity and to determine litter sizes. These female mice were able to deliver normal offspring. However, in both the control and exposed groups, 2 female mice were not able to deliver any offspring and these were discarded from the analysis. Litter sizes differed significantly between unexposed and $\mathrm{B}[\mathrm{a}] \mathrm{P}$ exposed groups with significantly smaller litter sizes in the 
$\mathrm{B}[\mathrm{a}] \mathrm{P}$ exposed group $(8.5 \pm 1.5$ vs. $6.1 \pm 2.3$, respectively, $\mathrm{p}=0.014)$. Smaller litter sizes are indicative for possible cytotoxicity to the sperm cells of $\mathrm{B}[\mathrm{a}] \mathrm{P}$ exposed $\mathrm{Xpc}^{-/-}$ mice, but can also be the result of increased implantation loss due to high levels of DNA damage [23]. Moreover, we found a negative correlation between mutant frequencies in testes and litter sizes produced by the $B[a] P$ exposed mice $(R=-0.636, p$ $=0.048$ ), which is further indicating that the amount of permanent damage might be related with reduced fertility, but we did not find a correlation between DNA adduct levels found in testes and the litter sizes produced by B[a]P exposed mice.

\section{Discussion}

Until now, it was unclear whether exposure to the mutagenic compound $B[a] P$ can cause heritable mutations in the spermatogonial stem cells in an in vivo model. Therefore, we studied the mutagenic capacity of $B[a] P$ in testis and sperm cells of $\mathrm{Wt}$ and $X p c^{--/}$male mice containing the pUR288 lacZ reporter gene. This plasmid-based model has already been used in many in vivo mutagenicity studies, because of its high rescue efficiency and its sensitivity to a broad spectrum of mutations including large deletions [20]. In addition, the $X p c^{-/-}$mouse model is deficient in GGR/NER and known to be more sensitive for DNA damage, mutation induction and tumour development $[10,16]$, and therefore, the combination of these models was expected to be ideal to study the mutagenic properties of $\mathrm{B}[\mathrm{a}] \mathrm{P}$ in reproductive tissues.

To determine the effectiveness of the exposure we studied lacZ mutant frequencies in the spleen of $\mathrm{B}[\mathrm{a}] \mathrm{P}$ exposed and control mice of both genotypes and a doseresponse relationship was found for $X p c^{-/-}$mice. As expected, we found higher mutant frequencies in $X p c^{-/-}$mice as compared to Wt mice after 6 weeks exposure, which confirms the sensitivity of the GGR/NER deficient $X p c^{-/-}$model. In addition, mutant frequencies were also significantly increased in $\mathrm{Wt}$ and $\mathrm{Xpc}^{-/-}$mice after exposure to ENU. ENU is a highly reactive alkylating agent, known to be mutagenic to both somatic cells and the rodent germ line. Its DNA damage is mainly repaired by base excision repair (BER), rather than by NER. This explains the equal responses in $\mathrm{Wt}$ and $\mathrm{Xpc}^{-/-}$mice after ENU exposure. The results in testis did not show any increase in mutant frequencies after $\mathrm{B}[\mathrm{a}] \mathrm{P}$ exposure in both genotypes, whereas the mutant frequency was significantly increased by ENU. In contrast to testis and spleen, mutant frequencies were significantly increased in germ cells after 6 weeks of $\mathrm{B}[\mathrm{a}] \mathrm{P}$ exposure in $\mathrm{Wt}$ mice, while no effect was seen in $\mathrm{Xpc}^{-/-}$mice. These contradicting results indicate that the mutagenic potential of a genotoxic compound may be different in somatic, testicular and germ cells; in spleen, the GGR/NER deficiency increased mutant frequencies as compared to Wt mice, while in sperm cells no effect was found in $X p c^{-/-}$mice.

The fact that the relationship between $\mathrm{B}[\mathrm{a}] \mathrm{P}$ exposure and germ line mutations remains less clear as compared to somatic cells, might indicate that testes and germ cells are well protected against the fixation of DNA damage by $B[a] P$. Still, the increased mutant frequencies in sperm cells of Wt mice indicates that $B[a] P$ is capable of inducing heritable mutations, that could be transmitted to the offspring and increase health risks. In addition, the results show that $X p c^{-/-}$mice are not per se a more sensitive model for the induction of heritable mutations by $\mathrm{B}[\mathrm{a}] \mathrm{P}$, which seems in contrast with the results found in our previous study, showing that $X p c^{-/-}$mice were more sensitive towards the formation of $B[a] P$ induced DNA damage [10]. For the 
current study, the $X p c^{--}$mouse model might have been too sensitive, because of the lack of the appropriate DNA repair mechanism GGR/NER. It might be that the repetitive dose of $\mathrm{B}[\mathrm{a}] \mathrm{P}$ was cytotoxic to the germ cells of $X p c^{-/-}$mice, preventing the transmission of heritable DNA damage to the offspring. Apoptosis is a common process in the testis to discard excessive germ cells, or to remove damaged cells [24]. It has been shown that exposure to high acute doses of B[a]P indeed induced apoptosis, mainly in spermatogonia [9], which eliminates immature damaged germ cells during spermatogenesis and prevents fertilization by mutated sperm cells. In line with this, we found a significant decrease in the number of offspring between control and $B[a] P$ exposed groups of $X p c^{-/-}$mice $(p=0.014)$. However, it is unlikely that $B[a] P$ caused major spermatogonial killing in $X p c^{-/-}$mice, which would lead to sterility, since the number of female mice that gave birth to progeny (10 out of 12) was equal for control and exposed mice. Taking the reduced litter sizes into consideration, it is still possible that the 6 week dose of $\mathrm{B}[\mathrm{a}] \mathrm{P}$ induced cytotoxicity in germ cells that were heavily damaged. As a result, the accumulation of mutations was prevented in $X p c^{-/-}$ mice without long term sterility.

Another explanation for the differences in germ cell mutagenesis found between $\mathrm{Xpc}^{-/}$and Wt mice could be ascribed to a significant delay in spermatogenesis because of severe DNA damage [25]. As mentioned before, our previous results imply that germ cells of $X p c^{-/-}$mice were more severely damaged than germ cells of $\mathrm{Wt}$ mice [10]. This DNA damage needs to be repaired in order to maintain the genetic integrity of the cells, and cell turnover will be delayed. In another previous study, we indeed detected differences in cell cycle regulation between $\mathrm{Wt}$ and $\mathrm{Xpc}^{-/-}$mice after a single exposure to $B[a] P$ [26]. Therefore, spermatogenesis, which lasts 42 days in the mouse, can be delayed in $X p c^{-1-}$ mice after $\mathrm{B}[\mathrm{a}] \mathrm{P}$ exposure. As a result, an increase in mutant frequencies in sperm cells of $X p c^{--1}$ mice would be measurable only after a prolonged period of time. Future studies need to take this into account when measuring mutagenesis in spermatogonial stem cells. Six weeks exposure time and 6 weeks recovery would have given enough time to induce mutations in germ cells at an early stage of spermatogenesis. Nevertheless, it still remains to be determined whether the increased mutations in sperm cells of Wt mice were induced in spermatogonial stem cells or later cell stages.

In the past, classical methods showed contradicting results regarding the mutagenicity of $\mathrm{B}[\mathrm{a}] \mathrm{P}$ in male germ cells $[1,2]$. However, newly established methods have suggested a role for PAHs in inducing germ line mutations in environmentally exposed animals [4-6]. In this study, we showed by using the lacZ gene mutation assay that $\mathrm{B}[\mathrm{a}] \mathrm{P}$ possibly induces mutations in germ cells of male mice. Still, it remains to be elucidated whether mutated sperm cells can fertilize an egg, because then these mutations are transmitted to the offspring. We did not find increased mutant frequencies in $\mathrm{Xpc}^{-/-}$mice after $\mathrm{B}[\mathrm{a}] \mathrm{P}$ exposure, and additional research is necessary to elucidate why $X p c^{-/-}$mice were not responsive. Since B[a]P is known as an environmental compound we are regularly exposed to, via for example food or inhalation of exhaust, there may be an increased chance for health effects in offspring.

\section{Acknowledgements}

The authors thank E.C. Friedberg for providing the $X p c^{-/-}$mice, and the animal technicians of the animal facilities of the Netherlands Vaccine Institute (NVI, the Netherlands) for their skilful 
assistance during this study. This work was supported by the Cefic Long-range Research Initiative's (LRI) Innovative Science Award [to R.W.L.G] and the European Network of Excellence (NoE) 'Environmental cancer, nutrition and individual susceptibility' (ECNIS) under Sixth Framework Programme (FP6) [grant number FOOD-CT-2005-513943]. 


\section{References}

1. Russell, L.B., Selby, P.B., von Halle, E., Sheridan, W. and Valcovic, L. (1981) The mouse specific-locus test with agents other than radiations: interpretation of data and recommendations for future work. Mutation research, 86, 329-354.

2. Generoso, W.M., Cain, K.T., Hellwig, C.S. and Cacheiro, N.L. (1982) Lack of association between induction of dominant-lethal mutations and induction of heritable translocations with benzo[a]pyrene in postmeiotic germ cells of male mice. Mutat Res, 94, 155-163.

3. Yauk, C.L., Fox, G.A., McCarry, B.E. and Quinn, J.S. (2000) Induced minisatellite germline mutations in herring gulls (Larus argentatus) living near steel mills. Mutat Res, 452, 211-218.

4. Yauk, C.L. and Quinn, J.S. (1996) Multilocus DNA fingerprinting reveals high rate of heritable genetic mutation in herring gulls nesting in an industrialized urban site. Proc Natl Acad Sci U S A, 93, 1213712141.

5. Somers, C.M., McCarry, B.E., Malek, F. and Quinn, J.S. (2004) Reduction of particulate air pollution lowers the risk of heritable mutations in mice. Science, 304, 1008-1010.

6. Somers, C.M., Yauk, C.L., White, P.A., Parfett, C.L. and Quinn, J.S. (2002) Air pollution induces heritable DNA mutations. Proc Natl Acad Sci USA, 99, 15904-15907.

7. Godschalk, R.W., Van Schooten, F.J. and Bartsch, H. (2003) A critical evaluation of DNA adducts as biological markers for human exposure to polycyclic aromatic compounds. J Biochem Mol Biol, 36, 1-11.

8. Wyrobek, A.J. and Bruce, W.R. (1975) Chemical induction of sperm abnormalities in mice. Proc Natl Acad Sci U S A, 72, 4425-4429.

9. Revel, A., Raanani, H., Younglai, E., Xu, J., Han, R., Savouret, J.F. and Casper, R.F. (2001) Resveratrol, a natural aryl hydrocarbon receptor antagonist, protects sperm from DNA damage and apoptosis caused by benzo(a)pyrene. Reprod Toxicol, 15, 479-486.

10. Verhofstad, N., van Oostrom, C.T., van Benthem, J., van Schooten, F.J., van Steeg, H. and Godschalk, R.W. (2010) DNA adduct kinetics in reproductive tissues of DNA repair proficient and deficient male mice after oral exposure to benzo(a)pyrene. Environ Mol Mutagen, 51, 123-129.

11. Cordier, S., Lefeuvre, B., Filippini, G., Peris-Bonet, R., Farinotti, M., Lovicu, G. and Mandereau, L. (1997) Parental occupation, occupational exposure to solvents and polycyclic aromatic hydrocarbons and risk of childhood brain tumors (Italy, France, Spain). Cancer Causes Control, 8, 688-697.

12. Cordier, S., Monfort, C., Filippini, G., Preston-Martin, S., Lubin, F., Mueller, B.A., Holly, E.A., PerisBonet, R., McCredie, M., Choi, W., Little, J. and Arslan, A. (2004) Parental exposure to polycyclic aromatic hydrocarbons and the risk of childhood brain tumors: The SEARCH International Childhood Brain Tumor Study. Am J Epidemiol, 159, 1109-1116.

13. Boffetta, P., Tredaniel, J. and Greco, A. (2000) Risk of childhood cancer and adult lung cancer after childhood exposure to passive smoke: A meta-analysis. Environ Health Perspect, 108, 73-82.

14. Olsen, A.K., Lindeman, B., Wiger, R., Duale, N. and Brunborg, G. (2005) How do male germ cells handle DNA damage? Toxicol Appl Pharmacol, 207, 521-531.

15. Gillet, L.C. and Scharer, O.D. (2006) Molecular mechanisms of mammalian global genome nucleotide excision repair. Chem Rev, 106, 253-276.

16. Melis, J.P., Wijnhoven, S.W., Beems, R.B., Roodbergen, M., van den Berg, J., Moon, H., Friedberg, E., van der Horst, G.T., Hoeijmakers, J.H., Vijg, J. and van Steeg, H. (2008) Mouse models for xeroderma pigmentosum group $A$ and group $C$ show divergent cancer phenotypes. Cancer Res, 68, 1347-1353.

17. Cheo, D.L., Ruven, H.J., Meira, L.B., Hammer, R.E., Burns, D.K., Tappe, N.J., van Zeeland, A.A., Mullenders, L.H. and Friedberg, E.C. (1997) Characterization of defective nucleotide excision repair in XPC mutant mice. Mutat Res, 374, 1-9.

18. Hoogervorst, E.M., van Oostrom, C.T., Beems, R.B., van Benthem, J., van den Berg, J., van Kreijl, C.F., Vos, J.G., de Vries, A. and van Steeg, H. (2005) 2-AAF-induced tumor development in nucleotide excision repair-deficient mice is associated with a defect in global genome repair but not with transcription coupled repair. DNA Repair (Amst), 4, 3-9.

19. Lowe, X.R., de Stoppelaar, J.M., Bishop, J., Cassel, M., Hoebee, B., Moore, D., 2nd and Wyrobek, A.J. (1998) Epididymal sperm aneuploidies in three strains of rats detected by multicolor fluorescence in situ hybridization. Environ Mol Mutagen, 31, 125-132.

20. Dolle, M.E., Martus, H.J., Gossen, J.A., Boerrigter, M.E. and Vijg, J. (1996) Evaluation of a plasmidbased transgenic mouse model for detecting in vivo mutations. Mutagenesis, 11, 111-118.

21. de Vries, A., Dolle, M.E., Broekhof, J.L., Muller, J.J., Kroese, E.D., van Kreijl, C.F., Capel, P.J., Vijg, J. and van Steeg, H. (1997) Induction of DNA adducts and mutations in spleen, liver and lung of XPAdeficient/lacZ transgenic mice after oral treatment with benzo[a]pyrene: correlation with tumour development. Carcinogenesis, 18, 2327-2332.

22. Russell, L.D. and de Franca, L.R. (1995) Building a testis. Tissue \& cell, 27, 129-147.

23. Ahmadi, A. and Ng, S.C. (1999) Fertilizing ability of DNA-damaged spermatozoa. Journal of experimental zoology, 284, 696-704. 
24. Tripathi, R., Mishra, D.P. and Shaha, C. (2009) Male germ cell development: turning on the apoptotic pathways. Journal of reproductive immunology, 83, 31-35.

25. van Delft, J.H. and Baan, R.A. (1995) Germ cell mutagenesis in lambda lacZ transgenic mice treated with ethylnitrosourea; comparison with specific-locus test. Mutagenesis, 10, 209-214.

26. Verhofstad, N., Pennings, J. L., van Oostrom, C. T., van Benthem, J., van Schooten, F. J., van Steeg, H., and Godschalk, R. W. (2010) Benzo(a)pyrene induces similar gene expression changes in testis of DNA repair proficient and deficient mice. BMC Genomics, 11, 333. 



\section{Chapter 6}

\section{Expanded Simple Tandem Repeat (ESTR) mutations in offspring of benzo(a)pyrene exposed DNA repair deficient male mice}

Nicole Verhofstad Joost O. Linschooten Conny Th.M. van Oostrom Andrea Rowan-Carroll Caitlin Ritz Jan van Benthem Harry van Steeg

Carole L. Yauk Frederik J. van Schooten Roger W.L. Godschalk 


\section{Abstract}

Exposure to polycyclic aromatic hydrocarbons (PAHs) have recently been associated with the induction of paternally transmitted germ line mutations in free-living herring gulls (Larus argentatus) and environmentally exposed caged mice. Exposure to these compounds may thus also pose a genetic risk to the human population. Humans are regularly exposed to the wellstudied PAH, benzo(a)pyrene, and therefore, it is important to establish whether benzo(a)pyrene induces germ line mutations that can be transmitted to the offspring. To study this, we used DNA fingerprints of two expanded simple tandem repeat (ESTR) loci Ms6-hm and $\mathrm{Hm}-2$ in offspring of benzo(a)pyrene exposed and unexposed control male mice, deficient for nucleotide excision repair $\left(\mathrm{Xpc}^{-/}\right)$. Male $\mathrm{Xpc^{-/ }}$ mice $(\mathrm{C} 57 \mathrm{BL} / 6)$ were exposed to benzo(a)pyrene during 6 weeks (13 mg/kg bw, 3x per week) by gavage and were crossed with female mice $(B a l b / C) 6$ weeks after the last exposure to obtain offspring and to ensure the analysis of mutations originating from spermatogonial stem cells. The ESTR mutation rates did not statistically significantly differ between offspring of benzo(a)pyrene exposed and control male mice. In fact, mutation rates were nonsignificantly higher $(1.4$-fold $)$ in the paternal and maternal alleles of control families. Litter sizes of successful breeding pairs were significantly lower for benzo(a)pyrene exposed mice as compared to the control group $(p=0.014)$, which may indicate that the 6 weeks exposure was cytotoxic to the germ cells. Nonetheless, paternally transmitted B[a]P-induced ESTR mutation rates correlated with previously found lacZ mutant frequencies in testis $(R=0.791)$, while such a correlation was not found in controls $(R=-0.069)$, which suggests that ESTR mutation frequencies can be used to study transmittance of paternally induced germ line mutations to the offspring. However, the number of offspring tested in this pilot study was relatively low to draw any firm conclusions, and therefore, the number of offspring has to be expanded in future studies. These future studies should also include the analysis of offspring from DNA repair proficient male mice. So far, it remains unclear whether benzo(a)pyrene is capable of inducing germ line ESTR mutations in exposed families. 


\section{Introduction}

Polycyclic aromatic hydrocarbons (PAHs) are important occupational and environmental pollutants, and may pose a genetic risk to the human population. These compounds are formed during the incomplete combustion of organic material, and many of them are known to be mutagenic and carcinogenic. Recently, PAHs have been associated with the induction of paternally transmitted germ line mutations in free-living herring gulls (Larus argentatus), living near steel mills [1] and environmentally exposed laboratory mice caged near steel mills $[2,3]$. Benzo(a)pyrene (B[a]P), the most studied model PAH, has been found in for example diesel exhaust, charbroiled meat and tobacco smoke, making exposure to this compound unavoidable. Therefore, it is important to further establish the role of $\mathrm{B}[\mathrm{a}] \mathrm{P}$ in producing germ line mutations, which increases potential health risks in the offspring.

Until now, it is unclear whether exposure to $B[a] P$ is inducing heritable gene mutations. In the past, results from the classical specific locus test for visible markers (SLT) were negative or inconclusive for detecting heritable point mutations after $\mathrm{B}[\mathrm{a}] \mathrm{P}$ exposure in male mice [4]. However, results were positive for inducing dominant lethal mutations in postmeiotic germ cells [5]. Recently, we found that $B[a] P$ is capable of inducing lacZ gene mutations in premeiotic germ cells after 6 weeks of exposure to $\mathrm{B}[\mathrm{a}] \mathrm{P}$ in mice (see chapter 5), but it remains to be determined whether these mutations are actually transmitted to the offspring.

For this purpose, the analysis of lacZ mutations in offspring mice is inappropriate, because the spontaneous and induced mutant frequency is low and therefore too many progeny have to be analyzed to find an effect of exposure. Expanded simple tandem repeat (ESTR) DNA loci have a higher spontaneous and induced mutation rate, and analysis of these loci may thus be a useful and sensitive tool to investigate $\mathrm{B}[\mathrm{a}] \mathrm{P}$ as a germ line mutagen in mice [6]. ESTRs consist of 4 to $6 \mathrm{bp}$ repeat units in long tandem arrays that are unstable in the germ line and tend to mutate by insertion or deletion of a number of repeat units [7-9]. Studies using this tool have already been successful in establishing chemicals [10], radioactive mutagens [11, 12] and air pollution [3] as inducers of germ line mutations. Mutations are identified as novel fragments present in the DNA fingerprints of offspring that can not be ascribed to either parent.

In this pilot study, we used the DNA fingerprints of two ESTR loci Ms6-hm and $\mathrm{Hm}-2$ to establish whether $\mathrm{B}[\mathrm{a}] \mathrm{P}$ is capable of inducing heritable gene mutations that are transmitted to the offspring. Male mice (C57BL/6) deficient for the nucleotide excision repair gene $X p c\left(X p c^{---}\right)$were used because of their sensitivity for mutation induction [13], and were exposed to B[a]P during 6 weeks. Six weeks after the last exposure, male mice were crossed with female mice (Balb/C) to obtain offspring, and to ensure mutation fixation in spermatogonial stem cells. We used male and female mice of different strains that had different ESTR length, so we were able to distinguish paternally and maternally transmitted mutations.

\section{Materials and methods}

\section{Animal experiments}

DNA repair deficient $X p c^{-/-}$male mice $(\mathrm{C} 57 \mathrm{BL} / 6)$, as previously described [14, 15], were subchronically exposed for 6 weeks to B[a]P (3 times per week, $13 \mathrm{mg} / \mathrm{kg}$ 
bw dissolved in sunflower oil) by oral gavage. Unexposed $X p c^{-/-}$male mice received sunflower oil 3 times per week during 6 weeks. All male mice ( 6 mice per group) were subsequently crossed with $2 \mathrm{Balb} / \mathrm{C}$ female mice 6 weeks after the final exposure to obtain offspring and to ensure that the mutations detected in the offspring originate from spermatogonial stem cells (please note that it takes 6 weeks for sperm cells to reach the epididymides after the first mitotic division of a spermatogonial stem cell). Male mice were sacrificed after successful fertilization, while female and offspring mice were sacrificed approximately 3-4 weeks after birth of offspring mice. From all mice, tails were collected, snap frozen in liquid nitrogen and stored at $-80^{\circ} \mathrm{C}$. A schematic overview of the experiment is given in figure 1.

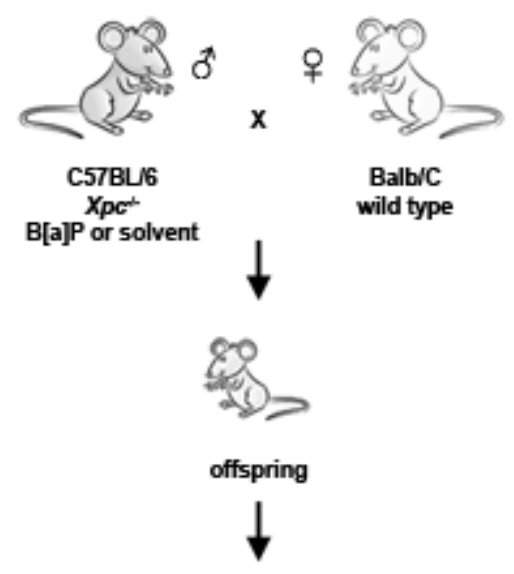

Fingerprint of tail DNA

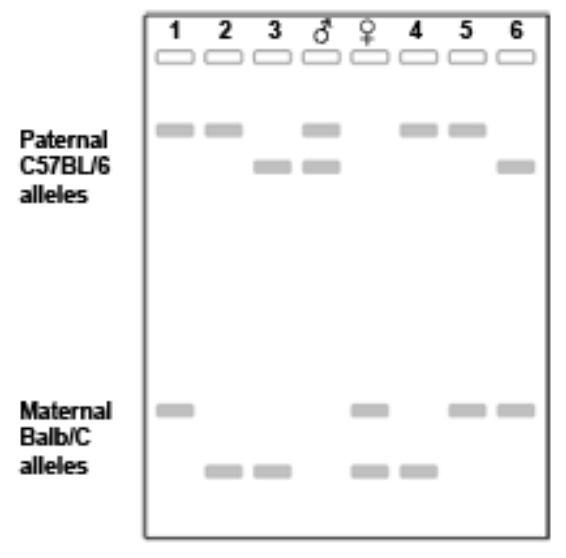

Figure 1. Experimental overview. B[a]P exposed $\mathrm{Xpc}^{-/-}$male mice (C57BL/6) were crossed with female wild type mice of a different strain (Balb/C). Tail DNA from offspring and parental mice was used for DNA fingerprinting. Paternal and maternal alleles are easily recognized, because allele sizes are different for the various strains. Offspring mice inherit one allele from each parent. In this hypothetical fingerprint, 6 non-mutated offspring mice are shown (1-6) next to the paternal ( $\precsim$ ) and maternal $(+)$ alleles. 
Mice were bred and maintained under specific pathogen-free conditions in a 12hr light-dark cycle at the animal facilities of the Netherlands Vaccine Institute (NVI, Bilthoven, the Netherlands) and received food and water ad libitum. Experiments were approved by the NVI's Animal Ethics Committee and were carried out according to their guidelines.

\section{DNA isolation}

Mouse tails were cut into small pieces and lysed overnight in $2 \mathrm{ml}$ lysis buffer (50 $\mathrm{mM} \mathrm{NaCl}, 18.75 \mathrm{mM}$ EDTA, $15 \mathrm{mM}$ Tris HCl pH 8.5 and $0.5 \%$ SDS) and $30 \mu \mathrm{l}$ proteinase $\mathrm{K}[25 \mathrm{mg} / \mathrm{ml}]$ in a shaking water bath at $56^{\circ} \mathrm{C}$. Genomic DNA was extracted sequentially with phenol: chloroform: isoamyl alcohol $(25: 24: 1, \mathrm{v} / \mathrm{v} / \mathrm{v})$ and chloroform: isoamyl alcohol $(24: 1, \mathrm{v} / \mathrm{v})$. DNA was precipitated with 2 volumes of cold $100 \%$ ethanol and $10 \% 3 \mathrm{M} \mathrm{NaAc}(\mathrm{pH} 5.2)$. Pelleted DNA was washed with $80 \%$ ethanol, dried under nitrogen and dissolved in $\mathrm{mQ}$-water. Concentrations and purity of all samples were spectrophotometrically determined using a NanoDrop (Isogen-Lifescience).

\section{ESTR mutation analysis}

First, DNA $(12 \mu \mathrm{g})$ was digested overnight at $37^{\circ} \mathrm{C}$ to completion with Alul restriction enzyme (New England Biolabs), and digestions were checked for completion on an agarose gel. DNA was size-fractionated in $40 \mathrm{~cm}$ long $0.8 \%$ agarose gels (120V) until the $2 \mathrm{~kb}$ size marker had just run of the gel, and DNA was transferred to a nylon membrane (Hybond-XL, Amersham Pharmacia) by Southern blotting. DNA fingerprints were generated by sequential hybridization with ${ }^{32} \mathrm{P}$-labelled synthetic ESTR probes for Ms6-hm [7] and $\mathrm{Hm}-2$ [8], and were visualized by using FujiFilm imaging system FLA-3000 (Raytest). Blots were completely stripped of probe DNA between hybridizations by boiling in $0.1 \%$ SDS and shaking during 2 minutes. All samples were run with $10 \mathrm{ng}$ of $1 \mathrm{~kb}$ ladder as size standard. Fingerprint bands in offspring that deviated from the parental progenitor alleles for more than $1 \mathrm{~mm}$ were scored as mutations. Scoring was performed without knowledge of exposure regimen and verified by a second experienced observer.

\section{Statistics}

Mutation rates were calculated as the number of mutant bands out of the total amount of scored alleles and compared using a modified two-tailed Fisher's exact test. Mutation rates are presented with $95 \%$ confidence intervals (between brackets) for the Ms6-hm and Hm-2 data combined. The relation between overall ESTR mutation rates and lacZ mutant frequencies, DNA adduct levels and litter sizes (also see chapter 5) were assessed by Pearson correlation. SPSS v. 15.0 was used for statistical analysis. A difference was considered significant at $p<0.05$.

\section{Results}

\section{Breeding}

To obtain offspring, $X p c^{--/}$male mice were crossed with unexposed female Balb/C mice. Twelve breeding pairs were established in both the B[a]P exposed and control group, of which ten pairs successfully produced offspring in each group. Litter sizes of successful pairs showed a significant difference between B[a]P exposed and 
control groups, with significantly smaller litter sizes in the B[a]P exposed groups (8.5 \pm 1.5 vs. $6.1 \pm 2.3, p=0.014$ ).

\section{Mutation frequencies}

Mutation frequencies were determined in the offspring of $\mathrm{B}[\mathrm{a}] \mathrm{P}$ exposed and control male mice by using DNA fingerprints of Ms6-hm and Hm-2 ESTR loci. An example of a mutant band detected with the ESTR single-locus probe for Ms6-hm is shown in figure 2. The two single ESTR probes did not detect an elevation in germ line mutation frequency in the B[a]P exposed group as compared to the control group ( $p$ $=0.91$, table 1). Unexpectedly, mutations rates were slightly (1.4-fold) higher in the maternal and paternal loci of the control group as compared to the B[a]P exposed group (0.038 vs. 0.027 and 0.062 vs. 0.045 , for maternal and paternal loci respectively). In addition, the mutation rates in the paternal loci were overall (1.6-fold) higher as compared to the maternal loci $(0.054$ vs. $0.033, p=0.372)$. All these differences were not statistically significant, mainly due to the relatively low number of offspring animals that were analyzed.

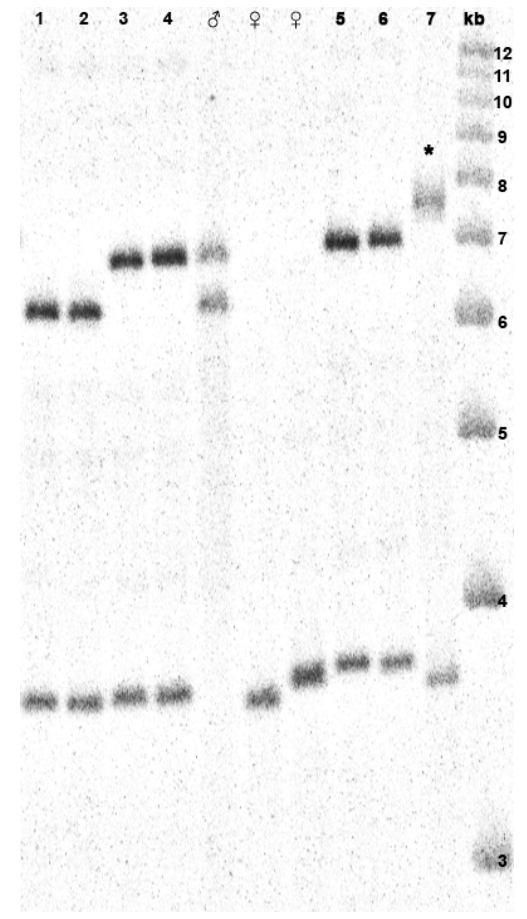

Figure 2. DNA fingerprint of a mouse family exposed to $B[a] P$ at ESTR locus Ms6-Hm. The parents are labelled as $\hat{\partial}$ (father) and o (mother); pups are labelled 1 to 7 . Pup 7 is a mutant in the paternal allele (as indicated by *), because the allele size differs more than $1 \mathrm{~mm}$ from the 2 alleles found in the father. Two mothers are indicated on the gel, because each father was mated with 2 females. Size range is indicated with a $1 \mathrm{~kb}$ ladder $(\mathrm{kb})$. 
Table 1. Germ line DNA mutation rates in offspring of benzo(a)pyrene exposed and control male mice. The data are combined for single loci Ms6-hm and $\mathrm{Hm}-2$.

\begin{tabular}{|c|c|c|c|c|c|c|c|}
\hline \multirow[t]{2}{*}{ Group } & \multirow{2}{*}{$\begin{array}{l}\text { Pups } \\
\text { scored }\end{array}$} & \multicolumn{2}{|c|}{ Total \# of mutations } & \multicolumn{2}{|c|}{ Mutation rates } & \multirow{2}{*}{$\begin{array}{l}\text { Ratio to } \\
\text { control }\end{array}$} & \multirow{2}{*}{$\begin{array}{c}\text { Fisher's } \\
\text { exact test } \\
\text { P value }\end{array}$} \\
\hline & & maternal & paternal & maternal & paternal & & \\
\hline $\mathrm{B}[\mathrm{a}] \mathrm{P}$ & 55 & 3 & 5 & $0.027(0.01,0.08)$ & $0.045(0.01,0.11)$ & $0.7(0.0,2.4)$ & 0.91 \\
\hline Control & 65 & 5 & 8 & $0.038(0.01,0.09)$ & $0.062(0.03,0.12)$ & & \\
\hline
\end{tabular}

\section{Correlations of ESTR mutation rates with other parameters}

In this study, the same $X p c^{-/-}$mice were used as in the study for detecting lacZ mutant frequencies in testis (see chapter 5). Therefore, it is possible to visualize correlations between the lacZ mutant frequencies in testis and ESTR mutation rates in the offspring of $\mathrm{B}[\mathrm{a}] \mathrm{P}$ exposed and control mice. A correlation was found between the lacZ mutant frequencies found in testis and the paternal ESTR mutation rate in offspring of $\mathrm{B}[\mathrm{a}] \mathrm{P}$ exposed $\mathrm{Xpc}^{-/-}$mice (figure 3), although this was not statistically significant $(R=0.791, p=0.061)$. In controls, such a correlation was not observed $(R$ $=-0.069, p=0.896)$. The overall relationship between lacZ mutations in testis and ESTR mutations in offspring was $R=0.558(p=0.059)$. These results indicate that paternally induced mutations in the testis may represent mutations in the germ line that are transmitted to the offspring.

Studies on ESTR mutations induced by radiation suggest that exposure of the father, may also lead to genetic instability in the maternal allele [12]. However, in our study, ESTR mutation rates in the maternal allele did not correlate with the lacZ mutant frequencies $(R=-0.430, p=0.395)$. The DNA adduct levels found in testes of the B[a]P exposed mice (see chapter 5) showed no correlation with paternal nor maternal ESTR mutation rates. In addition, the litter sizes were not related to the paternal and/or maternal ESTR mutation rates of $\mathrm{B}[\mathrm{a}] \mathrm{P}$ exposed and control mice.

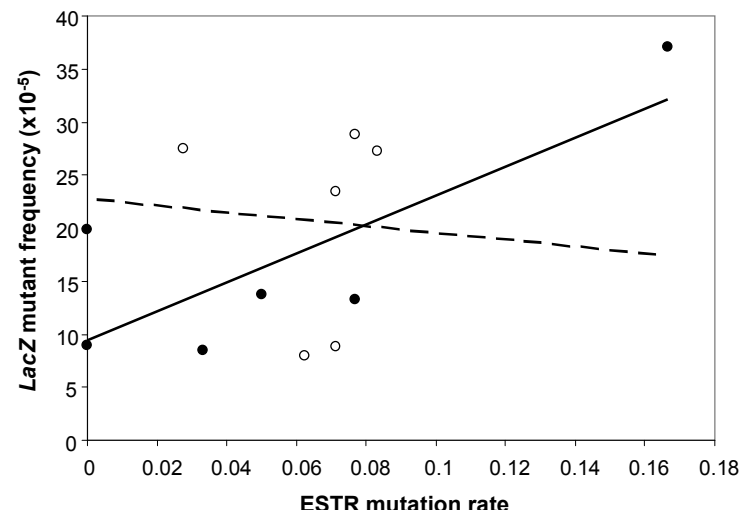

Figure 3. Correlations of paternal ESTR mutation rates with lacZ mutant frequencies in testis. The paternally transmitted B[a]P-induced ESTR mutation rate $(\bullet)$ is strongly correlated with the lac $Z$ mutant frequency in testis $(R=0.791,-)$, while the ESTR mutation rate in control $(0)$ is not correlated with the lac $Z$ mutant frequency in testis $(R=-0.069,--)$. 


\section{Discussion}

In this pilot study, we evaluated whether DNA fingerprints of two ESTR loci Ms6$\mathrm{hm}$ and $\mathrm{Hm}-2$ can be used to establish whether B[a]P is capable of inducing heritable gene mutations in mice and whether these are subsequently transmitted to the offspring. The $\mathrm{Xpc}^{-/-}$mouse model we used is thought to be a sensitive model for mutation induction, since spontaneous mutant frequencies (in spleen, liver and lung) and $\mathrm{B}[\mathrm{a}] \mathrm{P}$-induced DNA adduct levels in spermatogonial cells were higher in $\mathrm{Xpc^{-- }}$ mice than in its wild type counterpart $[13,16]$. However, in our previous experiments (see chapter 5), we already noticed that this is not necessarily the case; lacZ mutant frequencies were significantly elevated in sperm cells of wild type mice after 6 weeks exposure to $\mathrm{B}[\mathrm{a}] \mathrm{P}$, while no effect was observed in $\mathrm{Xpc}^{-/-}$mice. The absence of an increase in mutant frequencies in sperm cells of $X p c^{-/-}$mice still needs further investigation, but may be due to higher levels of cytotoxicity in testes and sperm cells of these mice.

The results of this study showed that ESTR mutation rates did not significantly differ between offspring of $\mathrm{B}[\mathrm{a}] \mathrm{P}$ exposed and control male mice with an $X p c^{-/}$genotype, and therefore, it resembles the results of chapter 5 with regard to the lac $Z$ mutant frequencies in testes and sperm cells of $X p c^{-/-}$mice. ESTR mutation rates in offspring of exposed male mice were even 1.4-fold lower than in the parental alleles of the control families, which may again be explained by potential cytotoxic effects as suggested previously, leading to a selection of cells that carry less DNA damage. Nonetheless, the ESTR mutation rates in offspring of $B[a] P$ exposed male mice correlated with the lacZ mutant frequencies found in the testis of these mice $(R=0.791$, $p=0.06$ ), while the control and maternal rates were not. Although the number of observations is low and need to be increased in future studies, this finding suggests that induced mutations in testis may represent mutations in the germ line that are transmitted to the offspring. In addition, DNA adduct levels and litter sizes were not correlated with ESTR mutation rates.

Previous results also showed that DNA adducts were still present in the reproductive tissues and possibly also in the germ cells of exposed mice at the time of conception, but these DNA adduct levels did not correlate with ESTR mutation rates. Therefore, it can be excluded that ESTR mutations at post-spermatogonial cell stages are formed due to the presence of DNA adducts. In fact, it is already thought that DNA adducts are not directly responsible for the formation of ESTR mutations, but these mutations arise through an indirect mechanism [17].

Litter sizes of successful breeding pairs differed significantly between B[a]P exposed and control groups $(p=0.014)$, which may indicate that the 6 weeks exposure to $\mathrm{B}[\mathrm{a}] \mathrm{P}$ was cytotoxic to the germ cells or the damage to the germ cells renders the sperm incapable of effective fertilization. Interference with the fertilizing capacity of exposed male mice might have prevented the transmission of heritable DNA damage to the offspring due to selection of undamaged sperm. Although apoptosis is a common process in the testis to remove damaged or excessive sperm cells [18], it has been shown that exposure to high acute doses of B[a]P further induces apoptosis, mainly in spermatogonia [19], which eliminates immature damaged germ cells during spermatogenesis and prevents fertilization by mutated sperm cells. However, other mechanisms may also have played a role in the reduction of the litter sizes; for example, changes in the global DNA methylation affecting gene expression, chromatin 
structure or genome stability, which are all thought to contribute to the formation of ESTR mutations. It can not be excluded that such alterations were transmitted to the offspring, providing early zygote loss. Our B[a]P exposure did not lead to complete infertility of mice, because equal numbers (10/12) of B[a]P exposed and control mice were able to produce offspring, but the subchronic exposure of a sensitive animal model may have affected sperm quality as indicated by the smaller litter sizes.

From studies in the past, it is known that despite the relatively high sensitivity of ESTR mutation analysis, more than a hundred offspring are required for adequate analysis of mutation rates. As mentioned in the results section, the number of offspring used for our ESTR mutation analysis were 55 in the B[a]P exposed families and 65 in the control families. In the future, the number of offspring has to be expanded to complete this analysis and before we can draw any firm conclusions, future studies should also include families of $B[a] P$ exposed Wt male mice, since increased lacZ mutant frequencies were only found in sperm cells of exposed Wt male mice (see chapter 5). Thus, from the current pilot study, it remains unclear whether $\mathrm{B}[\mathrm{a}] \mathrm{P}$ is capable of inducing heritable gene mutations that are transmitted to the offspring, since ESTR mutation rates did not differ significantly between offspring of $\mathrm{B}[\mathrm{a}] \mathrm{P}$ exposed and control $X p c^{-/-}$male mice. However, despite the low number of observations, ESTR mutation rates correlated with previously found lacZ mutant frequencies in testis and might therefore represent germ line mutations that were transmitted to the offspring. We therefore suggest that the use of ESTR mutations could be effective in studying germ line mutations induced by $\mathrm{B}[\mathrm{a}] \mathrm{P}$, but sample sizes need to be increased and also offspring of DNA repair proficient male mice should be included.

\section{Acknowledgements}

The authors would like to thank E.C. Friedberg for providing the $\mathrm{Xpc}^{-/-}$mice, the animal technicians of the animal facilities of the Netherlands Vaccine Institute (NVI, the Netherlands) for their skilful assistance during this study and Y.E. Dubrova for providing the protocol for ESTR mutation analysis. This work was supported by the Cefic Long-Range Research Initiative (LRI) Innovative Science award 2004 (to R.G.). 


\section{References}

1. Yauk, C.L., Fox, G.A., McCarry, B.E. and Quinn, J.S. (2000) Induced minisatellite germline mutations in herring gulls (Larus argentatus) living near steel mills. Mutat Res, 452, 211-218.

2. Somers, C.M., McCarry, B.E., Malek, F. and Quinn, J.S. (2004) Reduction of particulate air pollution lowers the risk of heritable mutations in mice. Science, 304, 1008-1010.

3. Somers, C.M., Yauk, C.L., White, P.A., Parfett, C.L. and Quinn, J.S. (2002) Air pollution induces heritable DNA mutations. Proc Natl Acad Sci USA, 99, 15904-15907.

4. Russell, L.B., Selby, P.B., von Halle, E., Sheridan, W. and Valcovic, L. (1981) The mouse specific-locus test with agents other than radiations: interpretation of data and recommendations for future work. Mutation research, 86, 329-354.

5. Generoso, W.M., Cain, K.T., Hellwig, C.S. and Cacheiro, N.L. (1982) Lack of association between induction of dominant-lethal mutations and induction of heritable translocations with benzo[a]pyrene in postmeiotic germ cells of male mice. Mutat Res, 94, 155-163.

6. Verhofstad, N., Linschooten, J.O., van Benthem, J., Dubrova, Y.E., van Steeg, H., van Schooten, F.J. and Godschalk, R.W. (2008) New methods for assessing male germ line mutations in humans and genetic risks in their offspring. Mutagenesis, 23, 241-247.

7. Kelly, R., Bulfield, G., Collick, A., Gibbs, M. and Jeffreys, A.J. (1989) Characterization of a highly unstable mouse minisatellite locus: evidence for somatic mutation during early development. Genomics, $\mathbf{5}$, 844-856.

8. Gibbs, M., Collick, A., Kelly, R.G. and Jeffreys, A.J. (1993) A tetranucleotide repeat mouse minisatellite displaying substantial somatic instability during early preimplantation development. Genomics, 17, 121128.

9. Bois, P., Stead, J.D., Bakshi, S., Williamson, J., Neumann, R., Moghadaszadeh, B. and Jeffreys, A.J. (1998) Isolation and characterization of mouse minisatellites. Genomics, 50, 317-330.

10. Hedenskog, M., Sjogren, M., Cederberg, H. and Rannug, U. (1997) Induction of germline-length mutations at the minisatellites PC-1 and PC-2 in male mice exposed to polychlorinated biphenyls and diesel exhaust emissions. Environ Mol Mutagen, 30, 254-259.

11. Dubrova, Y.E., Jeffreys, A.J. and Malashenko, A.M. (1993) Mouse minisatellite mutations induced by ionizing radiation. Nat Genet, 5, 92-94.

12. Dubrova, Y.E., Plumb, M., Brown, J., Fennelly, J., Bois, P., Goodhead, D. and Jeffreys, A.J. (1998) Stage specificity, dose response, and doubling dose for mouse minisatellite germ-line mutation induced by acute radiation. Proc Natl Acad Sci USA, 95, 6251-6255.

13. Melis, J.P., Wijnhoven, S.W., Beems, R.B., Roodbergen, M., van den Berg, J., Moon, H., Friedberg, E., van der Horst, G.T., Hoeijmakers, J.H., Vijg, J. and van Steeg, H. (2008) Mouse models for xeroderma pigmentosum group $A$ and group $C$ show divergent cancer phenotypes. Cancer Res, 68, 1347-1353.

14. Cheo, D.L., Ruven, H.J., Meira, L.B., Hammer, R.E., Burns, D.K., Tappe, N.J., van Zeeland, A.A., Mullenders, L.H. and Friedberg, E.C. (1997) Characterization of defective nucleotide excision repair in XPC mutant mice. Mutat Res, 374, 1-9.

15. Hoogervorst, E.M., van Oostrom, C.T., Beems, R.B., van Benthem, J., van den Berg, J., van Kreijl, C.F., Vos, J.G., de Vries, A. and van Steeg, H. (2005) 2-AAF-induced tumor development in nucleotide excision repair-deficient mice is associated with a defect in global genome repair but not with transcription coupled repair. DNA Repair (Amst), 4, 3-9.

16. Verhofstad, N., van Oostrom, C.T., van Benthem, J., van Schooten, F.J., van Steeg, H. and Godschalk, R.W. (2010) DNA adduct kinetics in reproductive tissues of DNA repair proficient and deficient male mice after oral exposure to benzo(a)pyrene. Environ Mol Mutagen, 51, 123-129.

17. Yauk, C., Polyzos, A., Rowan-Carroll, A., Somers, C.M., Godschalk, R.W., Van Schooten, F.J., Berndt, M.L., Pogribny, I.P., Koturbash, I., Williams, A., Douglas, G.R. and Kovalchuk, O. (2008) Germ-line mutations, DNA damage, and global hypermethylation in mice exposed to particulate air pollution in an urban/industrial location. Proc Natl Acad Sci U S A, 105, 605-610.

18. Tripathi, R., Mishra, D.P. and Shaha, C. (2009) Male germ cell development: turning on the apoptotic pathways. Journal of reproductive immunology, 83, 31-35.

19. Revel, A., Raanani, H., Younglai, E., Xu, J., Han, R., Savouret, J.F. and Casper, R.F. (2001) Resveratrol, a natural aryl hydrocarbon receptor antagonist, protects sperm from DNA damage and apoptosis caused by benzo(a)pyrene. Reprod Toxicol, 15, 479-486. 




\section{Chapter 7}

Summary and general discussion 
Benzo(a)pyrene (B[a]P) is known as an environmental and occupational pollutant, to which we are regularly exposed. After uptake, B[a]P is metabolically transformed into compounds that can be excreted in urine or faeces. Occasionally active compounds are formed that can bind to the DNA and form bulky DNA adducts. DNA adducts may lead to the formation of mutations and the subsequent onset of cancer development, unless they are removed by DNA repair mechanisms. Besides its known mutagenic and carcinogenic potential in somatic cells, B[a]P may also affect the DNA in reproductive tissues and male germ cells, potentially increasing health risks in offspring. The European Community's guidance document for genotoxicity under REACH requires that chemical compounds should be considered for testing on mutagenicity in germ cells when they are mutagenic in somatic cells. Since the results from classical germ cell mutagenicity tests were inconclusive and polycyclic aromatic hydrocarbons (PAHs) have been found to induce germ line mutations in sentinel animals exposed to contaminated outdoor air, B[a]P should be tested for its mutagenic potential in male germ cells. In this thesis, we evaluated $\mathrm{B}[\mathrm{a}] \mathrm{P}$ as a potential germ line mutagen and investigated whether DNA repair represents a relevant molecular protective mechanism affecting the relation between DNA adduct formation and the production of germ line mutations.

\section{DNA adduct kinetics in testis and male germ cells}

In the first study (chapter 3 ), we examined the DNA damaging effects of $B[a] P$ and DNA adduct removal by global genome repair (GGR), as part of nucleotide excision repair (NER), in testes and sperm cells of exposed male mice. Wild type (Wt) and $X p c^{-/-}$male mice were exposed to a single dose of $B[a] P$ and sacrificed at day 1 , $4,7,10,14,21,32$ and 42 after exposure to study DNA adduct formation at different stages of spermatogenesis. Since spermatogenesis takes 42 days in mice, a measurement in spermatozoa at day 42 after exposure represents DNA adducts that are formed in exposed spermatogonial stem cells or early type A spermatogonia. DNA adduct kinetics were compared between $\mathrm{B}[\mathrm{a}] \mathrm{P}$ exposed $\mathrm{Wt}$ and $\mathrm{Xpc^{-/ }}$ male mice to study the contribution of GGR/NER in DNA damage removal in testes and male germ cells. For our studies, we used $X p c^{-/-}$rather than $X p a^{-/-}$mice, since it was previously shown that $X \mathrm{pa}^{-/-}$mice might be too sensitive to compounds that give bulky adducts [1]. The observed toxicity in these $X \mathrm{Xa}^{-/-}$mice was predominantly caused by the absence of transcription coupled repair (TCR), as part of NER. Therefore, to prevent unwanted toxicity in our studies, we decided to use $X p c^{-1-}$ mice, which are deficient for GGR/NER, but still have active TCR/NER.

We found DNA adducts in detectable amounts in whole testis and at all stages of spermatogenesis. In testes, $\mathrm{Xpc}^{-/-}$mice contained significantly higher DNA adduct levels compared to $\mathrm{Wt}$ mice over the entire 42-days observation period. Also a difference in adduct half-life was observed between $\mathrm{Wt}$ and $\mathrm{Xpc} c^{-/-}$mice, with $\mathrm{Xpc}^{-/-}$mice having more stable DNA adducts. These findings suggest that there is a significant role for GGR/NER in removing DNA adducts from testes. In spermatozoa, DNA adduct levels were only significantly higher in $X p c^{-/-}$mice as compared to Wt mice at 6 weeks after exposure (day 42). At this time point, DNA adducts were measured in spermatozoa that would have developed from exposed spermatogonial stem cells or that would have been in an early mitotic stage of spermatogenesis at the time of exposure, and these cells have had the chance to divide multiple times and to re- 
cover from the damage by DNA repair. It was also interesting to see that even in $\mathrm{Wt}$ mice DNA adducts were still detectable at 6 weeks after exposure, even though the levels were significantly lower as compared to $\mathrm{Xpc}^{-/-}$mice. The results from spermatozoa suggest that the initial DNA damage in spermatogonia was relatively high, and that accurate DNA repair mechanisms, such as GGR/NER, are important for efficient DNA damage removal. DNA adducts were also detected shortly after exposure in mature spermatozoa, which are considered to be unable to metabolically activate $\mathrm{B}[\mathrm{a}] \mathrm{P}$. These cells are however surrounded by tissues that can metabolize $\mathrm{B}[\mathrm{a}] \mathrm{P}$ (for instance Sertoli cells or epididymal epithelium) and the reactive metabolites could thus reach the spermatozoa. DNA damage that is not removed during spermatogenesis may lead to the formation of germ line mutations, but may also persist until fertilization and affect the growth and development of the embryo. Studies already showed paternal transmission of $B[a] P$ induced DNA adducts in spermatozoa of smoking fathers to their fertilized embryos [2], and a relation between environmental exposure and intrauterine growth retardation in the first gestational month [3]. Further, DNA damaged sperm was found to be able to fertilize oocytes, regardless of the degree of DNA damage, but the embryonic development is affected by the degree of DNA damage [4]. Fortunately, the oocyte has the capacity to repair damaged DNA of sperm after fertilization when it is damaged less than ca. $8 \%$; damage beyond this level will affect embryonic development and increase the chance of early pregnancy loss [4].

Although DNA damage in mature spermatozoa may affect the offspring's health, DNA damage in spermatogonial stem cells may be a more important problem, because DNA damage that is converted into mutations in these cells can affect an infinite number of generations thereafter.

\section{$\mathrm{B}[\mathrm{a}] \mathrm{P}$-induced gene expression changes in testis}

In chapter 3 we showed that B[a]P-induced DNA adducts were not efficiently removed from the DNA of testes and germ cells in $X p c^{-/-}$mice, even though germ cells are thought to be well-protected against exposures via a complex network of molecular mechanisms. Stress induced proteins have been found to play an important role in spermatogenesis. For instance, heat-shock proteins were found to be induced in response to environmental stress but are also essential for normal gametogenesis; in mice homozygous for a deletion in the Hsp70-2 gene, spermatocytes fail to complete meiotic prophase and become apoptotic [5]. HSP70-2 may protect germ cells in combination with the tumour suppressor gene $p 53$, which prevents the propagation of DNA damage to daughter cells by causing cell cycle arrest for efficient repair or by inducing apoptosis [6]. In the mouse, $p 53$ is expressed during the meiotic prophase in spermatocytes and appears to be important for normal spermatogenesis, since the testis of mice with reduced levels of p53 are histologically abnormal [7]. In other words, it seems that genes that are usually related to cellular stress responses are of importance for normal gametogenesis, even in the absence of additional exposures to genotoxins. In order to reveal the stress responses after $\mathrm{B}[\mathrm{a}] \mathrm{P}$ exposure in the testis, we investigated the changes in gene expression induced by $\mathrm{B}[\mathrm{a}] \mathrm{P}$ in testes from Wt and $X p c^{-/-}$male mice (chapter 4). Since $X p c^{--/}$mice lack GGR/NER, which is considered to be one of the most important protective mechanisms against $B[a] P$ induced DNA damage, we expected a different (adaptive) transcriptional response in 
these mice as compared to Wt mice to compensate for the lack of DNA repair activity. Although gene expression levels were similar in unexposed $\mathrm{Wt}$ and $\mathrm{Xpc}^{-/-}$mice and $\mathrm{B}[\mathrm{a}] \mathrm{P}$ induced similar gene expression changes in mice of both genotypes, the level in which these $\mathrm{B}[\mathrm{a}] \mathrm{P}$ exposure regulated genes were expressed differed significantly between $\mathrm{Wt}$ and $X p c^{-/-}$mice $(p=0.000000141)$, with an overall slightly higher expression in $X p c^{-/-}$mice as compared to their Wt counterparts. These differences were predominantly found within the regulation of cell cycle, but also at the level of translation, chromatin structure and spermatogenesis, indicative for a general stress response. Analysis of cell cycle phase dependent gene expression showed that expression of genes involved in G1-S and G2-M phase arrest was increased after B[a]P exposure in both genotypes.

A slightly higher induction of the average gene expression was observed the G2-M phase checkpoint in $X p c^{-/-}$mice, but this did not reach statistical significance ( $P$ $=0.086$ ). However, statistical significance was reached when the analysis was performed on up regulated genes only within this phase $(p=0.024)$, showing a trend towards a higher induction of G2-M phase genes in $\mathrm{Xpc}^{-/-}$mice. These findings indicate that the presence of unrepaired DNA damage in testis blocks cell proliferation to protect DNA integrity in both DNA repair proficient and deficient animals, which is a normal reaction and does thus not differ from somatic cells. The difference between $\mathrm{Wt}$ and $\mathrm{Xpc}^{-/-}$mice in $\mathrm{B}[\mathrm{a}] \mathrm{P}$-induced gene expression levels within the $\mathrm{G} 2-\mathrm{M}$ phase could be ascribed to more damaged cells in testes of $X p c^{-/-}$mice, instead of a stronger reaction in each individual cell. Unrepaired DNA damage can block the cell cycle in the late S-phase, until it is passed in an error-free or error-prone way with progression of the cell cycle and spermatogenesis. Eventually, sperm cells seem to continue their proliferation in the presence of DNA damage, because we have observed that DNA adducts can be carried along during spermatogenesis (chapter 3 ). Y-family polymerases can pass blocked replication forks by $\mathrm{B}[\mathrm{a}] \mathrm{P}$ induced DNA damage. In fact, polymerase $K$ is highly expressed in germ cells and replicates $B[a] P$ damaged DNA in a mostly error-free way. Undamaged cells or less damaged cells of which the DNA damage still can be removed, as is likely to occur in Wt mice, can continue the cell cycle more easily and show lower expression levels of G2-M phase genes.

Other processes that were expected to have changed by exposure, like apoptosis and DNA repair processes other than GGR/NER, were not found to be modulated at the level of gene expression. However, this does not mean that these processes were not affected by B[a]P exposure. Other aspects could have played a role in the activation of apoptosis; 1) the large number of apoptotic cells in normal testis will make it difficult to measure subtle changes in the apoptotic response after a single $\mathrm{B}[\mathrm{a}] \mathrm{P}$ exposure, 2) the apoptotic response after $\mathrm{B}[\mathrm{a}] \mathrm{P}$ exposure is an acute response that is probably hard to assess 4 days after exposure, and 3 ) the activation of the different caspases leading to fragmentation of DNA occurs by cleavage of procaspases already stored in the cell, a process that is unlikely to be found at the transcriptional level [8]. This last aspect may also hold true for DNA repair, which also relies on activation and translocation of already existing proteins. 


\section{Mutagenic effects of benzo(a)pyrene in sperm cells}

$\mathrm{B}[\mathrm{a}] \mathrm{P}$ has been studied extensively since its discovery in 1930 and it is clear that $\mathrm{B}[\mathrm{a}] \mathrm{P}$ has DNA damaging potential and mutagenic effects. However, it is less clear whether $\mathrm{B}[\mathrm{a}] \mathrm{P}$ induces mutations in germ cells in an in vivo situation. In chapter 3 we found that $\mathrm{B}[\mathrm{a}] \mathrm{P}$ induced DNA adducts in spermatogonial stem cells of exposed male mice, which were not completely removed within 42 days after exposure. This indicates that DNA damage is present during the mitotic expansion of germ cells and subsequent meiosis, which offers the opportunity to transform this DNA damage into heritable gene mutations. In addition, recent studies with environmentally exposed animals suggest that PAHs are indeed mutagenic in male germ cells $[9,10]$. Therefore, we studied in chapter 5 whether $\mathrm{B}[\mathrm{a}] \mathrm{P}$ was able to induce gene mutations in testis and sperm cells of Wt and $X p c^{-/-}$mice. To study this, we used mice that contain a plasmid-based shuttle vector with multiple copies of the lacZ reporter gene integrated in a head-to-tail organization in their genome [11]. The use of this transgenic mouse model permits the quantification and characterization of mutations in different organs and tissues over the life-time of an animal, and allows the detection of deletions, point mutations and chromosomal rearrangements, including translocations. DNA lesions induced by $\mathrm{B}[\mathrm{a}] \mathrm{P}$ are mainly point mutations, and therefore this model is appropriate to assess the mutagenic effects of $\mathrm{B}[\mathrm{a}] \mathrm{P}$ in reproductive tissues and sperm cells in an in vivo situation. The usefulness of this animal model was also demonstrated by a positive response in animals that were exposed to the well-known germ line mutagen ethyl nitrosourea (ENU).

Mice were sacrificed 6 weeks after the final B[a]P exposure to obtain sperm cells derived from exposed spermatogonial stem cells. Successful exposure was confirmed by a dose and time-dependent increase in mutant frequency in the known target organ spleen with higher mutant frequencies in $\mathrm{Xpc}^{-/-}$mice as compared to $\mathrm{Wt}$ mice. Although $\mathrm{B}[\mathrm{a}] \mathrm{P}$-related DNA adducts were detected in testis, mutant frequencies were not increased in this tissue. On the other hand, B[a]P significantly enhanced mutant frequencies in sperm of Wt mice after 6 weeks of exposure, but such an increase was not found in $\mathrm{Xpc}^{-/-}$mice. These results were in contrast with what we hypothesized, since it was expected that $X p c^{-/-}$mice would be a more sensitive model to study mutation induction [12]. Besides that, DNA adduct levels in $\mathrm{Xpc}^{-/-}$mice were significantly higher 42 days after a single exposure (representing spermatogonial stem cells) as compared to Wt mice (chapter 3 ). It remains to be investigated why $\mathrm{Xpc}^{-/-}$mice were not responsive towards the induction of mutants after $\mathrm{B}[\mathrm{a}] \mathrm{P}$ exposure. We consider that cytotoxicity induced by $\mathrm{B}[\mathrm{a}] \mathrm{P}$ in developing sperm cells might play a role in the lack of mutagenic effects in $X p c^{-/-}$mice. Previous studies showed that high exposure to $\mathrm{B}[\mathrm{a}] \mathrm{P}$ may lead to sterility due to cytotoxicity of $\mathrm{B}[\mathrm{a}] \mathrm{P}$ to spermatogonia [13]. However, in our study no sterility was induced because the exposed mice did produce offspring. Though, the same 6 week exposure dose applied to the more DNA damage sensitive $X p c^{---}$mice lead to a significant decrease in the number of offspring mice, which could be an indication of cytotoxicity. Moreover, a selection of cells may have occurred by favouring those cells that were not heavily damaged, and as a result no increased mutant frequencies could be detected. It would be interesting for future studies to investigate whether DNA damage is not homogenously distributed throughout the testis, which would make a selection of less damaged cells possible. 
Histopathological analysis of the testis will be performed to confirm this hypothesis and future studies should elucidate whether B[a]P exposure also reduces litter sizes of Wt male mice. For now, we can conclude that $\mathrm{B}[\mathrm{a}] \mathrm{P}$ can induce gene mutations in spermatogonial stem cells of mice. It is likely that these mutations are transmitted to the offspring, since they were detected in out-grown spermatozoa that were present in the epididymides and prepared for conception. Only selection could prevent the existence of these mutations in the progeny during or after fertilization.

\section{Inherited mutations in offspring mice}

Although we demonstrated that $\mathrm{B}[\mathrm{a}] \mathrm{P}$ induced mutations in spermatogonial stem cells (chapter 5), it remains uncertain whether these mutations are transmitted to the offspring. This may possibly depend on the exposure dose and exposure duration affecting the germ cells; high doses and long-term exposure to B[a]P can be cytotoxic to germ cells [13]. In chapter $\mathbf{5}$, we found that mutations induced in spermatogonial stem cells are still present in mature spermatozoa in the epididymides of Wt mice, but not in $\mathrm{Xpc}^{-/-}$mice. The combination of exposure dose and the genetic background of the animal model can therefore affect the outcome of the experiment.

It is unlikely that the lacZ mouse model can be used to study mutations in the offspring, because the mutant frequency is too low and large numbers of offspring would be needed to detect the transmittance of such mutations with sufficient power. Therefore, we set up a pilot study using a sensitive method to analyze expanded simple tandem repeat (ESTR) mutation rates in DNA fingerprints of offspring mice, which has been described in chapter 2, in combination with the DNA repair deficient $\left(X p c^{-/-}\right)$mouse model. The analysis of ESTR mutations has proven to be a successful method for the analysis of transmittable mutations in the offspring of animals and humans (see chapter 2). As compared to the classical germ cell assays, the analysis of ESTR mutations is a more sensitive method that requires reduced number of animals, takes less time and is more cost-effective. However, the disadvantages of this assay are that only a few laboratories are equipped to perform the analysis, that it measures mutation induction in non-coding DNA without phenotypic effects, and that the defined mechanism of mutation induction is yet unknown. It is suggested that tandem repeat mutations arise through an indirect mechanism of mutation induction [14]. Still, we chose this method because it has been successfully applied as a germ line mutation assay.

The results from this pilot study showed that $B[a] P$ exposure did not increase ESTR mutation rates in offspring of $\mathrm{B}[\mathrm{a}] \mathrm{P}$ exposed male $\mathrm{Xpc}^{-/-}$mice as compared to offspring of control male mice ( $p=0.91$, chapter 6 ). In fact, paternal and maternal mutation rates seemed even higher in offspring of control male mice. Although these results are in concordance with the lack of response found in chapter 5 and a correlation was observed between ESTR mutations and lacZ mutant frequencies, it remains to be elucidated why the $X p c^{-/-}$mouse model is not responsive towards mutation induction in reproductive tissues after $\mathrm{B}[\mathrm{a}] \mathrm{P}$ exposure and whether the ESTR mutations reflect lacZ gene mutations in Wt animals. We already suggested that $\mathrm{B}[\mathrm{a}] \mathrm{P}$-induced cytotoxicity to the germ cells is causing this lack of response in $X p c^{-/-}$ mice, since the number of offspring was significantly lower after $\mathrm{B}[\mathrm{a}] \mathrm{P}$ exposure as compared to the control group. In addition, the DNA adduct levels in testes rather decreased after 6 weeks exposure as compared to 4 weeks exposure, while an ac- 
cumulation of DNA damage was expected. This suggests that testicular and germ cells with high levels of DNA damage are triggered to enter apoptosis/necrosis, thereby decreasing overall DNA adduct levels. On the other hand, the apoptotic pathway was not found to be modulated at the levels of gene expression (chapter 4) after acute exposure to a single dose of $\mathrm{B}[\mathrm{a}] \mathrm{P}$. Therefore, it can not be excluded that other processes are involved in this lack of effect. Gene expression analysis also revealed that $\mathrm{B}[\mathrm{a}] \mathrm{P}$ exposure affected mitochondrial function and oxidative phosphorylation which is indicative for a decreased motility and fertilizing capacity of the sperm (chapter 4). B[a]P exposure is known to affect spermatogenesis by reduced motility and lower sperm concentrations. But also epigenetic alterations changing the methylation pattern could have affected the spermatogenic process and therefore the quality and the fertilizing capacity of the sperm [15].

For future studies, it is recommended to expand the number of offspring tested, since this would improve the reliability of the results. At least 100 , but preferably more offspring have to be tested per group to obtain significant results. Unfortunately, this was not achieved in this pilot study in which we tested 55 and 65 offspring in the $\mathrm{B}[\mathrm{a}] \mathrm{P}$ exposed and control group, respectively. Since a significant lacZ mutant induction was found in sperm cells of exposed Wt mice after 6 weeks exposure and 6 weeks of recovery, it is also proposed to study the formation of $\mathrm{B}[\mathrm{a}] \mathrm{P}$-induced germ line mutations in offspring of Wt mice. These results may further reveal whether $B[a] P$ can be classified as a germ line mutagen, affecting the health of progeny.

\section{Overall Conclusion}

From the results in this thesis it can be concluded that $\mathrm{B}[\mathrm{a}] \mathrm{P}$ possesses DNA damaging effects in testis and especially male germ cells, and that XPC, a key protein in GGR/NER, plays an important role in the efficient removal of B[a]P-induced DNA adducts in these reproductive cells. Nonetheless, in response to B[a]P exposure, gene expression changes were relatively the same in testes of $\mathrm{Wt}$ and $X p c^{-/-}$ mice, mainly showing that cell cycle is arrested to provide additional time for repair. Since $\mathrm{Xpc}^{-/-}$mice lack the most important repair mechanism for B[a]P induced DNA damage, cell cycle arrest is more induced in testes of $X p c^{-/-}$mice than of Wt mice, especially at the G2-M phase transition.

$\mathrm{B}[\mathrm{a}] \mathrm{P}$-induced mutation induction was only observed in sperm cells of exposed Wt mice, representing germ line mutations in spermatogonial stem cells. Our results were recently confirmed in a paper by Olsen et al., in which they showed that de novo mutations had been induced in spermatozoa originating from B[a]P exposed (3 $\times 50 \mathrm{mg} / \mathrm{kg} \mathrm{bw}$ ) spermatogonia [16]. Characterization of the mutations from exposed spermatogonia showed increased levels of GC-TA transversions, which are produced mostly by $\mathrm{B}[\mathrm{a}] \mathrm{P}$ exposure. In our studies, $X p \mathrm{c}^{-/-}$mice seemed to be too sensitive for $\mathrm{B}[\mathrm{a}] \mathrm{P}$ after subchronic exposure, which may have lead to cytotoxicity. Future studies should expand the number of offspring tested and further evaluate inherited mutations in offspring of $\mathrm{B}[\mathrm{a}] \mathrm{P}$ exposed male mice. 


\section{References}

1. Klein, J.C., Beems, R.B., Zwart, P.E., Hamzink, M., Zomer, G., van Steeg, H. and van Kreijl, C.F. (2001) Intestinal toxicity and carcinogenic potential of the food mutagen 2-amino-1-methyl-6-phenylimidazo[4,5b]pyridine (PhIP) in DNA repair deficient XPA-/- mice. Carcinogenesis, 22, 619-626.

2. Zenzes, M.T., Puy, L.A., Bielecki, R. and Reed, T.E. (1999) Detection of benzo[a]pyrene diol epoxideDNA adducts in embryos from smoking couples: evidence for transmission by spermatozoa. Mol Hum Reprod, 5, 125-131.

3. Srm, R.J., Binkov, B., Rssner, P., Rubes, J., Topinka, J. and Dejmek, J. (1999) Adverse reproductive outcomes from exposure to environmental mutagens. Mutation research, 428, 203-215.

4. Ahmadi, A. and Ng, S.C. (1999) Fertilizing ability of DNA-damaged spermatozoa. Journal of experimental zoology, 284, 696-704.

5. Dix, D.J. (1997) Hsp70 expression and function during gametogenesis. Cell stress \& chaperones, 2, 7377.

6. Smith, M.L. and Fornace, A.J., Jr. (1996) The two faces of tumor suppressor p53. The American journal of pathology, 148, 1019-1022.

7. Rotter, V., Schwartz, D., Almon, E., Goldfinger, N., Kapon, A., Meshorer, A., Donehower, L.A. and Levine, A.J. (1993) Mice with reduced levels of p53 protein exhibit the testicular giant-cell degenerative syndrome. Proc Natl Acad Sci U S A, 90, 9075-9079.

8. Boatright, K.M. and Salvesen, G.S. (2003) Mechanisms of caspase activation. Current opinion in cell biology, 15, 725-731.

9. Somers, C.M., Yauk, C.L., White, P.A., Parfett, C.L. and Quinn, J.S. (2002) Air pollution induces heritable DNA mutations. Proc Natl Acad Sci USA, 99, 15904-15907.

10. Somers, C.M., McCarry, B.E., Malek, F. and Quinn, J.S. (2004) Reduction of particulate air pollution lowers the risk of heritable mutations in mice. Science, 304, 1008-1010.

11. Dolle, M.E., Martus, H.J., Gossen, J.A., Boerrigter, M.E. and Vijg, J. (1996) Evaluation of a plasmidbased transgenic mouse model for detecting in vivo mutations. Mutagenesis, 11, 111-118.

12. Melis, J.P., Wijnhoven, S.W., Beems, R.B., Roodbergen, M., van den Berg, J., Moon, H., Friedberg, E., van der Horst, G.T., Hoeijmakers, J.H., Vijg, J. and van Steeg, H. (2008) Mouse models for xeroderma pigmentosum group $\mathrm{A}$ and group $\mathrm{C}$ show divergent cancer phenotypes. Cancer Res, 68, 1347-1353.

13. Revel, A., Raanani, H., Younglai, E., Xu, J., Han, R., Savouret, J.F. and Casper, R.F. (2001) Resveratrol, a natural aryl hydrocarbon receptor antagonist, protects sperm from DNA damage and apoptosis caused by benzo(a)pyrene. Reprod Toxicol, 15, 479-486.

14. Yauk, C.L., Berndt, M.L., Williams, A., Rowan-Carroll, A., Douglas, G.R. and Stampfli, M.R. (2007) Mainstream tobacco smoke causes paternal germ-line DNA mutation. Cancer Res, 67, 5103-5106.

15. Yauk, C., Polyzos, A., Rowan-Carroll, A., Somers, C.M., Godschalk, R.W., Van Schooten, F.J., Berndt, M.L., Pogribny, I.P., Koturbash, I., Williams, A., Douglas, G.R. and Kovalchuk, O. (2008) Germ-line mutations, DNA damage, and global hypermethylation in mice exposed to particulate air pollution in an urban/industrial location. Proc Natl Acad Sci U S A, 105, 605-610.

16. Olsen, A.K., Andreassen, A., Singh, R., Wiger, R., Duale, N., Farmer, P.B. and Brunborg, G. Environmental exposure of the mouse germ line: DNA adducts in spermatozoa and formation of de novo mutations during spermatogenesis. PLOS ONE, 5, e11349. 




\section{Samenvatting en algemene discussie}


Benzo(a)pyreen (B[a]P) staat bekend als een milieu- en beroepsmatige verontreinigende stof, waaraan iedereen regelmatig wordt blootgesteld. Na opname wordt $\mathrm{B}[\mathrm{a}] \mathrm{P}$ in het lichaam omgezet in verbindingen die kunnen worden uitgescheiden in de urine of feces. Hierbij worden echter af en toe actieve verbindingen gevormd die aan het DNA kunnen binden en zogenaamde DNA-adducten kunnen vormen. Deze DNAadducten kunnen leiden tot het ontstaan van mutaties en daaropvolgend tot de ontwikkeling van kanker, tenzij ze worden verwijderd door DNA-herstelmechanismen. Naast de bekende mutagene en carcinogene werking in somatische cellen kan B[a]P ook invloed hebben op het DNA in de reproductieve weefsels en mannelijke geslachtscellen, waardoor de gezondheidsrisico's voor het nageslacht mogelijk worden verhoogd. De richtlijnen van de Europese Gemeenschap (EG) voor genotoxiciteit in het kader van REACH vereist dat chemische stoffen moeten worden getest op mutageniteit in geslachtscellen als ze mutageen zijn in somatische cellen. Aangezien de resultaten van de klassieke mutageniteitstesten geen uitsluitsel geven en polycyclische aromatische koolwaterstoffen (PAKs) kiembaanmutaties blijken te induceren in vrijlevende dieren blootgesteld aan verontreinigde buitenlucht, zal B[a]P moeten worden getest voor de mutagene werking in mannelijke geslachtscellen. In dit proefschrift evalueerden we $\mathrm{B}[\mathrm{a}] \mathrm{P}$ als een potentiele kiembaanmutageen en onderzochten we of DNA-herstel een relevant beschermend moleculair mechanisme vertegenwoordigt dat invloed kan hebben op de relatie tussen DNA-adductvorming en het ontstaan van kiembaanmutaties.

\section{DNA-adduct kinetiek in testis en mannelijke geslachtscellen}

In de eerste studie (hoofdstuk 3), onderzochten we de DNA-beschadigende effecten van $B[a] P$ in de testis en geslachtscellen van blootgestelde mannelijke muizen, en de verwijdering van de door B[a]P-geïnduceerde DNA-schade door het globale genoomherstel (GGR) dat een onderdeel is van het nucleotide-excisie herstel (NER). Wild type $(\mathrm{Wt})$ en $X p c^{-/-}$mannelijke muizen werden blootgesteld aan een eenmalige dosis $\mathrm{B}[\mathrm{a}] \mathrm{P}$ en werden opgeofferd op dag 1, 4, 7, 10, 14, 21, 32 en 42 na blootstelling om de vorming en verwijdering van DNA-adducten te bestuderen tijdens de verschillende stadia van de spermatogenese. Aangezien de spermatogenese in muizen 42 dagen duurt, zal de meting in geslachtscellen op dag 42 na de blootstelling DNA-adducten vertegenwoordigen die gevormd werden in blootgestelde spermatogoniale stamcellen of vroege type A spermatogonia. DNA-adduct kinetiek werd vergeleken tussen de aan $\mathrm{B}[\mathrm{a}] \mathrm{P}$-blootgestelde $\mathrm{Wt}$ en $\mathrm{Xp} \mathrm{c}^{-/-}$mannelijke muizen om de bijdrage van GGR/NER bij de verwijdering van DNA-schade in testis en mannelijke geslachtscellen te bestuderen. Voor onze studies hebben we gebruik gemaakt van $\mathrm{Xpc}^{-\gamma_{-}}$muizen in plaats van $\mathrm{Xpa}^{-/-}$muizen, omdat eerder al was aangetoond dat $X \mathrm{pa}^{-/-}$muizen hoogstwaarschijnlijk te gevoelig zijn voor blootstelling aan stoffen die omvangrijke DNA-adducten kunnen vormen [1]. De waargenomen toxiciteit in $\mathrm{Xpa}^{-/-}$muizen werd voornamelijk veroorzaakt door het ontbreken van het transcriptie-gekoppelde herstel (TCR), dat ook onderdeel is van NER. Om ongewenste toxiciteit in onze studies te voorkomen, hebben we gekozen voor $X p c^{-/-}$muizen, die deficiënt zijn voor GGR/NER, maar nog steeds actieve TCR/NER bezitten.

DNA-adducten werden aangetroffen in testes en in alle stadia van de spermatogenese. Testes van $X p c^{-/-}$muizen bevatten over de gehele observatieperiode van 42 dagen hogere DNA-adductniveaus in vergelijking met de 
testes van Wt muizen. Ook werd er tussen $\mathrm{Wt}$ en $X p c^{-/-}$muizen een verschil in de halfwaardetijd van adducten waargenomen, met meer stabiele DNA-adducten in $X p c^{-/-}$ muizen. Deze bevindingen veronderstellen dat er een belangrijke rol is voor GGR/NER bij het verwijderen van DNA-adducten in de testis. In de geslachtscellen waren de DNA-adductniveaus alleen op dag 42 significant hoger in $\mathrm{Xpc}^{-/-}$muizen in vergelijking met $\mathrm{Wt}$ muizen. Op dit tijdstip werden DNA-adducten gemeten in geslachtscellen die zich hebben ontwikkeld uit blootgestelde spermatogoniale stamcellen of uit cellen die zich in een vroeg stadium van de mitotische spermatogenese bevonden op het moment van blootstelling. Deze cellen hebben de kans gehad om zich meerdere keren te delen en om zich te herstellen van de schade door DNA-herstelmechanismen. Het was ook interessant om te zien dat zelfs in Wt muizen DNA-adducten nog steeds detecteerbaar waren op 6 weken na de blootstelling, hoewel de niveaus significant lager waren in vergelijking met de $\mathrm{Xpc}^{-/-}$ muizen. De resultaten in de geslachtscellen veronderstellen dat het oorspronkelijke niveau van DNA-schade in spermatogonia relatief hoog moet zijn geweest en dat accurate DNA-herstelmechanismen, zoals GGR/NER, belangrijk zijn voor een efficiënte verwijdering van deze DNA-schade. DNA-adducten werden ook kort na de blootstelling ontdekt in volgroeide spermatozoa, waarvan wordt gedacht dat ze eigenlijk niet in staat zijn om B[a]P metabool te activeren. Deze volgroeide cellen zijn echter omgeven door cellen die wel B[a]P kunnen metaboliseren (bijvoorbeeld Sertoli cellen of epididymale epitheel cellen), waardoor de reactieve metabolieten van $B[a] P$ de geslachtscellen konden bereiken. DNA-schade die niet wordt verwijderd gedurende de spermatogenese kan leiden tot de vorming van kiembaanmutaties, maar deze schade kan ook blijven bestaan tot aan de bevruchting en invloed hebben op de groei en ontwikkeling van het embryo. Studies toonden reeds de overdracht van $\mathrm{B}[\mathrm{a}] \mathrm{P}$-geïnduceerde DNA-adducten aan in geslachtscellen van rokende vaders naar de bevruchte eicel en DNA-adducten werden vervolgens ook aangetroffen in embryo's [2]. Verder is er een relatie gevonden tussen blootstelling aan milieufactoren en intra-uteriene groeivertraging in de eerste maanden van de zwangerschap [3]. Het is aangetoond dat DNA-beschadigde spermacellen in staat zijn om eicellen te bevruchten, ongeacht de mate van DNA-schade, maar de embryonale ontwikkeling wordt wel beïnvloed door de mate van DNA-schade [4]. Gelukkig heeft de eicel het vermogen om beschadigd DNA, afkomstig van spermacellen, te repareren wanneer deze minder dan $8 \%$ is beschadigd; schade boven dit niveau zal de embryonale ontwikkeling beïnvloeden en de kans op een abortus verhogen [4].

Hoewel de DNA-schade in volgroeide spermatozoa de gezondheid van nakomelingen kan beïnvloeden, is DNA-schade in spermatogoniale stamcellen mogelijk een belangrijker probleem. DNA schade in deze cellen kan worden omgezet naar mutaties die vervolgens een oneindig aantal generaties erna kan beïnvloeden.

\section{$\mathrm{B}[\mathrm{a}] \mathrm{P}$-geïnduceerde genexpressieveranderingen in testis}

In hoofdstuk 3 hebben we laten zien dat B[a]P-geïnduceerde DNA-adducten niet efficiënt werden verwijderd van het DNA in testis en geslachtscellen van $X p c^{-/-}$ muizen, hoewel van geslachtscellen wordt gedacht dat ze goed beschermd zijn tegen zulke blootstellingen door een complex netwerk van moleculaire mechanismen. Stress-geïnduceerde eiwitten blijken inderdaad een belangrijke rol in de spermatogenese te spelen. Zo werden heat-shock eiwitten gevonden die worden 
gestimuleerd in antwoord op stress uit de omgeving, maar ze blijken ook essentieel te zijn voor een normale gametogenese; bij muizen die homozygoot zijn voor een deletie in het Hsp70-2 gen zijn de spermatocyten niet in staat om de meiotische profase te voltooien waardoor ze in apoptose gaan [5]. Hsp70-2 beschermt mogelijk de geslachtscellen in combinatie met het tumorsuppressorgen p53, zodat het doorgeven van DNA-schade aan dochtercellen wordt voorkomen door efficiënte reparatie tijdens een stop van de celcyclus of het induceren van geprogrammeerde celdood, oftewel apoptose [6]. In de muis komt p53 tot expressie tijdens de meiotische profase in spermatocyten, en lijkt $p 53$ belangrijk voor de normale spermatogenese, omdat testes van muizen met een verminderde expressie van p53 histologisch abnormaal zijn [7]. Met andere woorden, het lijkt erop dat genen die meestal gerelateerd zijn aan cellulaire stressreacties belangrijk zijn voor de normale gametogenese, zelfs bij het ontbreken van een blootstelling aan genotoxische stoffen. Om de stressreacties na B[a]P-blootstelling in de testis verder te onthullen, onderzochten we de door $\mathrm{B}[\mathrm{a}] \mathrm{P}$ veroorzaakte veranderingen in genexpressie in testes van $\mathrm{Wt}$ en $X p c^{-/-}$mannelijke muizen (hoofdstuk 4). Omdat $X p c^{-/-}$muizen gebrekkig zijn in GGR/NER, wat wordt beschouwd als één van de belangrijkste beschermingsmechanismen tegen $\mathrm{B}[\mathrm{a}] \mathrm{P}$-geïnduceerde DNA-schade, verwachtten we een andere (adaptieve) transcriptionele reactie in deze muizen in vergelijking met Wt muizen om te compenseren voor het gebrek aan DNA-herstelactiviteit. Hoewel genexpressieniveaus sterk vergelijkbaar waren in onbehandelde $\mathrm{Wt}$ en $\mathrm{Xpc}^{-/-}$muizen en $\mathrm{B}[\mathrm{a}] \mathrm{P}$ vergelijkbare genexpressieveranderingen induceerde in de muizen van beide genotypen, verschilde de mate waarin deze $\mathrm{B}[\mathrm{a}] \mathrm{P}$-gereguleerde genen tot expressie kwamen aanzienlijk tussen Wt en $X p c^{-/-}$muizen $(p=0,000000141)$, met in totaal een hogere expressie in $X p c^{-/-}$muizen in vergelijking met Wt muizen. Deze verschillen werden voornamelijk gevonden in de regulering van de celcyclus, maar ook op het niveau van de translatie, chromatine structuur en de spermatogenese, wat inderdaad indicatief is voor een algemene reactie op cellulaire stress. Uit analyse van de celcyclusfase-afhankelijke genexpressie bleek dat de expressie van genen die betrokken zijn bij de G1/S- en G2/M-controle was toegenomen na B[a]Pblootstelling in beide genotypen.

Een iets hogere inductie van de gemiddelde genexpressie werd waargenomen bij de G2/M-controle in $X p c^{-/-}$muizen, maar dit bleek statistisch niet significant ( $p=$ $0,086)$. Statistische significantie werd bereikt wanneer de analyse werd uitgevoerd op alleen hoger gereguleerde genen binnen deze fase $(p=0,024)$, waarbij een hogere inductie van de G2/M-controlegenen in $X p c^{-/-}$muizen werd aangetoond. Dit geeft aan dat de aanwezigheid van niet-herstelde DNA-schade in testis de celproliferatie blokkeert om zo de integriteit van het DNA in zowel $\mathrm{Wt}$ als $X p c^{-/-}$muizen te beschermen, wat een normale reactie is die niet afwijkt van somatische cellen. Het verschil tussen de Wt en $\mathrm{Xpc}^{-/-}$muizen in $\mathrm{B}[\mathrm{a}] \mathrm{P}$-geïnduceerde genexpressieniveaus binnen de G2/M-controle kan mogelijk worden toegeschreven aan meer ernstig beschadigde cellen in de testes van $\mathrm{Xpc}^{-/-}$muizen in plaats van een sterkere reactie in elke individuele cel. Niet-herstelde DNA-schade kan de celcyclus blokkeren in de late S-fase, totdat het wordt voorbijgegaan in een fout-vrije of fout-inducerende manier met vervolgens progressie van de celcyclus en spermatogenese. Uiteindelijk lijken geslachtscellen hun proliferatie zelfs in de aanwezigheid van DNA-schade te continueren, omdat we eerder hebben vastgesteld dat DNA-adducten kunnen worden meegedragen tijdens de spermatogenese (hoofdstuk 3). Y-familie 
polymerasen kunnen de door DNA-schade geblokkeerde replicatievorken passeren. Polymerase $\mathrm{k}$ komt bijvoorbeeld hoog tot expressie in geslachtscellen en kopieert door $\mathrm{B}[\mathrm{a}] \mathrm{P}$ beschadigd DNA in een fout-vrije manier. Onbeschadigde of minder beschadigde cellen waarvan de DNA-schade nog steeds kan worden verwijderd, wat waarschijnlijk het geval is in Wt muizen, kunnen de celcyclus makkelijker continueren en tonen als gevolg een lager expressieniveau van de G2/M-controle genen.

Andere processen die werden verwacht te zijn veranderd door de blootstelling, zoals apoptose en andere DNA-herstelprocessen dan GGR/NER, werden niet gedifferentieerd op het niveau van genexpressie. Echter, dit betekent niet dat deze processen niet beïnvloed werden door de B[a]P-blootstelling. Andere aspecten kunnen een rol hebben gespeeld bij de activatie van apoptose; 1) het grote aantal apoptotische cellen in de normale testis zal het moeilijk maken om subtiele veranderingen in de apoptotische respons na een $\mathrm{B}[\mathrm{a}] \mathrm{P}$-blootstelling te meten, 2) de apoptotische respons na $\mathrm{B}[\mathrm{a}] \mathrm{P}$-blootstelling is een acute respons die waarschijnlijk moeilijk is vast te stellen 4 dagen na de blootstelling, en 3) de activering van verschillende caspasen die leiden tot fragmentatie van het DNA gebeurt door splitsing van pro-caspasen die reeds zijn opgeslagen in de cel; een proces dat waarschijnlijk niet te meten is op transcriptioneel niveau [8]. Dit laatste aspect kan ook het geval zijn voor DNA-herstelmechanismen, die ook afhankelijk zijn van activering en transport van al aanwezige eiwitten.

\section{Mutagene effecten van benzo(a)pyreen in spermacellen}

$\mathrm{B}[\mathrm{a}] \mathrm{P}$ werd uitgebreid bestudeerd sinds haar ontdekking in 1930 en het is duidelijk dat $\mathrm{B}[\mathrm{a}] \mathrm{P}$ DNA-beschadigende en mutagene effecten heeft. Het is echter minder duidelijk of $\mathrm{B}[\mathrm{a}] \mathrm{P}$ in vivo mutaties induceert in geslachtscellen. In hoofdstuk 3 vonden we dat B[a]P-geïnduceerde DNA-adducten in spermatogoniale stamcellen van blootgestelde mannelijke muizen niet volledig waren verwijderd binnen 42 dagen na de blootstelling. Dit geeft aan dat DNA-schade aanwezig is tijdens de mitotische expansie van geslachtscellen en de daaropvolgende meiose, waarin de mogelijkheid bestaat dat DNA-schade wordt omgezet in erfelijke genmutaties. Bovendien suggereerden recente studies met dieren blootgesteld aan verontreinigde omgevingslucht, dat PAK's mutageen kunnen zijn in mannelijke geslachtscellen [9, 10]. Daarom hebben we in hoofdstuk 5 onderzocht of $B[a] P$ in staat was om genmutaties te induceren in de testis en spermacellen van Wt en $\mathrm{Xpc}^{-/-}$muizen. Om dit te onderzoeken gebruikten we muizen die een plasmide-gebaseerde shuttlevector bevatten met meerdere kopieën van het lacZ-reportergen geïntegreerd in een nekaan-staart-organisatie in hun genoom [11]. Het gebruik van dit transgene muismodel maakt het kwantificeren en karakteriseren van mutaties in de verschillende organen en weefsels mogelijk gedurende de levensduur van een dier, en laat de detectie van deleties, puntmutaties en chromosomale herschikkingen toe. DNA-beschadigingen veroorzaakt door B[a]P zijn voornamelijk puntmutaties, en daarom is dit model geschikt om de mutagene effecten van $\mathrm{B}[\mathrm{a}] \mathrm{P}$ in de reproductieve weefsels en spermacellen te beoordelen in een in vivo situatie. De bruikbaarheid van dit diermodel werd ook aangetoond door een positieve reactie bij dieren die blootgesteld werden aan de bekende kiemcelmutagene stof ethylnitrosoureum (ENU).

Muizen werden 6 weken na de laatste B[a]P-blootstelling opgeofferd om geslachtscellen te verkrijgen uit blootgestelde spermatogoniale stamcellen. 
Succesvolle blootstelling werd bevestigd door een dosis- en tijdsafhankelijke toename in mutantfrequentie in het bekende doelorgaan de milt, met hogere mutantfrequenties in $X p c^{-/-}$muizen in vergelijking met $\mathrm{Wt}$ muizen. Hoewel $\mathrm{B}[\mathrm{a}] \mathrm{P}$ gerelateerde DNA-adducten werden gedetecteerd in testes, werden geen verhoogde mutantfrequenties in dit weefsel teruggevonden. Aan de andere kant, B[a]P verhoogde de mutantfrequenties wel in het sperma van Wt muizen na 6 weken blootstelling, terwijl een dergelijke stijging niet werd teruggevonden in $X p c^{-/-}$muizen. Deze resultaten waren in tegenstelling tot wat we veronderstelden, omdat werd verwacht dat de $X p c^{---}$muis een gevoeliger model zou zijn voor het bestuderen van mutatie-inductie [12]. Daarbij waren de DNA-adductniveaus in $\mathrm{Xpc}^{-/-}$muizen significant hoger op dag 42 na een eenmalige blootstelling (die spermatogoniale stamcellen vertegenwoordigen) in vergelijking met Wt muizen (hoofdstuk 3). Er moet nog worden onderzocht waarom $\mathrm{Xpc}^{-/-}$muizen niet ontvankelijk waren voor de inductie van mutanten na $\mathrm{B}[\mathrm{a}] \mathrm{P}$-blootstelling. Wij vermoeden dat cytotoxiciteit geïnduceerd door $\mathrm{B}[\mathrm{a}] \mathrm{P}$ in de ontwikkelende geslachtscellen een rol kan spelen bij het ontbreken van de mutagene effecten in de $X p c^{-/-}$muizen. Eerdere studies toonden aan dat hoge blootstelling aan B[a]P kan leiden tot onvruchtbaarheid als gevolg van cytotoxiciteit van B[a]P voor spermatogonia [13]. In onze studie werd geen steriliteit geïnduceerd, aangezien de blootgestelde muizen nakomelingen produceerden. Echter, dezelfde 6 weken blootstelling toegediend aan de voor DNA-schade gevoeligere $X p c^{-/-}$muizen resulteerde wel in een aanzienlijke daling van het aantal nakomelingen, wat een indicatie voor cytotoxiciteit kan zijn. Bovendien kan zich een selectie van de cellen hebben voorgedaan door begunstiging van deze cellen die niet zwaar werden beschadigd en als gevolg daarvan kunnen geen verhoogde mutantfrequenties worden opgespoord. Het is interessant voor toekomstige studies om te onderzoeken of DNA-schade inderdaad niet homogeen verspreid is over de testis, die een selectie van minder beschadigde cellen mogelijk zou maken.

Histopathologische analyse van de testis zal worden uitgevoerd om deze hypothese te bevestigen en toekomstige studies moeten uitwijzen of blootstelling aan $\mathrm{B}[\mathrm{a}] \mathrm{P}$ ook de nestgrootte (worpen) van Wt mannelijke muizen vermindert. Voor nu kunnen we concluderen dat $\mathrm{B}[\mathrm{a}] \mathrm{P}$ genmutaties kan induceren in spermatogoniale stamcellen van muizen. Het is waarschijnlijk dat deze mutaties worden doorgegeven aan het nageslacht, omdat ze werden ontdekt in volgroeide spermatozoa die aanwezig waren in de epididymes en voorbereid waren voor conceptie. Alleen selectie tijdens of na de bevruchting kan het bestaan van deze mutaties in het nageslacht voorkomen.

\section{Erfelijke mutaties in het nageslacht van muizen}

Hoewel we hebben aangetoond dat $\mathrm{B}[\mathrm{a}] \mathrm{P}$ mutaties kan induceren in spermatogoniale stamcellen (hoofdstuk 5) blijft het onduidelijk of deze mutaties worden doorgegeven aan het nageslacht. Deze mogelijkheid kan afhangen van de dosis en de blootstellingsduur die de kiemcellen aantasten; een hoge dosis en een lange-termijn blootstelling aan $\mathrm{B}[\mathrm{a}] \mathrm{P}$ kunnen cytotoxisch zijn voor geslachtscellen [13]. In hoofdstuk 5 vonden we dat mutaties die geïnduceerd werden in spermatogoniale stamcellen nog aanwezig zijn in volgroeide spermatozoa uit de epididymes van Wt muizen, maar niet van $X p c^{-/-}$muizen. De combinatie van blootstelling, 
blootstellingsduur en de genetische achtergrond van het diermodel kan dus van invloed zijn op de uitkomst van het experiment.

Het is onwaarschijnlijk dat het lacZ-muismodel kan worden gebruikt om mutaties te bestuderen in het nageslacht, omdat de mutantfrequentie te laag is en een te groot aantal nakomelingen nodig zou zijn om de overdracht van deze mutaties met voldoende statistische kracht op te sporen. Daarom hebben we gebruik gemaakt van een gevoelige methode om zogenaamde Expanded Simple Tandem Repeat (ESTR) mutatiefrequenties in DNA-profielen van de nakomelingen te analyseren, welke is beschreven in hoofdstuk 2, in combinatie met het DNA-hersteldeficiënte $\left(X p c^{--/}\right)$ muismodel. De analyse van ESTR-mutaties blijkt een succesvolle methode te zijn voor de analyse van overdraagbare mutaties in de nakomelingen van dieren en mensen (zie hoofdstuk 2). In vergelijking met de klassieke mutageniteitstesten is de analyse van ESTR-mutaties een gevoeligere methode dat minder dieren eist, minder tijd in beslag neemt en meer kosteneffectief is. Echter, de nadelen van deze test zijn dat slechts enkele laboratoria zijn uitgerust om de analyse uit te voeren, dat het mutatie-inductie meet in niet-coderend DNA zonder fenotypische effecten, en dat het mechanisme van mutatie-inductie grotendeels nog onbekend is. Verondersteld wordt dat Tandem Repeat mutaties ontstaan door een indirect mechanisme van mutatieinductie [14]. Toch hebben we gekozen voor deze methode, omdat het succesvol is toegepast als een kiembaanmutageniteitstest.

De resultaten van deze experimentele studie toonden aan dat $\mathrm{B}[\mathrm{a}] \mathrm{P}$-blootstelling de ESTR-mutatiefrequenties niet verhogen in nakomelingen van $\mathrm{B}[\mathrm{a}] \mathrm{P}$-blootgestelde mannelijke $X p c^{-/-}$muizen in vergelijking met de nakomelingen van de mannelijke controlemuizen ( $p=0,91$, hoofdstuk 6). In feite, vaderlijke en moederlijke mutatiefrequenties waren zelfs 1,4 keer hoger bij de nakomelingen van de mannelijke controlemuizen. Hoewel deze resultaten in overeenstemming zijn met het gebrek aan respons, gevonden in hoofdstuk $\mathbf{5}$ en een correlatie werd gevonden tussen ESTR-mutaties en lacZ-mutantfrequenties, moet nog worden opgehelderd waarom het $\mathrm{Xpc}^{-/-}$muismodel niet reageert in de richting van mutatie-inductie in reproductieve weefsels na $\mathrm{B}[\mathrm{a}] \mathrm{P}$-blootstelling. We hebben al verondersteld dat het ontbreken van een reactie wordt veroorzaakt door B[a]P-geïnduceerde cytotoxiciteit in de geslachtscellen, aangezien het aantal nakomelingen significant lager was na de $\mathrm{B}[\mathrm{a}] \mathrm{P}$-blootstelling in vergelijking met de controlegroep. Bovendien namen de DNAadductniveaus in testis af na 6 weken chronische blootstelling in vergelijking tot 4 weken chronische blootstelling, terwijl een verdere ophoping van DNA-schade werd verwacht. Dit veronderstelt dat testis en geslachtscellen met hoge DNAschadeniveaus apoptose/necrose ondergaan en zodoende de DNA-adductniveaus en mogelijk ook het aantal mutaties verlagen. Aan de andere kant, de apoptotische pathway werd niet als gedifferentieerd gevonden op het niveau van de genexpressie (hoofdstuk 4) na acute blootstelling aan een enkele dosis B[a]P. Derhalve kan niet worden uitgesloten dat er andere processen betrokken zijn bij dit gebrek aan effect. Bijvoorbeeld, genexpressie-analyse toonde ook dat B[a]P-blootstelling invloed heeft op de mitochondriële functie en oxidatieve fosforylering, die indicatief zijn voor een verminderde beweeglijkheid en bevruchtend vermogen van het sperma (hoofdstuk 4). Van B[a]P-blootstelling is inderdaad bekend dat het de spermatogenese beïnvloed door verminderde beweeglijkheid en lagere spermaconcentraties. Maar ook epigenetische veranderingen die het methyleringspatroon aanpassen kunnen de 
spermatogenese en daarmee de kwaliteit en het bevruchtend vermogen van de geslachtcellen beïnvloeden [15].

Voor toekomstige studie's is het aan te bevelen om het aantal nakomelingen uit te breiden, omdat dit de betrouwbaarheid van de resultaten verbetert. Ten minste 100, maar bij voorkeur meer nakomelingen dienen per groep te worden getest om significante resultaten te behalen. Helaas was dit aantal niet bereikt in deze experimentele studie waarin 55 en 65 nakomelingen, in respectievelijk de B[a]Pblootgestelde en controlegroep, werden getest. Aangezien een significante lacZmutantinductie werd gevonden in spermacellen na 6 weken blootstelling en 6 weken herstel, wordt ook voorgesteld om de vorming van B[a]P-geïnduceerde kiembaanmutaties in het nageslacht van de blootgestelde Wt muizen te bestuderen. Deze resultaten kunnen verder uitwijzen of $\mathrm{B}[\mathrm{a}] \mathrm{P}$ inderdaad kan worden geclassificeerd als een kiembaanmutageen, die de gezondheid van het nageslacht aantast.

\section{Algemene conclusie}

Uit de resultaten van dit proefschrift kan worden geconcludeerd dat B[a]P DNAbeschadigende effecten bezit in de testis en met name mannelijke geslachtscellen, en dat XPC, een belangrijk eiwit in GGR/NER, een belangrijke rol speelt in de efficiënte verwijdering van $\mathrm{B}[\mathrm{a}] \mathrm{P}$-geïnduceerde DNA-adducten in deze geslachtscellen. Desalniettemin, in antwoord op B[a]P-blootstelling waren de genexpressieveranderingen relatief hetzelfde in testes van $\mathrm{Wt}$ en $\mathrm{Xpc}^{-/}$muizen, waaruit blijkt dat voornamelijk de celcyclus is geblokkeerd om extra tijd te geven voor herstel. Aangezien $X_{p c}^{-/-}$muizen gebrekkig zijn in het meest belangrijke herstelmechanisme voor $\mathrm{B}[\mathrm{a}] \mathrm{P}$-geïnduceerde DNA-schade, is de celcyclus meer tegengehouden in testes van $X p c^{-/-}$muizen dan van $\mathrm{Wt}$ muizen, met name in de overgang van de G2-fase naar de M-fase.

$\mathrm{B}[\mathrm{a}] \mathrm{P}$-geïnduceerde mutatie-inductie werd alleen waargenomen in spermacellen van blootgestelde $\mathrm{Wt}$ muizen, wat in feite neerkomt op kiembaanmutaties in spermatogoniale stamcellen. Onze resultaten werden onlangs bevestigd in een artikel van Olsen et al., waarin zij aantoonden dat de novo mutaties waren geïnduceerd in spermatozoa, afkomstig van B[a]P-blootgestelde (3 x $50 \mathrm{mg} / \mathrm{kg} \mathrm{bw})$ spermatogonia [16]. Karakterisering van de mutaties uit blootgestelde spermatogonia toonde verhoogde niveaus van GC-TA transversies, die voornamelijk worden geproduceerd door $\mathrm{B}[\mathrm{a}] \mathrm{P}$-geinduceerde DNA-schade. In onze studies leken $\mathrm{Xpc}^{-/-}$muizen te gevoelig voor een subchronische blootstelling aan $\mathrm{B}[\mathrm{a}] \mathrm{P}$, die heeft kunnen leiden tot cytotoxiciteit. Toekomstig onderzoek dient het aantal geteste nakomelingen uit te breiden en erfelijke mutaties in de nakomelingen van aan B[a]P-blootgestelde mannelijke muizen verder te evalueren. 


\section{Referenties}

1. Klein, J.C., Beems, R.B., Zwart, P.E., Hamzink, M., Zomer, G., van Steeg, H. and van Kreijl, C.F. (2001) Intestinal toxicity and carcinogenic potential of the food mutagen 2-amino-1-methyl-6-phenylimidazo[4,5b]pyridine (PhIP) in DNA repair deficient XPA-/- mice. Carcinogenesis, 22, 619-626.

2. Zenzes, M.T., Puy, L.A., Bielecki, R. and Reed, T.E. (1999) Detection of benzo[a]pyrene diol epoxideDNA adducts in embryos from smoking couples: evidence for transmission by spermatozoa. Mol Hum Reprod, 5, 125-131.

3. Srm, R.J., Binkov, B., Rssner, P., Rubes, J., Topinka, J. and Dejmek, J. (1999) Adverse reproductive outcomes from exposure to environmental mutagens. Mutation research, 428, 203-215.

4. Ahmadi, A. and Ng, S.C. (1999) Fertilizing ability of DNA-damaged spermatozoa. Journal of experimental zoology, 284, 696-704.

5. Dix, D.J. (1997) Hsp70 expression and function during gametogenesis. Cell stress \& chaperones, 2, 7377.

6. Smith, M.L. and Fornace, A.J., Jr. (1996) The two faces of tumor suppressor p53. The American journal of pathology, 148, 1019-1022.

7. Rotter, V., Schwartz, D., Almon, E., Goldfinger, N., Kapon, A., Meshorer, A., Donehower, L.A. and Levine, A.J. (1993) Mice with reduced levels of p53 protein exhibit the testicular giant-cell degenerative syndrome. Proc Natl Acad Sci U S A, 90, 9075-9079.

8. Boatright, K.M. and Salvesen, G.S. (2003) Mechanisms of caspase activation. Current opinion in cell biology, 15, 725-731.

9. Somers, C.M., Yauk, C.L., White, P.A., Parfett, C.L. and Quinn, J.S. (2002) Air pollution induces heritable DNA mutations. Proc Natl Acad Sci USA, 99, 15904-15907.

10. Somers, C.M., McCarry, B.E., Malek, F. and Quinn, J.S. (2004) Reduction of particulate air pollution lowers the risk of heritable mutations in mice. Science, 304, 1008-1010.

11. Dolle, M.E., Martus, H.J., Gossen, J.A., Boerrigter, M.E. and Vijg, J. (1996) Evaluation of a plasmidbased transgenic mouse model for detecting in vivo mutations. Mutagenesis, 11, 111-118.

12. Melis, J.P., Wijnhoven, S.W., Beems, R.B., Roodbergen, M., van den Berg, J., Moon, H., Friedberg, E., van der Horst, G.T., Hoeijmakers, J.H., Vijg, J. and van Steeg, H. (2008) Mouse models for xeroderma pigmentosum group $A$ and group $C$ show divergent cancer phenotypes. Cancer Res, 68, 1347-1353.

13. Revel, A., Raanani, H., Younglai, E., Xu, J., Han, R., Savouret, J.F. and Casper, R.F. (2001) Resveratrol, a natural aryl hydrocarbon receptor antagonist, protects sperm from DNA damage and apoptosis caused by benzo(a)pyrene. Reprod Toxicol, 15, 479-486.

14. Yauk, C.L., Berndt, M.L., Williams, A., Rowan-Carroll, A., Douglas, G.R. and Stampfli, M.R. (2007) Mainstream tobacco smoke causes paternal germ-line DNA mutation. Cancer Res, 67, 5103-5106.

15. Yauk, C., Polyzos, A., Rowan-Carroll, A., Somers, C.M., Godschalk, R.W., Van Schooten, F.J., Berndt, M.L., Pogribny, I.P., Koturbash, I., Williams, A., Douglas, G.R. and Kovalchuk, O. (2008) Germ-line mutations, DNA damage, and global hypermethylation in mice exposed to particulate air pollution in an urban/industrial location. Proc Natl Acad Sci U S A, 105, 605-610.

16. Olsen, A.K., Andreassen, A., Singh, R., Wiger, R., Duale, N., Farmer, P.B. and Brunborg, G. Environmental exposure of the mouse germ line: DNA adducts in spermatozoa and formation of de novo mutations during spermatogenesis. PLOS ONE, 5, e11349. 

Dankwoord 


\section{Deze promotie werd mede mogelijk gemaakt door...}

De promoters, prof. dr. Frederik-Jan van Schooten en prof. dr. Harry van Steeg.

Beste Frederik-Jan en Harry, allereerst wil ik jullie bedanken voor de prettige samenwerking die jullie zijn aangegaan binnen dit project. De afstand tussen Maastricht en Bilthoven gecombineerd met drukke agenda's, maakte het plannen van een overleg gelukkig niet onmogelijk. Of het overleg in Maastricht of Bilthoven was, maakte mij niet veel uit, ik heb ze als zeer zinvol ervaren. Frederik-Jan, bedankt voor de begeleiding gedurende het gehele project en de reis naar Canada. Door jou kon ik de rode draad door het verhaal volgen en het overzicht bewaren. Harry, bedankt voor het inbrengen van je wetenschappelijke kennis en 'andere' kijk op het onderzoek. Je bracht me altijd weer op nieuwe ideeën.

De co-promoters, dr. Roger Godschalk en dr. Jan van Benthem.

Beste Roger, bedankt voor het vertrouwen dat je in me hebt gehad om me je winnende CEFIC-project te laten uitvoeren. Met deze prijs is mijn promotieproject als zodanig van de grond gekomen. Tevens wil ik je bedanken voor de begeleiding, je enthousiasme en het feit dat je deur altijd open stond. Een kort gesprek bracht me altijd weer stappen verder. Beste Jan, bedankt voor je medewerking aan dit project, voor alle project aanvragen bij de Dier Experimenten Commissie (DEC) en voor je belangstelling en overige hulp als ik weer in Maastricht was. Ook al ben je officieel geen co-promoter, voor mij ben je dat wel.

De leden van de beoordelingscommissie. Ik wil prof. dr. J.G.R. de Mey, dr. G. Brunborg, dr. C.T.A. Evelo, prof. dr. J.C.S. Kleinjans en prof. dr. A.H. Piersma, bedanken voor het beoordelen van mijn proefschrift.

The co-authors. Dear Yuri, thank you for your contribution to the review paper, for providing the minisatellite protocol en the crash course on your lab in Leicester. Dear Carole, thank you for inviting Joost and me to visit your lab at Health Canada, so I could run all my samples in a month. I was amazed by your intelligence and knowledge of the pedigree analysis. Without your help, and the help of Andrea and Caitlin, I would not have finished chapter 6 on time.

De collega's van GRAT. Ik wil jullie allemaal hartelijk bedanken voor de plezierige samenwerking en gezellige tijd bij GRAT. Op kamer 4.106 heb ik het altijd naar mijn zin gehad, mede dankzij mijn kamergenootjes. Yvonne, Sabine, Nejla en Karen, ik wil jullie met name bedanken voor al jullie interesse, behulpzaamheid en de nodige gesprekken, tijdens en na werktijd. Kirsten, bedankt voor het carpoolen. Het carpoolen heeft de start vanuit Eindhoven zeker makkelijker gemaakt. Lou, bedankt voor het leren van het postlabellen en het genereren van de postlabelresultaten uit hoofdstuk 5. Marcel en Ralph, bedankt voor jullie hulp bij de microarrayexperimenten. Daniëlle, bedankt voor de snelle qPCR-resultaten. Marie-Claire, bedankt voor alle antwoorden op mijn vragen en het uitvoeren van de administratieve klusjes.

De collega's van het RIVM. Ik wil jullie allemaal bedanken voor jullie openheid, behulpzaamheid en gezellige pauzes als ik weer eens wat experimenten kwam doen bij GBO. Conny, ik wil met name jou bedanken voor al het werk dat je in mijn project 
hebt gestopt. Je hebt er onder andere voor gezorgd dat alle dierexperimenten keurig werden uitgevoerd en je hebt me het rescuen geleerd. Jeroen, ik wil jou bedanken voor de grondige data-analyse van de microarrayexperimenten. Ook al waren de verschillen tussen de groepen klein, dankzij jouw hulp hebben we er toch een mooi artikel over kunnen schrijven. Edwin, bedankt dat je de allerlaatste rescues voor me hebt gedaan terwijl ik in Canada was. Mede hierdoor konden alle experimenten tijdig worden afgerond.

Familie, schoonfamilie, vrienden en andere bekenden. Ik kon merken dat promoveren voor velen van jullie een onbekend begrip was, maar dat weerhield jullie er niet van om te vragen hoe het met mij en mijn promotie ging. Ik wil jullie dan ook allemaal heel erg bedanken voor jullie interesse en medeleven in de afgelopen jaren. Dit boekje is het resultaat en hier heb ik in Maastricht en de afgelopen maanden thuis aan gewerkt. Julia, Joyce en Imke, jullie weten daarentegen als geen ander hoe het is om te promoveren. Ook al hebben jullie het al weer even achter de rug, ik kan er met jullie nog altijd over praten. Bedankt voor alle steun en alle supergezellige en ontspannende uren, dagen en nachten die ik de afgelopen jaren met jullie heb mogen doorbrengen. Ik kijk al uit naar ons volgende uitje!

De paranimfen. Hoewel ik liever niet had willen kiezen tussen jullie drie, meiden, heb ik dat toch gedaan. Julia, ik ben blij dat je mijn paranimf wil zijn en me bij wil staan op deze mooie dag. Met jouw ervaring moet dat goed komen! Joost, hoever zou ik zonder jouw hulp zijn gekomen!? Het begon met het opzetten van de minisatelliteanalyse, terwijl ik aan het rescuen was op het RIVM. Hoewel het in het begin niet echt wilde lukken, ging je toch stug door. Het heeft je heel wat uren gekost! Om de kleine kneepjes van het vak te leren, zijn we met zijn tweeën naar Canada gegaan. Jouw aanwezigheid daar heeft ervoor gezorgd dat ik al mijn analyses heb kunnen voltooien en het erg naar mijn zin heb gehad, ook buiten de werkuren. Wat hebben we in een korte tijd veel moois gezien! Daarnaast kan ik nog steeds altijd bij je aankloppen voor wat dan ook. Ik wil je heel erg bedanken voor al je hulp en Brabantse gezelligheid. Ik ben blij dat ook jij mijn paranimf wil zijn.

Bas, Kristel, Lynn, Maud, Tom en Fabiënne. Wat een gezellige boel is het toch altijd als we met zijn allen bij elkaar zijn. Ik wil jullie bedanken voor al jullie steun en interesse. Bas en Kristel, bedankt voor alle etentjes, ontspannende potjes tennis en hulp bij het zoeken naar geschikte foto's. Lynn en Maud, bedankt voor het mogen oppassen, het heeft voor voldoende afleiding gezorgd. Vanaf januari ben ik weer volledig beschikbaar. Tom en Fabiënne, ik wens jullie veel succes voor de toekomst.

Pap en mam. Ik waardeer het enorm dat jullie altijd voor me klaarstaan en me de kans hebben gegeven om dit te bereiken. Ik wil jullie dan ook bedanken voor alle steun en liefde die jullie mij hebben gegeven. Mam, ik wil je tevens bedanken voor je komst naar Canada, al het leeswerk en de nodige correcties die je hebt doorgevoerd.

Marcel, mijn lief, mijn grapjas. Jij steunde me door dik en dun, je liet me vrij in mijn doen en laten, en moedigde me aan om door te zetten. Zo kwam het einde in zicht. Bedankt voor alles! 



\section{Curriculum Vitae}



Nicole Verhofstad was born on October 29, 1980, in Best, the Netherlands. She completed secondary school at Pleincollege Bisschop Bekkers in Eindhoven in 2000. In the same year she started her academic education at Maastricht University, where she studied Biological Health Sciences at the Faculty of Health Sciences. During her internship in 2004 at the Angiogenesis Laboratory (department of Pathology, University Hospital Maastricht), she validated and characterized the interaction of a synthetic angiogenesis inhibitor, anginex, with its possible receptor galectin-1, and she graduated in 2005. In the meantime, she worked as a student assistant and after graduation as a research assistant at the department Human Biology, Maastricht University, to assist the coordination of a human intervention study on the effects of plant stanol and statin on the risk variables for cardiovascular diseases in metabolic syndrome patients. From September 2005 until February 2010 she was appointed as a PhD student at the department of Health Risk Analysis and Toxicology, Maastricht University. During this period she studied the DNA damaging and genotoxic effects of benzo(a)pyrene in reproductive tissues, germ cells and offspring of exposed male mice, which are described in this thesis. In 2007, she won a price for Best Poster Presentation at the PhD student meeting of the Netherlands Society of Toxicology. A year later, she successfully organized the PhD student meeting of the Netherlands Society of Toxicology, which was held in Wageningen. Her publication 'DNA adduct kinetics in reproductive tissues of DNA repair proficient end deficient male mice after oral exposure to benzo(a)pyrene' has been selected as the best student publication in Environmental and Molecular Mutagenesis for 2009. Currently, she is working as a Scientific Researcher at the department of Vascular Surgery, Catharina Hospital Eindhoven. 



\section{List of publications}



Verhofstad N, van Oostrom CT, Zwart E, Maas LM, van Benthem J, van Schooten FJ, van Steeg H, Godschalk RW. Evaluation of benzo(a)pyrene-induced gene mutations in male germ cells. Accepted for publication in Toxicological Sciences.

Verhofstad N, Pennings JL, van Oostrom CT, van Benthem J, van Schooten FJ, van Steeg H, Godschalk RW. Benzo(a)pyrene induces similar gene expression changes in testis of DNA repair proficient and deficient mice. BMC Genomics. 2010 May 26;11(1):333.

Verhofstad N, van Oostrom CT, van Benthem J, van Schooten FJ, van Steeg $H$, Godschalk RW. DNA adduct kinetics in reproductive tissues of DNA repair proficient and deficient male mice after oral exposure to benzo(a)pyrene. Environ Mol Mutagen. 2010 Mar;51(2):123-9.

Verhofstad N, Linschooten JO, van Benthem J, Dubrova YE, van Steeg $\mathrm{H}$, van Schooten FJ, Godschalk RW. New methods for assessing male germ line mutations in humans and genetic risks in their offspring. Mutagenesis. 2008 Jul;23(4):241-7. Review.

Thijssen VL, Postel R, Brandwijk RJ, Dings RP, Nesmelova I, Satijn S, Verhofstad N, Nakabeppu Y, Baum LG, Bakkers J, Mayo KH, Poirier F, Griffioen AW. Galectin-1 is essential in tumor angiogenesis and is a target for antiangiogenesis therapy. Proc Natl Acad Sci USA. 2006 Oct 24;103(43):15975-80. 
